\title{
MÉtodos de Amostragem no LeVANTAMENTo DA DIVERSIDADE ARBóREA dO CERRADÃO DA ESTAÇÃo ECOLÓGICA DE ASSIS
}

\author{
Daniela ANDRAde MedeIRos
}

Dissertação apresentada à Escola Superior de

Agricultura "Luiz de Queiroz", Universidade de São Paulo, para a obtenção do título de mestre em Ecologia de Agroecossistemas.

PIR A C I C A B A

Estado de São Paulo - Brasil

Dezembro - 2004 


\title{
MÉtodos de Amostragem no LeVANTAMENTo dA Diversidade ARBóREA do CERRADÃo DA ESTAÇÃo ECOLÓGICA DE ASSIS
}

\author{
DANIELA ANDRADE MEDEIROS \\ Engenheiro Florestal
}

Orientador: Prof. Dr. HILTON THADEU Z. DO COUTO

Dissertação apresentada à Escola Superior de Agricultura "Luiz de Queiroz", Universidade de São Paulo, para a obtenção do título de mestre em Ecologia de Agroecossistemas.

\author{
P I R A C I C A B A \\ Estado de São Paulo - Brasil \\ Dezembro - 2004
}


Dados I nt er naci onais de Cat al ogação na Publi cação ( CI P) DI VI SÃO DE BI BLI OTECA E DOCUMENTAÇÃO - ESALQI USP

Medeiros, Daniela Andrade

Métodos de amostragem no levantamento da diversidade arbórea do cerradão da

Estação Ecológica de Assis / Daniela Andrade Medeiros. - - Piracicaba, 2004.

85 p. : il.

Dissertação (Mestrado) - - Escola Superior de Agricultura Luiz de Queiroz, 2005.

Bibliografia.

1. Amostragem (método) 2. Biodiversidade 3. Cerrado 4. Comunidade vegetal

5. Conservação biológica 6 . Estação ecológica 7. Floresta 8. Inventário florestal

I. Título

CDD 634.9

"Permi tida a cópia total ou parcial deste documento, desde que citada a

f ont e - O aut or" 
DEDICO

Aos meus pais, Carlos e Santina À minha irmã, Juliana Às minhas avós, Ana e Nair 


\section{AGRADECIMENTOS}

À Escola Superior de Agricultura "Luiz de Queiroz", pela oportunidade e pelo aprendizado desde a graduação.

Ao Prof. Dr. Hilton Thadeu Z. do Couto, pela orientação e confiança depositada. Ao Prof. Dr. João Luís Ferreira Batista, pelas sugestões ao trabalho e auxílio no programa $R$.

Ao Pq. Dr. João Batista Baitello, pelas sugestões apresentadas a este trabalho. À Prof. Dra. Ilse Silberbauer-Gottsberger, pelo envio dos artigos pelo correio. À FAPESP, pelo apoio financeiro na execução do trabalho de campo.

À equipe de campo, que muito contribuiu na identificação e coleta dos indivíduos arbóreos: Ana Cláudia Pereira, Ana Paula Savassi, André Gracioso, André Keppe, Carlos Eduardo Anselmo, Jefferson Polizel e Marcos Scaranello. Ao amigo e funcionário do Laboratório de Métodos Quantitativos (LMQ), Jefferson Lordello Polizel, pela disponibilidade em ajudar quando necessário.

Aos funcionários da Floresta Estadual de Assis, por viabilizarem a realização deste trabalho na área da Estação Ecológica.

Ao biólogo Osny Aguiar e equipe e à Ana Paula Savassi e Samira Rolim, pela ajuda na etapa final de identificação botânica.

Ao graduando de Eng. Florestal Samuel Figueiredo, pelo auxílio na tabulação dos dados de campo.

À Eliza Takashiba, pela edição da imagem de satélite, por todo o incentivo e apoio constante.

À Ana Schilling, pelo empréstimo dos livros e artigos, pelas anotações na qualificação, enfim, por toda a colaboração. 
Aos funcionários da Biblioteca Central e IPEF, em especial à equipe de comutação bibliográfica da Biblioteca Central, Silvio e Vilma.

Às secretárias do PPGI-EA e da Diretoria do CIAGRI.

Aos colegas do Laboratório de Métodos Quantitativos, pela agradável convivência: Silvana Bortoleto, Luis Faria, Edgar Vismara, Mauricio Gorenstein, Rubem Martins e Ezér Oliveira.

Aos queridos amigos e amigas da ESALQ: Silvia Kataoka, Ana Maria de Meira, Elvis França, Márcia Toffani, Fabiana Curti, Eliza Takashiba, Ana Schilling, Clariça Cacciamali, Daniela Talora, Marky Brito, Lana Silva, Camila Yazbek, Anna Júlia Passold, Vanderlei Stefanuto, Norberto Cornejo e Zayame Vegette. 


\section{SUMÁRIO}

Página

LISTA DE FIGURAS........................................................................... viii

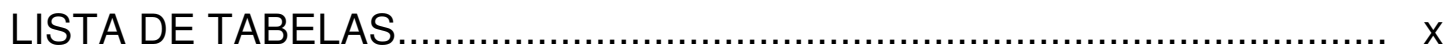





1 INTRODUÇÃO

2 REVISÃO DE LITERATURA........................................................ 3

2.1 Biodiversidade ....................................................................... 3

2.2 Medidas de diversidade................................................................... 4

2.2.1 Índice de Diversidade de Shannon................................................... 4

2.2.2 Índice de Diversidade de Simpson................................................... 5

2.3 Variáveis fitossociológicas............................................................. 5

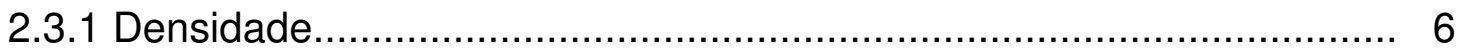

2.3.2 Freqüência...................................................................... 7





2.3.1 Método de Parcelas de Tamanho Fixo.......................................... 10

2.3.1.1 Tamanho e forma de parcela..................................................... 10

2.3.2 Método do Ponto Quadrante..................................................... 11

2.3.3 Curva de acumulação de espécies ou suficiência amostral................. 12

2.4 O Bioma Cerrado............................................................................ 12

2.4.1 O bioma cerrado visto como uma formação florestal......................... 15 
2.4.2 A influência do fogo no bioma cerrado......................................... 16

2.4.3 A Fisionomia Cerradão.................................................................. 17

2.4.3.1 Diferenciação geográfica e florística entre cerrado sensu lato

e mata estacional semidecidual....................................................... 18

2.4.4 Histórico de Desmatamento e Importância do Cerrado no

Estado de São Paulo.................................................................... 19

2.5 Histórico da Estação Ecológica de Assis............................................ 21

3 MATERIAL E MÉTODOS.............................................................. 22

3.1 Descrição da área de estudo........................................................ 22

3.1.1 Localização Geográfica.............................................................. 22



3.1.3 Geomorfologia e Rede Hídrica.................................................. 23

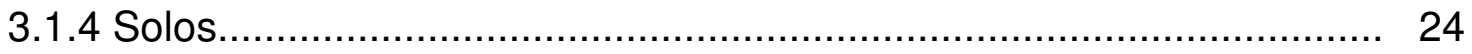

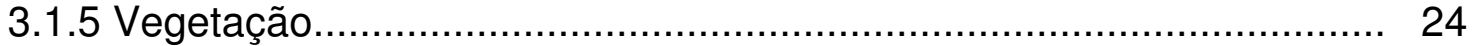

3. 2 Informações sobre a grade de amostragem....................................... 24

3.3 Procedimento de Campo.................................................................. 28

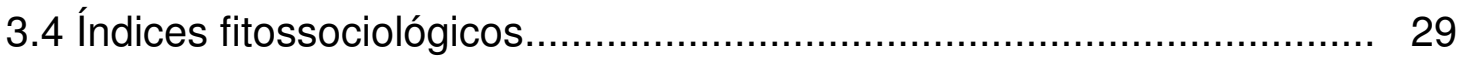

3.5 Índices de Diversidade.................................................................. 32

4 RESULTADOS E DISCUSSÃO......................................................... 36

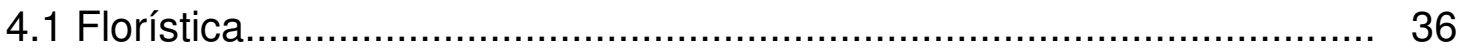

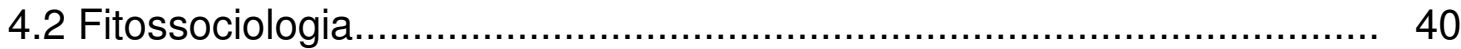

4.3 Suficiência amostral....................................................................... 59

4.4 Índices de Diversidade............................................................... 64

4.5 Densidade de indivíduos.............................................................. 69

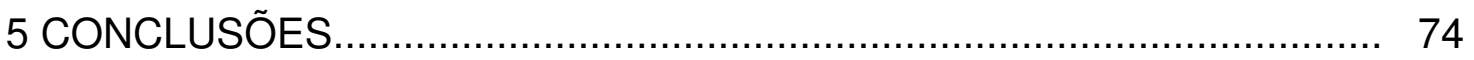

REFERÊNCIAS BIBLIOGRÁFICAS.................................................... 76 


\section{LISTA DE FIGURAS}

Página

1 Mapa do Estado de São Paulo, com seta indicativa no município de Assis..................................................................... 23

2 Imagem do satélite Landsat 7/ETM+, composição 5/4/3, de 15/08/2002, com a localização georreferenciada da grade amostral na área de cerradão da E. E. Assis, situada à direita.............................................. 25

3 Desenho esquemático da grade amostral............................................ 26

4 Desenho esquemático da parcela, com as subparcelas

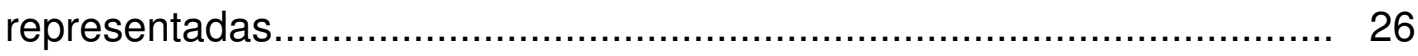

5 Placa com numeração em um indivíduo arbóreo inserido

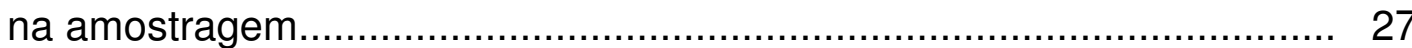

6 Comparação das fisionomias cerradão (à esquerda) e cerrado sensu stricto (à direita) na E. E. Assis.

7 Distribuição das espécies quanto ao IVI (\%) para parcelas de área fixa de diferentes tamanhos e pontos quadrante.................................. 47

8 Distribuição das espécies quanto à Dominância absoluta para parcelas de área fixa de diferentes tamanhos e pontos quadrante

9 Distribuição das espécies quanto à Densidade absoluta para parcelas de área fixa de diferentes tamanhos e pontos quadrante........ 49

10 Distribuição das espécies quanto à Freqüência absoluta para parcelas de área fixa de diferentes tamanhos e pontos quadrante. 
11 Distribuição das principais espécies quanto ao IVI (\%)

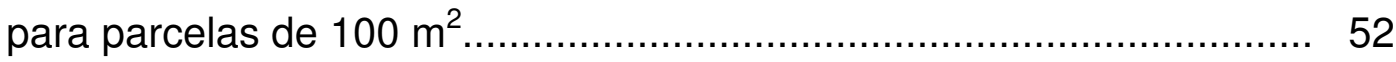

12 Distribuição das principais espécies quanto ao IVI (\%)

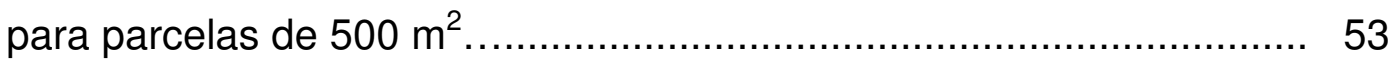

13 Distribuição das principais espécies quanto ao IVI (\%) para parcelas de $900 \mathrm{~m}^{2}$.

14 Distribuição das principais espécies quanto ao IVI (\%) para o método de ponto quadrante

15 Riqueza relativa das principais famílias no método de parcelas de $900 \mathrm{~m}^{2}$ 57

16 Riqueza relativa das principais famílias no método de pontos quadrante 58

17 Curva de suficiência amostral para parcelas de $900 \mathrm{~m}^{2}$ e para o método do ponto quadrante. 59

18 Curva de suficiência amostral para parcelas de $200 \mathrm{~m}^{2}$ e para o método do ponto quadrante. 60

19 Curva de suficiência amostral para os nove tamanhos de parcelas testados

20 Coeficiente de Variação dos Índices de Diversidade de Shannon e Simpson nos nove tamanhos de parcela testados......... 66

21 Gráfico "box-plot" para o Índice de Shannon........................................ 67

22 Gráfico "box-plot" para o Índice de Simpson........................................... 68

23 Coeficiente de Variação da estimativa da densidade para os nove tamanhos de parcela testados...................................... 71

24 Gráfico "box-plot” para a variação da densidade............................... 72 


\section{LISTA DE TABELAS}

Página

1 Lista de ocorrência de espécies na amostragem pelo método de parcelas de $900 \mathrm{~m}^{2}$

2 Estimativas de parâmetros fitossociológicos encontrados por espécie para o método de parcela de área fixa de $900 \mathrm{~m}^{2}$.

3 Estimativas de parâmetros fitossociológicos encontrados por espécie para o método do ponto quadrante

4 Número de indivíduos (\%) e número de espécies por família, para os métodos de parcelas e pontos quadrante.

5 Esforço amostral (ind/sp) para os diferentes tamanhos de parcela e para o método de ponto quadrante.

6 Média dos índices de diversidade de Shannon e Simpson para parcelas de 100 a $900 \mathrm{~m}^{2}$, comparadas com os valores obtidos no método de ponto quadrante e na grade amostral.................................. 64

7 Média e intervalo de confiança (95\%) da estimativa da densidade para parcelas de 100 a $900 \mathrm{~m}^{2}$, pontos quadrantes e subparcelas 


\title{
MÉTODOS DE AMOSTRAGEM NO LEVANTAMENTO DA DIVERSIDADE ARBÓREA DO CERRADÃO DA ESTAÇÃO ECOLÓGICA DE ASSIS
}

\author{
Autora: DANIELA ANDRADE MEDEIROS \\ Orientador: Prof. Dr. HILTON THADEU Z. DO COUTO
}

\section{RESUMO}

Apesar de ocupar cerca de $25 \%$ do território nacional e abrigar, potencialmente, um terço da fauna e flora brasileira, o bioma cerrado é classificado como um "hotspot" por apresentar expressiva redução de biodiversidade. Perante este quadro, este trabalho teve por objetivo comparar os métodos de amostragem de parcelas de área fixa e de ponto quadrante em uma área com predominância da fisionomia cerradão (savana florestada) na Estação Ecológica de Assis (SP), estando inserido no projeto temático "Métodos de Inventário da Biodiversidade de Espécies Arbóreas", do Programa BIOTA/FAPESP. A área estudada é representada por uma grade amostral sistemática que contém 64 parcelas de $90 \times 10 \mathrm{~m}\left(900 \mathrm{~m}^{2}\right)$, inseridas em 8 linhas distantes $100 \mathrm{~m}$ entre si, com 8 parcelas em cada linha. Estas foram subdivididas em 9 subparcelas de $10 \times 10 \mathrm{~m}$, com um intervalo de $10 \mathrm{~m}$ não amostrado entre as parcelas nas linhas. Os pontos quadrantes foram instalados em cada limite entre as subparcelas. Os indivíduos arbóreos com DAP maior ou igual a $4,77 \mathrm{~cm}$ foram inseridos nesta amostragem, sendo posteriormente identificados. Partindo-se deste delineamento amostral e, diante da ocorrência 
de fragmentos de cerrado strictu sensu juntamente com áreas de cerradão, simulou-se a existência de nove tamanhos de parcela, variando de 100 a 900 $\mathrm{m}^{2}$, a fim de avaliar como esses diferentes tamanhos, bem como o método do ponto quadrante, interferem no esforço amostral, na estimativa da densidade e nos índices fitossociológicos e de diversidade. Ao final do levantamento, o método de parcelas de $900 \mathrm{~m}^{2}$ incluiu 102 espécies, distribuídas em 45 famílias, enquanto que o método do ponto quadrante amostrou 71 espécies, distribuídas em 37 famílias. Os resultados encontrados em ambos os métodos quanto ao Índice de Valor de Importância apontaram as espécies Copaifera langsdorffii, Vochysia tucanorum e Ocotea corymbosa como as mais importantes; já a família Myrtaceae se destacou nestes dois métodos quanto à riqueza de espécies. A curva de esforço amostral do método do ponto quadrante incluiu um número de espécies semelhante à curva das parcelas de $200 \mathrm{~m}^{2}$, com a vantagem de apresentar maior praticidade de instalação no campo. Os valores do Índice de Diversidade de Shannon foram inferiores a outros biomas, enquanto que o Índice de Diversidade de Simpson não pôde ser o mais indicado para o cerradão estudado, por não ser sensível à ocorrência de espécies com apenas um indivíduo na parcela. Para a determinação da diversidade arbórea do cerradão da E. E. Assis, recomendou-se o uso da parcela de $400 \mathrm{~m}^{2}$. Já na estimativa da densidade, as parcelas de $700 \mathrm{~m}^{2}$ foram as mais adequadas; entretanto, devido à grande variabilidade deste parâmetro na área, sugeriu-se uma estratificação da área de amostragem. 


\title{
SAMPLING METHODS USED IN THE TREE DIVERSITY SURVEY IN CERRADÃO AT THE ECOLOGICAL STUDY STATION IN THE CITY OF ASSIS
}

\author{
Author: DANIELA ANDRADE MEDEIROS \\ Adviser: Prof. Dr. HILTON THADEU Z. DO COUTO
}

\section{SUMMARY}

Cerrado biome is classified as a hotspot, because it presents an expressive reduction on the biodiversity, despite of occupying around $25 \%$ of the national territory and potentially sheltering one third of the Brazilian fauna and flora. In this scenario, this work had as objective to compare the fixed area plots and the point-centered quarter sampling methods in an area with a cerradão (savanna woodland) physiognomy at the Ecological Study Station in the city of Assis (SP), which is part of the "Tree Species Biodiversity Inventory Methods", a thematic project of BIOTA/FAPESP Program. The studied area is represented by a systematic sampling frame containing 64 plots, measuring $90 \times 10 \mathrm{~m}(900$ $\mathrm{m}^{2}$ ), inserted in 8 lines, which is $100 \mathrm{~m}$ away from each other, with 8 plots in each line. They were divided into 9 sub-plots measuring $10 \times 10 \mathrm{~m}$, with a $10-\mathrm{m}$ non-sampled gap between the plots in the lines. The point-centered points were installed in each limit between the sub-plots. The arboreal individuals with DBH equal or larger than $4.77 \mathrm{~cm}$ were set in this sampling and identified later. From this sampling design and due to the presence of fragments of cerrado strictu sensu together with areas of cerradão, it was simulated the existence of nine 
size samples varying from 100 to $900 \mathrm{~m}^{2}$ aiming evaluating how these different sizes and the point-centered quarter method interfere in the sampling effort, in the density estimates, and in the phytossociological and diversity indexes. At the end of the surveying, the $900-\mathrm{m}^{2}$-plot method included 102 species, distributed in 45 families, whereas in the center-pointed quarter method 71 species were sampled, distributed in 37 families. The results found in both methods in relation to the Importance Value Index showed Copaifera langsdorffii, Vochysia tucanorum, and Ocotea corymbosa as the most important ones; Myrtaceae family stood out on both methods in relation to species richness. The sampling effort curve of the point-center quarter method included a number of species similar to the 200- $\mathrm{m}^{2}$ plots' curve, with an advantage of being easier to be installed in the field. The Shannon Index values were lower than in the other biomes, whereas the Simpson Index could not be the best indicated for the cerradão under study, because it was not sensitive to the presence of species with only one individual in the plot. It was recommended the use of $400-\mathrm{m}^{2}$ plots in order to determine the tree diversity in the cerradão at the Ecological Study Station in the city of Assis. The most adequate plots to estimate the density were the $700-\mathrm{m}^{2}$ ones. However, stratification on the sampling area was suggested due to the great variability of this parameter in the area. 


\section{INTRODUÇÃO}

O valor econômico e o papel ecológico do bioma cerrado ainda são pouco conhecidos e pouco estudados. De acordo com a Base de Dados Tropical (2004), o cerrado é o segundo bioma brasileiro em extensão geográfica, abrangendo mais de 200 milhões de hectares e ocupando cerca de $25 \%$ do território nacional. A região do cerrado abriga, potencialmente, um terço da biodiversidade brasileira, o que significa $5 \%$ da flora e da fauna mundiais. A riqueza mínima estimada para a região é da ordem de 166 mil espécies, entre animais e plantas. Mesmo com toda essa riqueza, apenas cerca de $1 \%$ da extensão territorial do cerrado encontra-se em Unidades de Conservação Federais, valor modesto quando comparado à Amazônia, que apresenta 6\% de sua extensão protegida em unidades de conservação.

Myers et al. (2000) consideram o cerrado como um dos 25 "hotspots", termo criado para as regiões do mundo que, apesar de possuírem elevada concentração de espécies endêmicas, vêm apresentando expressiva redução de biodiversidade.

Perante este quadro, o conhecimento da biodiversidade local e o uso de metodologia de amostragem apropriada facilitam a tomada de decisões sobre ações de manejo para fins de conservação.

Índices de diversidade e de riqueza de espécies são comumente usados em estudos ecológicos e de conservação da biodiversidade, porque fornecem informações úteis para avaliar distúrbios de ordem ambiental, incluindo-se os efeitos adversos da poluição. Normalmente, uma comunidade ecológica sujeita a experiências de estresse sofre perdas de espécies e aumento nas 
abundâncias de poucas espécies - daí a dominância. Os índices de diversidade ponderada quantificam estas alterações em abundância relativa, possibilitando, assim, a elaboração de planos de manejo com o intuito de reduzir essas alterações (Orians, 1994).

A maneira economicamente viável de quantificar a diversidade de um ambiente ocorre por meio da amostragem. Para Krebs (1999), uma análise representativa da população de estudo pode ser obtida quando se mede corretamente uma amostra. Por isso, a decisão sobre um método de amostragem deve ser fundamentada nas peculiaridades da população alvo.

Este estudo está inserido no projeto temático "Métodos de Inventário da Biodiversidade de Espécies Arbóreas", do Programa BIOTA/FAPESP, que visa desenvolver métodos para caracterizar e monitorar a biodiversidade de espécies arbóreas, por meio do uso de sistemas de amostragem adequados para medições e coleta de informações. A aplicação desta metodologia está sendo realizada nos biomas Floresta Ombrófila Densa do Parque Estadual Carlos Botelho, Floresta Estacional Semidecidual da Estação Ecológica dos Caetetus e na Savana Florestada (Cerradão) da Estação Ecológica de Assis.

Logo, o objetivo geral deste trabalho é comparar os efeitos do levantamento de espécies arbóreas em uma fisionomia com predominância de cerradão, utilizando-se dois métodos de amostragem: (1) o método de ponto quadrante e (2) o método de parcela de área fixa, testadas em dimensões variadas.

Como objetivo específico, espera-se: (a) indicar um método e um tamanho ótimo de parcela para a área estudada, de acordo com os resultados de índices de diversidade, índices fitossociológicos e curvas de suficiência amostral e (b) verificar, diante da ocorrência de trechos da fisionomia cerrado sensu stricto na área, a variação de densidade arbórea entre essas fisionomias e sua influência diante dos métodos de ponto quadrante e parcelas de área fixa. 


\section{REVISÃO DE LITERATURA}

\subsection{Biodiversidade}

Para Magurran (1988), medidas da diversidade de espécies podem ser divididas em três categorias principais. A primeira se refere aos índices de riqueza de espécies, que são essencialmente uma medida do número de espécies em uma parcela definida. A segunda se refere aos modelos de abundância de espécies - no qual descreve-se sua distribuição - podendo variar desde aqueles que representam situações onde existe uma elevada paridade até aqueles casos que caracterizam uma abundância de espécies bastante desigual. Índices baseados na abundância proporcional de espécies formam o grupo final. Nesta categoria aparecem os índices de Shannon e Simpson, que ponderam riqueza e eqüabilidade.

Whittaker (1975) classifica o termo diversidade, para um dado bioma, em três níveis: a diversidade gama, como a diversidade total de uma grande área; a diversidade alfa (dentro de um hábitat), como sendo a riqueza de espécies de uma comunidade; e a diversidade beta (entre os hábitats), que corresponde ao grau de mudança na composição das espécies nas comunidades, ao longo de um gradiente.

Orians (1994) defende uma idéia mais ampla do termo biodiversidade. Segundo o autor, a biodiversidade não deve se restringir apenas à diversidade de espécies. Níveis múltiplos de organização e diferentes escalas espaciais e temporais devem ser considerados, como, por exemplo, os componentes composicional, estrutural e funcional de uma comunidade. Composição inclui a 
constituição genética das populações, a riqueza de espécies e suas abundâncias relativas na comunidade natural e os tipos de hábitats e de comunidades distribuídos pela paisagem. A estrutura inclui a disposição vertical e grau de heterogeneização horizontal da vegetação. Finalmente, as funções incluem processos climáticos, geológicos, hidrológicos, ecológicos e evolucionários, geradores de biodiversidade.

\subsection{Medidas de diversidade}

Krebs (1999) descreve que o mais antigo e mais simples conceito de diversidade de espécies é a riqueza de espécies, obtida pelo número de espécies na comunidade. Na prática, sua estimativa é dificultada porque, na maioria das vezes, não se consegue enumerar todas as espécies em uma comunidade natural. Peet (1974) já havia relatado o problema da dependência de qualquer medida de riqueza em relação ao tamanho da amostra, pois, quanto maior a amostra, maior o número de espécies.

Magurran (2004) lista dois métodos principais de expressar estimativas de riqueza de espécies: (1) a riqueza numérica de espécies, dada pelo número de espécies por um número especificado de indivíduos ou de biomassa e (2) a densidade de espécies, que é o número de espécies por área especificada ou unidade, sendo esta a preferida em estudos botânicos.

\subsection{1 Índice de Diversidade de Shannon}

Magurran (2004) relata que este índice é muito comum, porém é sensível ao tamanho de parcela e seu resultado pode ser de difícil interpretação. No entanto, seu uso persiste, uma vez que muitas pesquisas em longo prazo utilizam-se desta medida como referência para avaliar a diversidade biológica.

O índice de Shannon assume que os indivíduos são amostrados ao acaso em uma população infinita (Pielou, 1975; Magurran, 1988) e que todas as 
espécies estão representadas na amostra (Magurran, 1988). Normalmente essas pressuposições são feridas. Conforme Peet (1974), uma fonte significativa de erro ocorre porque na amostra não são incluídas todas as espécies da comunidade, sendo o termo riqueza, proposto por McIntosh (1967), mais indicado ao se referir à diversidade da população, ao invés de número de espécies. Quanto à distribuição aleatória dos indivíduos na população, os trabalhos de Fracker \& Brischle (1944) e Thomas (1949) evidenciaram que comumente as populações se apresentam em padrões agrupados de distribuição.

\subsection{2 Índice de Diversidade de Simpson}

Segundo Magurran (2004), o Índice de Diversidade de Simpson é uma das mais significativas e robustas medidas de diversidade. Captura, em sua essência, a discrepância em relação à distribuição de abundância de espécies. Martins \& Santos (1999) classificam este índice como a melhor medida de concentração de abundância das espécies.

Este índice apresenta uma relação inversa com a eqüabilidade (proporção entre a diversidade observada e a máxima diversidade): quanto maior a eqüabilidade, menor a concentração de abundância e vice-versa (Martins \& Santos, 1999).

\subsection{Variáveis fitossociológicas}

De acordo com Mitchell (2004), a medição de variáveis fitossociológicas facilita no entendimento dos estágios sucessionais de um bioma florestal. Nos mais variados estágios, diferentes espécies de árvores exercerão dominância sobre as demais. O Índice de Valor de Importância das espécies é uma maneira objetiva de medir esta dominância, podendo ser determinado a partir das 
variáveis densidade (no de indivíduos/ha), tamanho (área basal) e freqüência (distribuição).

\subsubsection{Densidade}

Para Chapman (1976), a densidade é definida como o número de indivíduos de uma determinada espécie por unidade de área. Seu cálculo é geralmente feito contando-se o número de árvores desta espécie dentro das parcelas, que em seguida são multiplicadas pela área de estudo depois divididas pela área amostrada, para gerar a densidade da área de estudo.

O termo abundância, sugerindo o mesmo significado de densidade, também é usado para se referir à densidade de uma determinada espécie. Segundo Magurran (1988) e Krebs (1999), a maioria das espécies possui baixa abundância, enquanto que um número reduzido de espécies é realmente abundante.

Magurran (1988) propôs alguns modelos de distribuição de abundância de espécies. Em comunidades com grande riqueza de espécies, a abundância das espécies normalmente segue uma distribuição logarítmica normal; enquanto que para comunidades onde a riqueza de espécie é baixa, sua distribuição segue freqüentemente uma série geométrica.

Martins \& Santos (1999) afirmam que variações na densidade da vegetação podem também influenciar no valor da densidade (ou abundância) das espécies. O fato de o cerrado apresentar grande variação fisionômica, sendo ora aberto (cerrado "campo limpo") ora fechado (cerradão), indica que as unidades amostrais com áreas iguais poderiam apresentar um número muito diferente de espécies, não porque as fisionomias mais abertas sejam mais pobres em espécies, mas porque o número de indivíduos por unidade de área é menor. 


\subsubsection{Freqüência}

Müeller-Dombois \& Ellenberg (1974) e Chapman (1976), consideram a freqüência de uma dada espécie como sendo o número de vezes em que a espécie ocorre em um determinado número de unidades amostrais, normalmente expressa em porcentagem. Entretanto, Chapman (1976) adverte para os seguintes aspectos:

- A freqüência pode variar com o tamanho da parcela;

- O valor de freqüência reflete o padrão de distribuição dos indivíduos, bem como suas densidades. Isto significa que uma área pode apresentar espécies de igual densidade, porém com valores de freqüência diferentes, devido ao padrão de distribuição das espécies.

Para Müeller-Dombois \& Ellenberg (1974), o valor da freqüência pode ser usado na determinação da densidade e de medidas de cobertura. Sua estimativa depende em parte do tamanho e forma da parcela, pois um leve aumento dessas variáveis pode resultar em uma freqüência diferente para espécies de abundância intermediária. Já Magurran (2004) afirma que dados de freqüência, além de serem comumente usados para calcular abundância (ou densidade), são extremamente úteis em medidas de diversidade. Como desvantagem, ressalta o fato de as abundâncias das espécies comuns serem subestimadas e a abundâncias das espécies raras serem superestimadas.

\subsubsection{Dominância}

A dominância reflete a taxa de ocupação de ambiente pelos indivíduos de uma espécie. Para comunidades florestais, a dominância é normalmente obtida por meio da área basal, que expressa o espaço em metros quadrados que uma espécie ocupa em uma unidade de área (Dias, 1993). 
Para Oosting (1956), embora densidade e freqüência indiquem números e distribuição, estes parâmetros não indicam tamanho, volume espacial ocupado, ou, ainda, cobertura de solo sombreada. Estas características de dominância são valores adicionais desejáveis e contribuem substancialmente para a compreensão da importância das espécies em determinada área.

Segundo Odum (1986), o termo dominância pode ter o sentido de abundância, pois relata que, do número total de espécies num componente trófico ou numa comunidade como um todo, uma porcentagem relativamente pequena é abundante ou dominante (representada por grandes números de indivíduos, uma grande biomassa ou produtividade), e uma porcentagem grande é rara (com pequenos valores de "importância"). Às vezes, não há espécies dominantes, mas sim muitas de abundância intermediária.

\subsection{Amostragem}

A obtenção de boas estimativas a um baixo custo é um dos objetivos da amostragem, podendo ser influenciada pelas técnicas empregadas, como, por exemplo, a determinação da localização das amostras, bem como seu tamanho e forma. Adotando-se um delineamento amostral adequado, para um dado objetivo e condição, é possível reduzir o tempo de trabalho em levantamentos florestais (Spurr, 1952). Espera-se que amostras escolhidas ao acaso reflitam as características da população das quais foram retiradas (Prodan, 1968).

De acordo com Krebs (1999), provavelmente não há nenhum assunto no qual o pesquisador de campo e os estatísticos diferem tanto quanto a amostragem ao acaso e a amostragem sistemática. Se os gradientes da área de estudo forem facilmente reconhecidos, a amostragem sistemática será mais adequada. De qualquer maneira, esta decisão poderá ser fortemente afetada pela exigência das questões ecológicas a serem estudadas. Assim, uma combinação da amostragem sistemática e ao acaso pode ser recomendada. 
Spurr (1952) explica que a amostragem aleatória pode ser usada quando não há nenhuma variação sistemática na população. Entretanto, o autor esclarece que em populações florestais isto normalmente não acontece, sendo indicada a amostragem sistemática na obtenção de melhores estimativas.

O uso da amostragem sistemática no campo é freqüente, e as razões habituais para seu uso na prática são a simplicidade de aplicação no campo e a pretensão de amostrar uniformemente o hábitat como um todo (Krebs, 1999).

Há diversos estudos sobre o bioma cerrado utilizando métodos de amostragem - tais como parcelas de área fixa e pontos quadrante - visando caracterizar a diversidade arbórea. Heiseke (1976) testou o método de ponto quadrante em vegetação de cerrado em Minas Gerais, e estimou, além dos parâmetros fitossociológicos, o volume de madeira para produção de carvão. Felfili \& Imaña-Encinas (2001), utilizaram parcelas de $1000 \mathrm{~m}^{2}$ para estudar o cerrado da Chapada do Espigão Mestre do São Francisco, englobando os Estados de Goiás, Piauí, Tocantins, Bahia e Minas Gerais. Já Cesar et al. (1988) demarcaram parcelas de 5 × 5 m para estudar o cerrado em Corumbataí (SP), enquanto que Toledo Filho et al. (1989) e Gomes et al. (2004) instalaram parcelas em áreas de cerradão em Moji-Mirim (SP) e Brotas (SP), respectivamente.

Os estudos desta natureza em outros biomas são também habituais. Martins (1979) e Cavassan et al. (1984) aplicaram o método de ponto quadrante em florestas estacionais, em Santa Rita do Passa Quatro (SP) e em Bauru (SP), respectivamente. Gorenstein (2002), além de parcelas e pontos quadrante, instalou pontos de Bitterlich na Estação Ecológica de Caetetus, em Gália (SP), já Rocha (2003) aplicou parcelas e pontos quadrante nesta mesma área. Dias (1993) e Aguiar (2003) estudaram a floresta ombróflia densa do Parque Estadual Carlos Botelho, abrangendo os municípios de São Miguel Arcanjo (SP) e Sete Barras (SP). O primeiro autor aplicou pontos quadrantes para árvores em duas classes de diâmetro (maior que $10 \mathrm{~cm}$ e entre 5 e $10 \mathrm{~cm}$ ) em um trecho de mata secundária, além de testar parcelas circulares de 7,5 m 
de raio para estudar a regeneração do palmito; o segundo, por sua vez, comparou os métodos de parcelas de área fixa e quadrantes.

\subsubsection{Método de Parcelas de Tamanho Fixo}

O método de parcelas de tamanho fixo é o procedimento de amostragem mais antigo e difundido, no qual as árvores são incluídas na unidade amostral se estiveram dentro dos limites da parcela. Em um delineamento amostral com parcelas de área fixa, a probabilidade de inclusão de uma árvore é proporcional à sua freqüência. Podem ser temporárias, quando se almeja um único levantamento, ou permanentes, quando a finalidade é a realização de inventários subseqüentes (Schereuder et al., 1993).

\subsubsection{Tamanho e forma de parcela}

Para Prodan (1968), as unidades amostrais podem ser representadas a partir de uma divisão natural da população, ou podem surgir de considerações práticas ou teóricas. Quanto à forma, podem ser quadradas, retangulares ou circulares.

O tamanho e a forma da unidade amostral pode afetar profundamente 0 custo do levantamento, sua precisão, ou ambos (Freese, 1971). A relação exata entre o tamanho da parcela e a variabilidade entre unidades amostrais não pode ser generalizada, depende da natureza da própria população. Pode ser influenciada fortemente pelo tamanho dos agrupamentos de indivíduos e pelo intervalo de espaço entre eles (clareira). Em geral, unidades amostrais grandes, de forma que quase sempre se inclua algum agrupamento e alguma clareira, apresentarão menores variações (Freese, 1961).

Ainda segundo Freese (1961), mudanças na forma ou na orientação das unidades amostrais podem afetar em sua variabilidade, mesmo se não houver nenhuma mudança em seu tamanho. Esta variação é normalmente menor entre 
unidades amostrais longas e estreitas, ao contrário das quadradas ou circulares, que apresentam variação maior.

\subsubsection{Método de ponto quadrante}

Krebs (1999) relata que o mais antigo método de distância é o método de ponto quadrante, desenvolvido pelos primeiros agrimensores norte-americanos, no século XIX. As quatro árvores mais próximas do ponto central de cada quadrante foram registradas nas primeiras pesquisas, formando um valioso banco de dados na composição das florestas do leste dos Estados Unidos, antes de se transformarem em agricultura.

Cottam \& Curtis (1956) aplicaram esta técnica em estudos de ecologia vegetal, na qual seleciona-se uma série de pontos ao acaso, distanciados entre si ao longo de um transecto, de maneira que um mesmo indivíduo não seja medido em dois pontos sucessivos. A área ao redor de cada ponto é dividida em quatro quadrantes (cada um com $90^{\circ}$ ), e a distância da árvore mais próxima ao ponto é medida em cada um dos quatro quadrantes.

Mitchell (2004) recomenda o método de ponto quadrante como uma metodologia eficiente por produzir resultados mais rápidos e cofiáveis, comparado com o método de parcela, além de o tempo de instalação e medição ser reduzido. Gibbs (1980), por sua vez, sugere o método de ponto quadrante instalado em uma grade de cerca de um hectare de extensão, para prover dados quantitativos das espécies comuns na comunidade florestal, juntamente com uma avaliação subjetiva da ocorrência de espécies adicionais de baixas freqüências, por meio de uma amostragem ao acaso na área.

Martins (1993) enumera algumas vantagens da aplicação do método de ponto quadrante, dentre as quais, destacam-se: (1) a eliminação da influência da forma de parcela sobre os resultados, (2) a mais fácil localização dos pontos de amostragem no campo, já que estes podem seguir as linhas de picada e (3) 
ganho de tempo no campo, pois o método de quadrantes é menos tedioso que o método de parcelas.

\subsubsection{Curva de acumulação de espécies ou suficiência amostral}

Para Colwell \& Coddington (1994), uma curva de acumulação de espécies, ou a curva de coletor, é a representação gráfica do número acumulado de espécies ocorrentes dentro de uma área definida, como uma função de medida do esforço gasto para encontrá-las.

Em toda a curva de acumulação de espécies, a ordem na qual são acrescentados os indivíduos amostrados afeta a forma da curva. A variação na forma de curva, devido a ordem de acumulação, expressa, além do erro amostral, uma heterogeneidade entre as unidades amostrais. Para eliminar esta arbitrariedade, a ordenação das unidades amostrais pode ser feita de forma aleatória (Colwell \& Coddington, 1994). Martins \& Santos (1999) explicam que dependendo da forma como as unidades amostrais são ordenadas, o formato da curva pode ser diferente. Para tanto, recomendam a utilização de técnicas de reamostragem, tais como "bootstrap" e "jackknife", que consideram a amostra obtida como um universo amostral.

Já para Magurran (2004), as curvas de acumulação de espécies ilustram até que ponto novas espécies são encontradas. No entanto, a autora salienta que estas curvas não revelam a total riqueza de espécies, já que se for realizado um maior esforço amostral, mais espécies serão incluídas na curva, que tenderá a ser infinitamente crescente.

\subsection{O Bioma Cerrado}

As fisionomias do bioma cerrado possuem diversas terminologias. Eiten (1979) conceitua os termos mais difundidos e também utilizados por Coutinho (1978) tais como cerradão, cerrado sensu stricto, campo cerrado, campo sujo e 
campo limpo, utilizando-se, respectivamente, das nomenclaturas arvoredo latifoliado semidecíduo, arvoredo de escrube e árvores latifoliado semidecíduo, escrube aberto latifoliado semidecíduo, savana curtigraminosa estacional com escrube latifoliado semidecíduo e campo curtigraminoso estacional. $\mathrm{Na}$ classificação de Coutinho (1978), aplica-se o termo cerrado sensu lato para fazer referência ao bioma cerrado, incluindo-se, deste modo, todas as suas fisionomias.

Veloso \& Góes-Filho (1982), dentro do Projeto RADAMBRASIL, classificaram a vegetação brasileira em regiões fitogeográficas, sendo o bioma cerrado inserido na Região Ecológica da Savana. Segundo esses autores, savana é uma denominação antiga e originária da Venezuela, correspondendo às várias formações herbáceas nas áreas tropicais e subtropicais da Zona Neotropical, intercaladas por pequenas plantas lenhosas até arbóreas, em geral cercadas de florestas de galeria.

A classificação de Veloso \& Góes-Filho (1982) foi oficialmente adotada pelo IBGE (1992), contando com as seguintes fisionomias:

a) Savana Florestada (Cerradão): Formação campestre florestada, sua fisionomia é restrita de áreas areníticas lixiviadas com solos profundos, ocorrendo em clima tropical eminentemente estacional. Sua principal característica estrutural é arbórea (até $10 \mathrm{~m}$ ), xeromorfa, de esgalhamento profuso, providas de grandes folhas coriáceas e perenes e casca corticosa, sem estrato arbustivo nítido e com um tapete graminoso hemicriptofítico em tufos, entremeados de plantas lenhosas raquíticas, munidas de xilopódios e palmeiras anãs.

b) Savana Arborizada (Campo-Cerrado): É uma formação campestre com arvoretas, exclusiva das áreas areníticas lixiviadas, em geral queimada todos os anos. Sua composição florística é semelhante à da Savana Florestada, mas de estrutura mais aberta e bem mais baixa (aproximadamente $5 \mathrm{~m}$ ). No Centro-Oeste brasileiro é chamada de Campo Cerrado e é caracterizada por um contínuo tapete gramíneo- 
lenhoso, entremeado de árvores gregárias, geralmente raquíticas ou degradadas pelo fogo anual.

c) Savana Parque: É uma formação essencialmente campestre; natural ou antrópica. Quando natural, tem posição geográfica delimitada pelas áreas encharcadas das depressões, onde o tapete graminóide apresenta uma cobertura arbórea esparsa com uma só espécie. Quando antrópica é encontrada em toda a Savana alterada pela devastação, ampliada para pastoreio e cuja cobertura arbórea esparsa é usada para o refúgio do gado nas horas de maior insolação.

d) Savana Gramíneo-Lenhosa: É uma formação campestre entremeada de plantas lenhosas anãs, sem cobertura arbórea, a não ser as faixas das florestas de galeria, presentes nos vales. Sua composição florística varia de acordo com a posição geográfica que ocupa.

Segundo Kronka (1998), no Estado de São Paulo, as formações do complexo cerrado não são contínuas, ocorrendo como encraves, em meio a outros tipos vegetacionais como a Floresta Mesófila, que é o bioma predominante no Estado. Sobre o cerrado se estabelecem as plantas arbustivoarbóreas que atingem até 10 metros de altura, apresentando normalmente altura variável de 2 a 6 metros. A densidade e o porte das árvores definem os diferentes tipos fisionômicos do cerrado.

As espécies de cerrado são heliófitas (com raras exceções de espécies que ocorrem no sub-bosque do cerradão) e apresentam excepcional capacidade de rebrota a partir de estruturas subterrâneas após o corte ou a passagem do fogo (Durigan, 2003). Em áreas de cerrado não ocorre o processo sucessional de substituição de espécies que ocorre em florestas, com as pioneiras cedendo lugar às secundárias e climácicas (Durigan, 1996).

Para Ferri (1980), a vegetação do cerrado tem a aparência de vegetação sob condições de escassez de água, apresentando árvores e arbustos com 
galhos tortuosos, casca grossa e folhas coriáceas de superfícies brilhantes ou revestidas por uma espessa camada de pêlos.

Por outro lado, Ferri (1980) também atenta para a ocorrência de plantas comuns aos cerrados que apresentam características opostas às condições de seca, por apresentarem folhas grandes, subdivididas ou não em folíolos, além de plantas que produzem na estação seca, antes das primeiras chuvas. Isto demanda grande quantidade de água, que as plantas encontram no solo geralmente bastante profundo, e cujas raízes podem atingir até $18 \mathrm{~m}$ de profundidade. Portanto, o fator limitante no surgimento de vegetação exuberante em áreas de cerrado não é a água, e sim os fatores edáficos como o excesso de alumínio, tóxico para a vegetação.

Em uma área de cerrado no Triângulo Mineiro, Goodland (1979) constatou um decréscimo somente no teor de alumínio do solo, entre os gradientes campo limpo e cerradão, enquanto houve aumento nos teores de todos os outros elementos. Deste modo, é fácil relacionar a vegetação de porte superior do cerradão com o baixo teor de alumínio presente no solo.

\subsubsection{O bioma cerrado visto como uma formação florestal}

Uma das questões mais relevantes na classificação do cerrado é se este bioma pode ser considerado uma formação florestal. Coutinho (1978) discutiu as divergências existentes entre pesquisadores no que se refere à conceituação fisionômica e florística do cerrado, e sua conclusão foi considerá-lo um complexo de formações oreádicas - cobertura vegetal campestre que não seja propriamente uma floresta -, que vão desde o campo limpo até o cerradão, sendo suas formas savânicas (campo sujo, campo cerrado e cerrado sensu stricto) verdadeiros ecótonos de vegetação entre a forma florestal, representada pelo cerradão, e a campestre, constituída pelo campo limpo. O autor explica que, dependendo das condições ecológicas, a fisionomia pode se aproximar do ótimo campestre (campo sujo) ou do ótimo florestal (cerradão). O ótimo 
campestre ocorre quando há a predominância de solos mais rasos ou acentuadamente oligotróficos e tóxicos, além da ação antropogênica; já o ótimo florestal ocorre quando há a presença de solos profundos, pouco mais férteis e menos tóxicos, com menor ação antropogênica.

Sarmiento (1983) descreve o cerradão como um bosque onde há sobreposição das copas das árvores, porém com camada herbácea persistente. Trata-se de uma referência útil na qual as formações abertas podem ser comparadas, e segue uma fisionomia similar a uma floresta. Já Eiten (1993) define que, estruturalmente, o cerradão pode ser floresta, com dossel fechado de $7 \mathrm{~m}$ ou mais de altura, ou arvoredo, com dossel aberto da mesma altura.

Ferri (1977) argumenta que, do ponto de vista da composição florística, as disparidades entre o cerradão e os diferentes tipos de florestas são muito acentuadas. Para Durigan et al. (1987) o cerradão está inserido na classificação cerrado sensu lato devido às semelhanças deste grupo quanto à composição florística, diferentemente do que acontece em relação às florestas, cuja semelhança é percebida somente quanto à estrutura.

\subsubsection{A influência do fogo no bioma cerrado}

O fator fogo é um dos condicionantes no desenvolvimento das fisionomias do bioma cerrado. Ratter et al. (1988), estudando uma área de cerrado em Angatuba (SP), constataram a presença de manchas de cerradão que se formaram devido à proteção prolongada contra o fogo, durante períodos que variaram de 19 a 35 anos. O adensamento desta vegetação foi provocado pelo estabelecimento de um grande número de novas árvores, sendo que muitas delas não apresentam estruturas resistentes ao fogo e não são verdadeiramente de cerradão, como, por exemplo, Daphnopsis fasciculata, Rapanea umbellata e Rapanea lancifolia. Também houve a ocorrência de Amaioua guianensis e Tapirira guianensis, espécies geralmente típicas de florestas, embora ocorram às vezes no cerradão. 
Já Felfili (2001) verificou que o estrato arbóreo do cerradão apresenta características morfológicas adaptadas a queimadas. No entanto, se estas ocorrerem em maior freqüência, provoca a mortalidade de várias espécies florestais. $O$ intervalo entre queimadas deveria ser longo o suficiente para que $o$ cerradão possa se recompor, mantendo suas características originais.

\subsubsection{A Fisionomia Cerradão}

Segundo Felfili (2001), a flora do cerradão é composta por uma composição de espécies comuns ao cerrado sensu stricto, à mata de galeria e à mata mesófila de encosta ou de mata mesófila em afloramentos calcáreos. Esta é dependente do tipo de solo onde ocorre, ou seja, distrófico ou mesotrófico. Nos solos distróficos predominam espécies comuns ao cerrado sensu stricto e de matas de galeria, enquanto que nos solos mesotróficos, predominam espécies de matas mesófilas de afloramentos calcáreos. O teor de matéria orgânica sob cerradão é mais elevado do que sob o cerrado sensu stricto das imediações, e a ciclagem de nutrientes da biomassa vegetal certamente desempenha um papel importante na dinâmica deste ambiente.

A dinâmica da comunidade e o ritmo fenológico das espécies do cerradão estão bastante influenciados pela estacionalidade do clima. O pico de queda de folhas, assim como a floração de muitas espécies, ocorre na estação seca. A reprodução, germinação e estabelecimento de várias espécies ocorrem no período entre o final da estação seca e o início da chuvosa (Felfili, 2001).

Vários autores caracterizaram a estrutura do bioma cerrado, incluindo a fisionomia cerradão. De modo geral, há três estratos levemente distintos, tais como o arbóreo, o arbustivo e o herbáceo (Rizzini, 1997). Para Eiten (1993), a altura do estrato arbóreo pode variar de 7 a $15 \mathrm{~m}$, enquanto que para Rizzini (1997) e Durigan et al. (2003) varia de 8 a 12 m. Árvores individuais podem atingir de 18 a 20 m de altura (Eiten, 1993; Rizzini, 1997). Em pontos especialmente desenvolvidos, pode surgir mais um estrato - o arbóreo inferior, 
atingindo altura de 3 a $5 \mathrm{~m}$. Neste caso, o dossel possui altura maior e o arbustivo chega a mostrar-se notavelmente denso. As copas das árvores tocam-se e a comunidade denota um aspecto fechado (Rizzini, 1997).

Para Eiten (1993), um trecho arbóreo de cerrado é chamado cerradão somente quando a porção do dossel de $7 \mathrm{~m}$ ou mais tem uma cobertura superior a $30 \%$. Há mais árvores por unidade de área e as copas das árvores são mais estreitas. O autor afirma ainda que em cerradão de dossel fechado ou aberto, ocorre sub-bosque constituído de arvoretas menores de $3 \mathrm{~m}$ de altura, além de arbustos, taquara ou taboca, palmeiras com troncos curtos e bromélias grandes terrestres. A camada rasteira varia de esparsa, quando o dossel arbóreo é contínuo, a fechada e contínua, quando a incidência de luz é grande.

Segundo Eiten (1993), o cerradão é a forma principal de cerrado original no Estado de São Paulo, ocorrendo também em extensões menores em quase todas as demais regiões com incidência deste tipo vegetacional.

\subsubsection{Diferenciação geográfica e florística entre cerrado sensu lato e mata estacional semidecidual}

De acordo com Rizzini (1997), o cerrado e o complexo da mata atlântica (no qual incluem-se as matas estacionais) incidem sob o mesmo clima geral dominado por uma estação seca. Por isso, freqüentemente ocorrem juntos, em mosaicos. No segundo, porém, o ambiente aéreo é muito mais úmido.

Tanto as matas estacionais como os cerrados são definidos por Rizzini (1997) como formações edafoclimáticas, indicando a formação destas vegetações são influenciadas principalmente pelo solo e clima. $\mathrm{Na}$ estação seca, estes tipos vegetacionais se diferenciam, visto que o cerrado depende de solos profundos, enquanto que a mata depende de água superficial. Ratter (1992) verificou que as florestas decíduas e semidecíduas, assim como os cerrados, parecem ser altamente resistentes ao fogo, de tal modo que a 
transição de floresta decídua para cerrado parece estar completamente relacionada a fatores edáficos, e não ao fogo.

Rizzini (1997) descreve que a flora do cerrado sensu stricto é heterogênea, sendo uma mistura de materiais florísticos de diferentes procedências. O cerradão, por sua vez, revela-se nitidamente aparentado com as florestais pluviais, e a maioria das suas espécies evoluíram localmente (planalto central) a partir de elementos vindos de florestas vizinhas. Portanto, apresentam espécies e gêneros comuns aos ocorrentes na floresta amazônica (Bowdichia virgilioides, Byrsonima coccolobifolia, Couepia spp.), na floresta atlântica (Machaerium acutifolium, Tabebuia spp.), nas matas secas (Copaifera langsdorffii, Platypodium elegans), além de espécies isoladas, sem afinidade imediata com outras já conhecidas, como a Plenckia populnea.

Diante disto, espécies abundantes do cerradão da E. E. Assis também não são exclusivas desta fisionomia, segundo a descrição de Lorenzi (1992). A espécie Tapirira guianenis ocorre em todo o território brasileiro, principalmente em terrenos úmidos e em quase todas as formações florestais, enquanto que Machaerium acutifolium está presente desde a região amazônica até São Paulo e Mato Grosso do Sul, principalmente no cerrado. Copaifera langsdorffii e Ocotea corymbosa aparecem principalmente nas regiões de transição entre a floresta latifoliada semidecídua e o cerradão. Já a Vochysia tucanorum e a Xylopia aromatica são características do cerrado e campo cerrado de Minas Gerais, São Paulo, Goiás e Mato Grosso do Sul, sendo a primeira típica de cerrados de altitude maior que $400 \mathrm{~m}$ e indiferente às condições químicas e físicas do solo.

\subsubsection{Histórico de Desmatamento e Importância do Cerrado no Estado de São Paulo}

Nas décadas de 60 e 70, grande parte dos cerrados foi destruída pelo estímulo de políticas públicas, como o reflorestamento incentivado, além do 
aumento das áreas de cultivo de cana-de-açúcar, pastagem, culturas temporais e citricultura (Kronka, 1998).

No estudo conduzido por Kronka (1998), foi verificada, na região de Assis, uma redução da ordem de 35.000 ha (76\%) nas áreas das diversas categorias de cerrado entre 1962 e 1992. Para Durigan et al. (2004), apenas $7 \%$ da área original deste bioma estão presentes no Estado de São Paulo.

A redução da área de cerrado no Estado de São Paulo resultou na ocorrência de 8.353 fragmentos, sendo que 4.372 deles $(53,3 \%)$ possuem área inferior a 10 ha e apenas 47 (0,5\%) são maiores que 400 ha (Kronka, 1998).

De acordo com Kronka (1998), a Constituição Federal de 1988 não considerava o cerrado como Patrimônio Nacional. Visando corrigir esta falha, foi proposta, em 1992, uma Emenda Constitucional, que incluiu no parágrafo 4ํㅜㅇ Art. 225 o "cerrado" nesta categoria. As motivações para a esta inclusão foram a necessidade de reconhecimento da riqueza faunística e florística do Cerrado - que em sua biodiversidade pode ser comparada à Amazônia - e na constatação de que, depois da Mata Atlântica, o Cerrado é o bioma brasileiro que mais vem sofrendo com a ocupação humana.

Hoje, menos de $1 \%$ do território do Estado ainda mantém esta formação vegetal. Estima-se que o cerrado possua entre 4 a 10 mil espécies vasculares, número superior à maioria das outras floras mundiais. Além disso, vários estudos apontam para o grande potencial econômico deste bioma na produção de alimentos, remédios, fibras, gomas, resinas e óleos de uso comercial (Kronka, 1998).

Durigan et al. (2003) realizaram um estudo em 86 fragmentos do bioma cerrado no Estado de São Paulo, verificando que o cerradão, presente em 70\% dos fragmentos e ocorrente principalmente no oeste do Estado, tinha sido pouco estudado e é ainda pouco representado em áreas naturais protegidas. Para esses autores, esforços devem ser dirigidos para políticas e estratégias de conservação e estudo dos últimos remanescentes de áreas naturais nesta região. 


\subsection{Histórico da Estação Ecológica de Assis}

Segundo o Instituto Florestal (2004), a criação da então Reserva Estadual de Assis surgiu em 1959, a partir de um convênio firmado entre o Serviço Florestal - SF (atual Instituto Florestal) e a Estrada de Ferro Sorocabana - EFS (depois FEPASA e atual Rede Ferroviária Federal S/A), no qual a EFS cede ao SF uma área de 1.815 ha para reflorestamento. Em 1970, a Reserva Estadual de Assis passou a ser denominada Estação Experimental de Assis, com a incorporação de 3.025 ha a seu patrimônio, que pertenciam à FEPASA. Mais tarde, em 1986, a área da estação foi reduzida em 360 ha, para a criação da "Estação Experimental de Agronomia do Vale do Paranapanema". Somente em 1992, por meio do Decreto Estadual № 35.687, de 21 de setembro, foi criada a Estação Ecológica de Assis, contando com uma área de 1.312,38 ha. Logo, a E. E. Assis passou a integrar a rede de áreas protegidas, com a finalidade de preservar a área natural de cerrado. 


\section{MATERIAL E MÉTODOS}

O presente estudo foi realizado na Estação Ecológica de Assis, Unidade de Conservação administrada pelo Instituto Florestal, estando inserido no projeto "Métodos de Inventário da Biodiversidade de Espécies Arbóreas", do Programa BIOTA/FAPESP (processo no 99/08515-0). A finalidade deste projeto é desenvolver um sistema de amostragem para caracterizar e monitorar a biodiversidade de comunidades de espécies arbóreas em 3 biomas do Estado de São Paulo: Floresta Ombrófila Densa, Floresta Estacional Semidecidual e Savana Florestada (Cerradão), objeto do presente estudo.

\subsection{Descrição da área de estudo}

\subsubsection{Localização Geográfica}

A área de estudo encontra-se na Estação Ecológica de Assis, localizada no município de Assis, oeste do Estado de São Paulo (Figura 1). Segundo o Instituto Florestal (2004), a Estação possui 1.312,38 ha de vegetação predominante de cerrado e cerradão, situando-se nas coordenadas de latitude $22^{\circ} 35^{\prime}$ S e longitude $50^{\circ} 22^{\prime} \mathrm{W}$. 


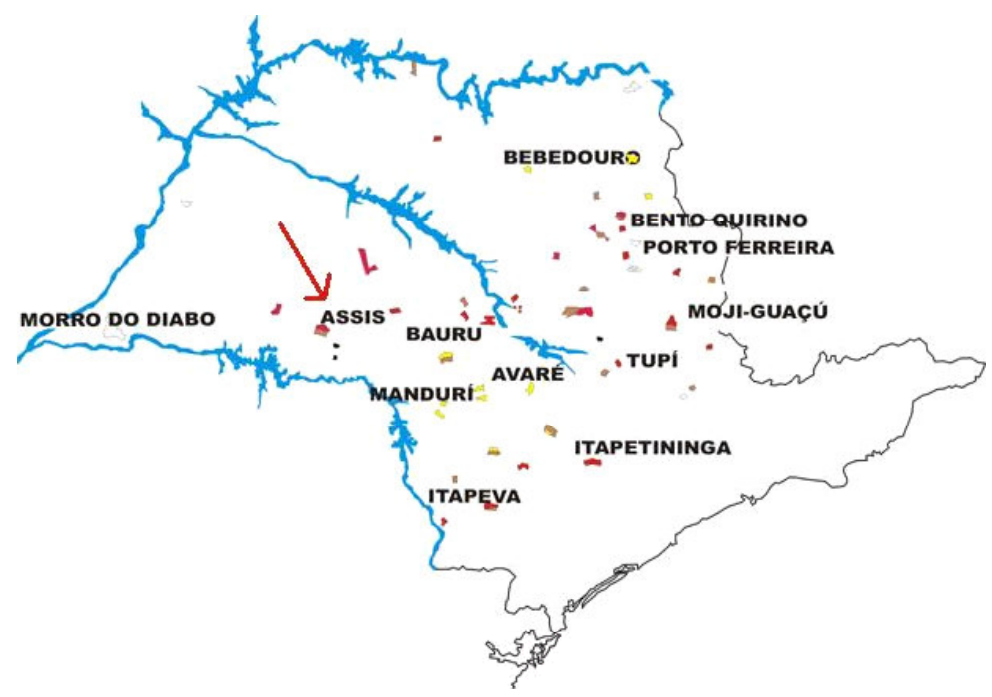

Figura 1 - Mapa do Estado de São Paulo, com seta indicativa no município de Assis

\subsubsection{Clima}

Apresenta clima mesotérmico (Cwa), segundo a classificação de Köppen, com temperaturas dos meses mais frios inferiores a $18^{\circ} \mathrm{C}$ e dos meses mais quentes, superiores a $22^{\circ} \mathrm{C}$. A precipitação anual é $1480 \mathrm{~mm}$; nos meses mais secos normalmente ultrapassa $40 \mathrm{~mm}$, podendo ocorrer geadas esporádicas (Instituto Florestal, 2004).

\subsubsection{Geomorfologia e Rede Hídrica}

De acordo com a CETESB (2004), a Estação Ecológica de Assis situa-se no planalto ocidental e seu relevo caracteriza-se pela presença de colinas amplas e topos extensos e aplainados, assentados sobre arenitos finos a muito finos. As declividades não ultrapassam 15\% (relevo suave ondulado), e suas altitudes variam de 500 a 580 metros. A rede hídrica local integra a bacia do Rio Paranapanema, possuindo as nascentes dos córregos mais importantes da área, como o Pirapitinga e o Campestre. 


\subsubsection{Solos}

Segundo o Instituto Florestal (2004), ocorrem dois tipos de solos na E. E. Assis, que, de acordo com a classificação da EMBRAPA (1999) são: Latossolo Vermelho Distrófico e o Argissolo Vermelho-Amarelo Distrófico típico, ácidos e de baixa fertilidade, com elevados teores de alumínio.

\subsubsection{Vegetação}

De acordo com Durigan et al. (1999), a vegetação da Estação Ecológica de Assis apresenta a forma cerradão como fisionomia predominante, notandose também manchas de vegetação de estrato arbóreo descontínuo, com fisionomia de cerrado sensu stricto. Esta é mais sujeita a queimadas e ocorre em áreas de menor altitude, onde as geadas esporádicas danificam a maior parte das espécies arbóreas, impedindo o adensamento do dossel.

Essas diferentes fisionomias formam um mosaico na cobertura vegetal da Estação, provavelmente relacionado às variações ambientais (umidade e fertilidade do solo), microclimáticas e até mesmo à ocorrência do fogo. Isto favorece a ocorrência de um grande número de espécies, de diferentes formas de vida e de exigências ambientais distintas (Durigan et al., 1999).

Pelo fato de serem mais conhecidos, os termos "cerradão" e cerrado sensu stricto serão adotados neste estudo para definir, respectivamente, a savana florestada e a savana arborizada.

\section{2 Informações sobre a grade de amostragem}

A área estudada é representada por uma grade sistemática de parcelas, podendo ser visualizada sobre área da E. E. Assis na Figura 2. Esta grade, previamente instalada, possui dimensões de 800 × 800 m (64 ha), contando 
com 64 parcelas retangulares de $90 \times 10 \mathrm{~m}\left(900 \mathrm{~m}^{2}\right)$, inseridas em 8 linhas distantes $100 \mathrm{~m}$ entre si, com 8 parcelas em cada linha (Figura 3). A Figura 4 ilustra o caminhamento nas parcelas através de uma trilha central, dividindo a parcela em lado esquerdo e direito, sendo cada uma delas subdividida em 9 subparcelas de $10 \times 10 \mathrm{~m}\left(100 \mathrm{~m}^{2}\right)$, com um intervalo de $10 \mathrm{~m}$ não amostrado entre as parcelas nas linhas. Portanto, a área de abrangência do estudo é de 64 ha, porém, a área efetivamente amostrada é de 5,76 ha, na qual incluem-se também os pontos quadrantes.

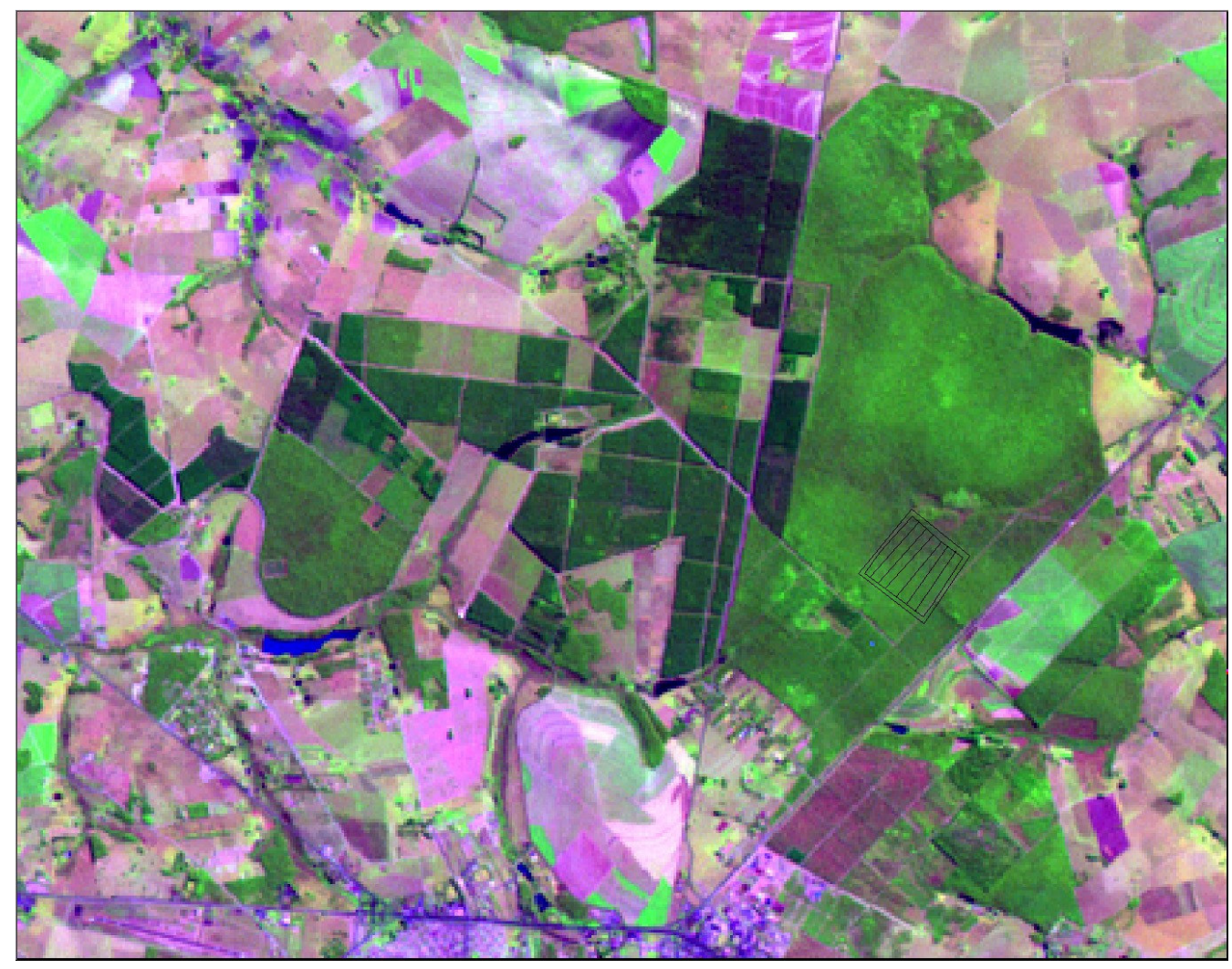

Figura 2 - Imagem do satélite Landsat 7/ETM+, composição 5/4/3, de 15/08/2002, com a localização georreferenciada da grade amostral na área de cerradão da E. E. Assis, situada à direita 


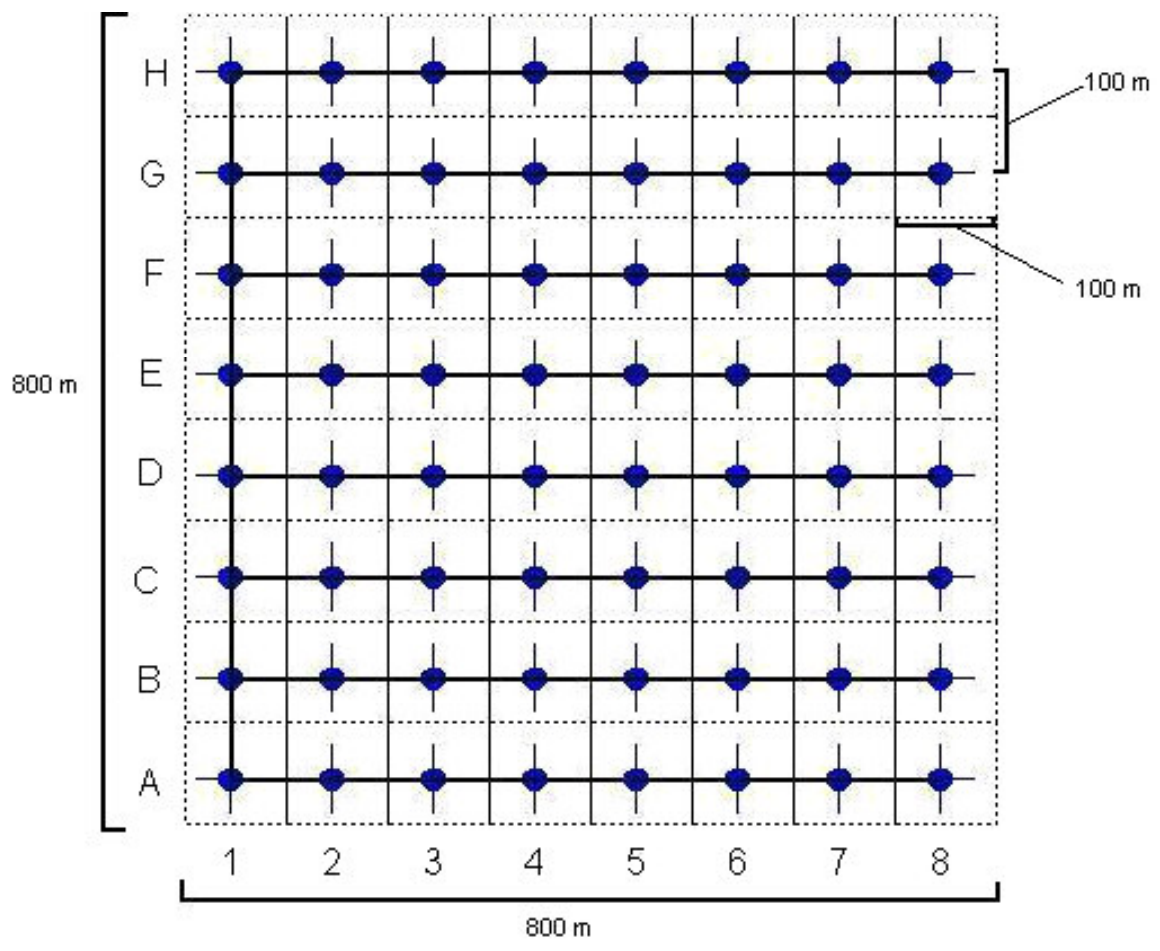

Figura 3 - Desenho esquemático da grade amostral
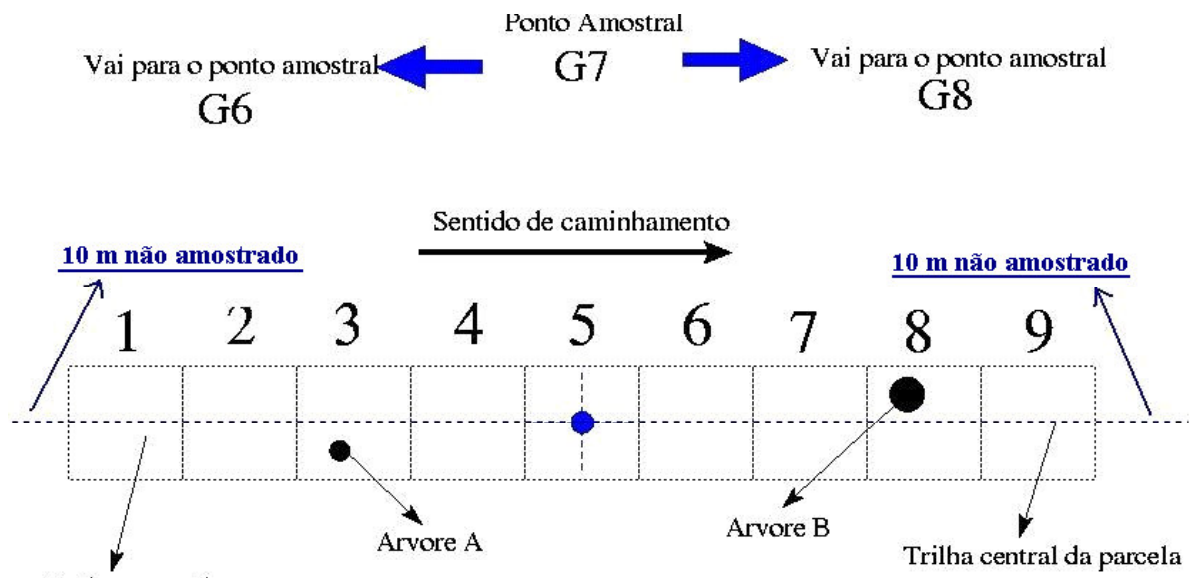

Subparcelas

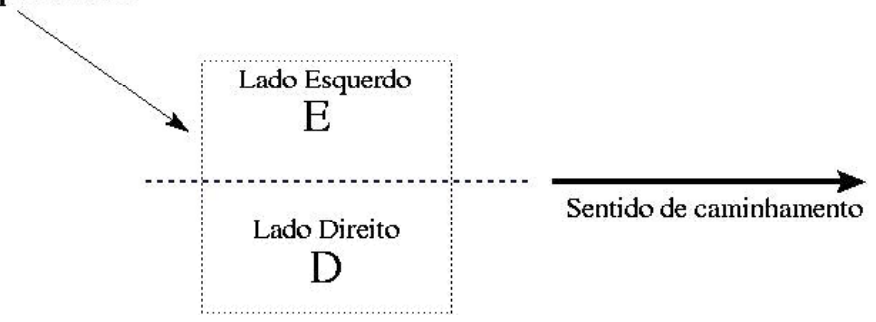

Figura 4 - Desenho esquemático da parcela, com as subparcelas representadas 
Foram amostrados na grade de parcelas os indivíduos arbóreos com CAP (circunferência à altura do peito) igual ou superior a $15 \mathrm{~cm}$, sendo marcados com placas de metal pregadas em seus fustes. No caso de indivíduos bifurcados, foram somados todos os seus fustes, incluindo os de CAP inferior a $15 \mathrm{~cm}$, desde que pelo menos um de seus fustes apresentasse CAP igual ou maior que o estabelecido e desde que a bifurcação incidisse no máximo a 1,30 $\mathrm{m}$ a partir do solo. As árvores mortas em pé incluídas na amostragem não foram consideradas nas análises deste estudo.

As placas de marcação das árvores continham a denominação "BiotaFapesp", o número do processo e a numeração da árvore, como mostra a Figura 5. Tal numeração é útil para representar cada indivíduo arbóreo, tanto no campo como na planilha de dados.

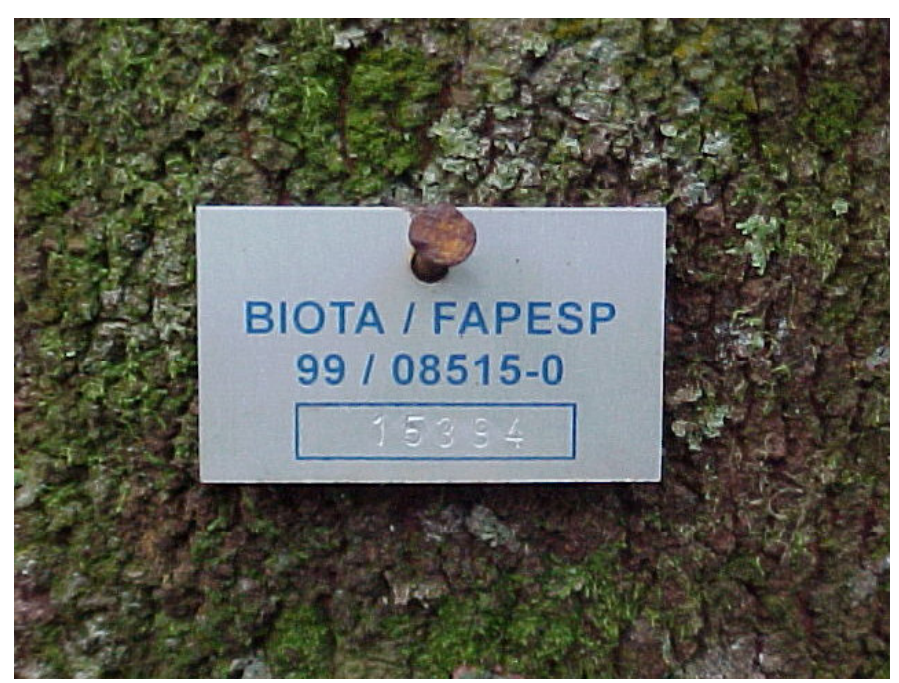

Figura 5 - Placa com numeração em um indivíduo arbóreo inserido na amostragem

Na planilha de dados foram anotadas informações referentes às linhas ( $A$ a $\mathrm{H}$ ), parcelas (1 a 8), numeração da árvore (contida na placa de metal), subparcelas (1 a 9), lado da subparcela (D: direito; E: esquerdo), CAP (circunferência à altura do peito, em $\mathrm{cm}$ ) e nome científico da espécie identificada. Também constavam dados referentes aos pontos quadrante, tais 
como: identificação com a letra " $Q$ ", informando que a árvore está inserida no quadrante, número do ponto quadrante em cada parcela (1 a 8), posição no quadrante ( $1^{\circ}$ ao $4^{\circ}$ ) e distância ponto-árvore (em metros).

Para o cálculo dos índices fitossociológicos, o CAP foi transformado em DAP (diâmetro à altura do peito, em cm), por meio da divisão do valor de CAP pela constante $\pi=3,141593$, resultando em um DAP mínimo de $4,77 \mathrm{~cm}$.

\subsection{Procedimento de Campo}

Após a demarcação e instalação da grade amostral com as parcelas já incluídas, foram instalados os pontos quadrante em cada limite entre as subparcelas, distantes entre si $10 \mathrm{~m}$. Estas possuíam estacas divisórias que serviram como ponto central do quadrante, a partir do qual visualizava-se uma linha abscissa e outra ordenada passando por este ponto, formando os quadrantes. O passo seguinte foi amostrar a árvore mais próxima do ponto central em cada quadrante, anotando-se a distância da mesma em relação a este ponto. A medida de distância é importante porque auxiliará na estimativa de densidade de árvores por hectare para este delineamento amostral.

No total, foram instalados 484 pontos quadrante na grade, totalizando 1.936 indivíduos amostrados. Além dos pontos que faziam limite com os $10 \mathrm{~m}$ não amostrados entre as parcelas, foram excluídos os pontos em que houve coincidência de árvores amostradas e os pontos em que não ocorreram árvores em um dos lados da subparcela (situados em áreas de cerrado sensu stricto, cujas densidades arbóreas são menores).

No trabalho de campo, foram utilizados os seguintes equipamentos: podão, facão, planilha de dados, saco de coleta, fita crepe para numerar o ramo coletado de espécies não conhecidas e trena (para medir a distância pontoárvore no método de ponto quadrante). A instalação dos pontos quadrante foi sendo feita simultaneamente à identificação das árvores incluídas em cada subparcela. 
Ao final de cada dia de trabalho, os materiais coletados eram prensados por meio dos procedimentos usuais de herborização, e, após seco, identificavase cada um deles por comparação com o material disponível nos herbários da Estação Ecológica de Assis, da ESALQ/USP e do Instituto Florestal (São Paulo), ou ainda, com o auxílio de especialistas.

\section{4 Índices fitossociológicos}

Para a obtenção das estimativas de índices fitossociológicos tais como densidade, freqüência, dominância, índice de valor de cobertura e índice de valor de importância, utilizou-se equações referentes aos conceitos de MüellerDombois \& Ellenberg (1974):
$D a_{i} p=\frac{n_{i}}{A}$
$D a_{i} q=\left(\frac{n_{i}}{N}\right) \times D_{T A}$
$D_{T A}=\frac{N}{A}$ (método de parcelas)
$D r_{i} p=\left(\frac{n_{i}}{N}\right) \times 100$
$D r_{i} q=\left(\frac{D a_{i} q}{D_{T A}}\right) \times 100$
$F a_{i}=\left(\frac{p_{i}}{P T}\right) \times 100$
$F r_{i}=\left(\frac{F a_{i}}{F a_{T}}\right) \times 100$
$F a_{T}=\sum F a_{i}$
$\operatorname{Doa}_{T}=\frac{A B_{T}}{A}$
$A B_{T}=\sum A B_{i}$
$A B_{i}=\sum A b_{i}$
$A b_{i}=\left(\frac{\pi \times D A P^{2}}{4}\right)$
$D o a_{i}=D a_{i} \times A B m_{i}$
$A B m_{i}=\frac{A B_{i}}{n_{i}}$
$\operatorname{Dor}_{i}=\left(\frac{A B_{i}}{A B_{T}}\right) \times 100$
$I V I_{i}=\frac{D r_{i}+F r_{i}+D o r_{i}}{3}$
$I V C_{i}=\frac{D r_{i}+D o r_{i}}{2}$ 
Sendo:

$N=$ número total de indivíduos amostrados, independentes da espécie;

$A$ = área amostrada (ha);

$D a_{i} p=$ densidade absoluta da espécie $i$ para o método de parcela. É o número de indivíduos de uma dada espécie, por unidade de área (ind/ha).

$D a_{i} q=$ densidade absoluta da espécie $i$ para o método de ponto quadrante. É o número de indivíduos de uma dada espécie, por unidade de área (ind/ha).

$D r_{i} p=$ densidade relativa da espécie $i$ para o método de parcelas. Expressa a relação (\%) entre o número de indivíduos de uma determinada espécie e o número total de indivíduos amostrados;

$D r_{i} q=$ densidade relativa da espécie $i$ para o método de ponto quadrante. Expressa a relação (\%) entre o número de indivíduos de uma determinada espécie e o número total de indivíduos amostrados;

$D_{T A}=$ densidade absoluta total ou Densidade Total por Área. Estima o número total de indivíduos, por unidade de área, independente da espécie. É expressa em $\mathrm{n}^{\circ}$ de indivíduos por hectare;

$n_{i}=$ número de indivíduos amostrados da espécie $i$;

$F a_{i}=$ freqüência absoluta da espécie $i$. É a porcentagem de unidades de amostragem em que a espécie $i$ ocorreu, em relação ao total de unidades amostradas;

$F a_{T}=$ freqüência absoluta total (soma das freqüências absolutas de todas as espécies amostradas);

$p_{i}=$ número de unidades de amostragem com a presença da espécie $i ;$

$P T=$ número total de unidades de amostragem;

$F r_{i}=$ freqüência relativa da espécie $i$. Expressa em porcentagem, é a relação entre a freqüência absoluta da espécie $i$ e as freqüências absolutas de todas as espécies amostradas;

$D o a_{i}=$ dominância absoluta da espécie $i$. Dá a taxa de ocupação do ambiente pelos indivíduos da espécie $i$, por unidade de área. É expressa em m²/ha; 
Dor $_{i}=$ dominância relativa da espécie $i$. Expressa, em porcentagem, a área ocupada pelos indivíduos da espécie $i$, em relação à área total ocupada pelos indivíduos de todas as espécies;

$D o_{T A}=$ dominância absoluta total. Estima 0 total de área ocupada pela vegetação, por unidade de área. É expressa em $\mathrm{m}^{2} / \mathrm{ha}$;

$A B_{T}=$ área basal total de todas as espécies amostradas $\left(\mathrm{m}^{2}\right)$;

$A b_{i}=$ área basal de um indivíduo da espécie $i\left(\mathrm{~m}^{2}\right)$;

$D A P=$ diâmetro à altura do peito

$\pi=3,14$ (constante)

$A B_{i}=$ área basal total da espécie $i\left(\mathrm{~m}^{2}\right)$;

$A B m_{i}=$ área basal média da espécie $i\left(\mathrm{~m}^{2}\right)$;

$I V C_{i}=$ Índice do valor de cobertura da espécie $i(\%) ;$

$I V I_{i}=$ Índice do valor de importância da espécie $i(\%)$.

Os índices de valor de cobertura e de valor de importância aparecem nas equações divididos por 2 e 3 , respectivamente, para que o valor encontrado seja facilmente interpretado em porcentagem.

No método de ponto quadrante, a estimativa da densidade do cerradão foi baseada no estimador proposto por Pollard (1971), sendo obtida por:

$$
N_{p}=\frac{10.000 \times[4 \times(4 n-1)]}{\sum\left(\pi \times r_{i j}^{2}\right)}
$$

Sendo:

$r_{i j}$ é a distância (em metros) do ponto $\mathrm{i}(\mathrm{i}=1,2,3, \ldots, 484)$ à árvore mais próxima no quadrante $\mathrm{j}(\mathrm{j}=1,2,3,4)$;

$n=\mathrm{n}^{\circ}$ total de pontos quadrante instalados.

$N_{p}=$ densidade, representada pelo número de indivíduos por hectare. 
O desvio padrão e o intervalo de confiança (95\%) para a estimativa da densidade foram obtidos pelas equações:

Desvio Padrão:

$$
s=\frac{N_{P}}{\sqrt{(4 \times n)-2}}
$$

Intervalo de Confiança:

- limite inferior: $\left(\frac{\sqrt{(16 \times n)-1)}-1,96}{\sqrt{\pi \times \sum r_{i j}^{2}}}\right)^{2}$

- limite superior: $\left(\frac{\sqrt{(16 \times n)-1)}+1,96}{\sqrt{\pi \times \sum r_{i j}^{2}}}\right)^{2}$

\section{5 Índices de Diversidade}

Para a estimativa da diversidade, fez-se uso dos índices de diversidade de Shannon e de Simpson, excluindo-se as árvores mortas e indeterminadas. Segundo Magurran (1988), para o cálculo do índice de diversidade de Shannon $\left(H^{\prime}\right)$, aplica-se a seguinte expressão:

$$
H^{\prime}=-\sum P_{i} \times \ln P_{i} \quad P_{i}=\frac{n_{i}}{N}
$$

Sendo:

$P_{i}=$ proporção de cada espécie em relação ao total de indivíduos;

$n_{i}=n^{\circ}$ de indivíduos da espécie;

$N=\mathrm{n}^{\circ}$ total de indivíduos. 
O índice de Simpson (1949) ou S', por sua vez, é representado pela equação a seguir:

$$
\begin{gathered}
S^{\prime}=1-D \\
D=\sum \frac{n_{i} \times\left(n_{i}-1\right)}{N \times(N-1)}
\end{gathered}
$$

Sendo:

$$
\begin{aligned}
& n_{i}=\mathrm{n}^{\circ} \text { de indivíduos da espécie; } \\
& N=\mathrm{n}^{\circ} \text { total de indivíduos. }
\end{aligned}
$$

Além da estimativa dos índices de diversidade de Shannon e de Simpson para a grade amostral e para o método de ponto quadrante, simulou-se a existência de nove tamanhos de parcelas nesta grade - com dimensões de 100, 200, 300, 400, 500, 600, 700, 800 e $900 \mathrm{~m}^{2}$. Estes tamanhos de parcela apresentam dimensões de $10 \times 10 \mathrm{~m}, 10 \times 20 \mathrm{~m}, 10 \times 30 \mathrm{~m}, 10 \times 40 \mathrm{~m}, 10 \times 50$ $\mathrm{m}$, e assim por diante até $10 \times 90 \mathrm{~m}$, para parcelas de $900 \mathrm{~m}^{2}$. Logo, as parcelas de $100 \mathrm{~m}^{2}$ se referem às primeiras subparcelas de cada uma 64 unidades amostrais da grade; as de $200 \mathrm{~m}^{2}$, por sua vez, se referem à junção da primeira e da segunda subparcela. Seguindo este procedimento, tem-se que as parcelas de $900 \mathrm{~m}^{2}$ representam a soma das nove subparcelas contíguas inseridas em cada uma das 64 unidades amostrais da grade.

Em seguida, estimou-se, para estes índices de diversidade, a média e o coeficiente de variação (\%) das 64 repetições que representam cada um desses nove tamanhos de parcela. A finalidade é determinar um tamanho ótimo de parcela, a partir da comparação dos tamanhos das parcelas e seus coeficientes de variação. Para uma melhor visualização da amplitude de variação dos índices entre os tamanhos de parcela, gráficos de caixa ou "box-plot" também foram gerados. 
A mesma metodologia de aumento progressivo do tamanho da parcela foi adotada para se estimar a densidade, acrescentando o cálculo do Intervalo de Confiança a uma probabilidade de $95 \%$. As equações aplicadas na determinação destes parâmetros são apresentadas a seguir:

Média:

$\bar{x}=\frac{\sum_{i=1}^{n} X_{i}}{n}$

Desvio Padrão:

$s=\sqrt{s_{\bar{x}}^{2}}$

Erro padrão da média:

$s_{\bar{x}}=\frac{s}{\sqrt{n}}$

Sendo:

$X_{i}=$ índice de diversidade ou densidade de cada parcela;

$n=n^{0}$ de parcelas;

$s=$ desvio padrão;

$\bar{x}=$ média estimada;

IC = Intervalo de Confiança;

$t=$ valor tabelado (Student);

$s_{\bar{x}}=$ erro padrão da média;

$\bar{X}=$ média verdadeira da população;

$P=$ probabilidade de a média estar dentro do intervalo calculado $(0,95$ ou $95 \%)$ 
Foram estimadas também a densidades de todas as subparcelas de 100 $\mathrm{m}^{2}$, separadamente, inseridas nas 64 unidades amostrais da grade, a fim de verificar a variação no número de indivíduos por hectare na área estudada, que diferencia os trechos com predomínio de savana florestada (cerradão) dos trechos com predomínio de savana arborizada (cerrado sensu stricto), de menor ocorrência. Este critério foi adotado para essas subparcelas porque, em algumas áreas da grade amostral, a mudança de fisionomia era percebida em pequenos trechos durante o caminhamento pela trilha principal de cada linha de amostragem. 


\section{RESULTADOS E DISCUSSÃO}

\subsection{Florística}

As famílias e espécies inseridas no método de parcelas de $900 \mathrm{~m}^{2}$, abrangendo toda a grade amostral, estão apresentadas na Tabela 1. As nomenclaturas estão atualizadas de acordo com o Missouri Botanical Garden (2004).

Tabela 1. Lista de ocorrência de espécies na amostragem pelo método de parcelas de $900 \mathrm{~m}^{2}$

\begin{tabular}{|c|c|c|}
\hline Famílias & Espécies & Nomes populares \\
\hline \multirow[t]{2}{*}{ Anacardiaceae } & Lithraea molleoides (Vell.) Engl. & Aroeirinha \\
\hline & Tapirira guianensis Aubl. ${ }^{(1)}$ & Peito-de-pombo \\
\hline \multirow[t]{2}{*}{ Annonaceae } & Annona crassiflora Mart. ${ }^{(1)}$ & Marolo-verdadeiro \\
\hline & Xylopia aromatica (Lam.) Mart. ${ }^{(1)}$ & Pimenta-de-macaco \\
\hline Apocynaceae & Aspidosperma tomentosum Mart. ${ }^{(1)}$ & Perobinha-do-campo \\
\hline Arecaceae & Syagrus romanzoffiana (Cham.) Glassman ${ }^{(1)}$ & Jerivá \\
\hline \multirow[t]{3}{*}{ Asteraceae } & Gochnatia polymorpha (Less.) Cabrera ${ }^{(1)}$ & Candeia \\
\hline & Piptocarpha axillaris (Less.) Baker ${ }^{(1)}$ & \\
\hline & Piptocarpha rotundifolia (Less.) Baker & Cambará \\
\hline \multirow[t]{2}{*}{ Bignoniaceae } & Tabebuia aurea (Silva Manso) Benth \& Hook. f. ex S. Moore ${ }^{(1)}$ & Ipê-amarelo \\
\hline & $\begin{array}{l}\text { Tabebuia ochracea (Cham.) Standl. } \\
\text { Tabebuia sp. }{ }^{(1)} \\
\text { Tabebuia sp. } 2\end{array}$ & Ipê-amarelo \\
\hline Bombacaceae & Eriotheca gracilipes (K. Schum.) A. Robyns ${ }^{(1)}$ & Paineira-do-campo \\
\hline Boraginaceae & Cordia sp. ${ }^{(1)}$ & \\
\hline Burseraceae & Protium heptaphyllum (Aubl.) Marchand ${ }^{(1)}$ & Amescla \\
\hline \multirow[t]{2}{*}{ Caesalpiniaceae } & Copaifera langsdorffii Desf. ${ }^{(1)}$ & Copaíba \\
\hline & Dimorphandra mollis Benth. ${ }^{(1)}$ & Canafístula-do-cerrado \\
\hline Caryocaraceae & Caryocar brasiliense Cambess. & Pequi \\
\hline
\end{tabular}




\section{Tabela 1. Lista de ocorrência de espécies na amostragem pelo método de parcelas de $900 \mathrm{~m}^{2}$}

\begin{tabular}{|c|c|c|}
\hline Famílias & Espécies & Nomes populares \\
\hline \multirow[t]{2}{*}{ Celastraceae } & Plenckia populnea Reissek ${ }^{(1)}$ & \\
\hline & Maytenus robusta Reissek & \\
\hline Chrysobalanaceae & $\begin{array}{l}\text { Couepia grandiflora (Mart. \& Zucc.) Benth. ex Hook. f. }{ }^{(1)} \\
\text { Licania humilis Cham. \& Schltdl. }\end{array}$ & \\
\hline Clethraceae & Clethra scabra Pers. & Guaperê, Vassourão \\
\hline Clusiaceae & Kielmeyera sp. & \\
\hline Combretaceae & Terminalia brasiliensis (Cambess. ex A. St.-Hil) Eichler ${ }^{(1)}$ & Capitão-do-campo \\
\hline Connaraceae & Connarus suberosus Planch. & Para-tudo \\
\hline Ebenaceae & Diospyros cf. hispida A. DC. ${ }^{(1)}$ & \\
\hline \multirow[t]{3}{*}{ Erythroxylaceae } & Erythroxylum cuneifolium (Mart.) O. E. Schulz ${ }^{(1)}$ & \\
\hline & Erythroxylum deciduum A. St.-Hil. & \\
\hline & Erythroxylum suberosum A. St.-Hil. & Mercúrio-do-campo \\
\hline \multirow[t]{3}{*}{ Euphorbiaceae } & Croton floribundus Spreng. ${ }^{(1)}$ & Capixingui \\
\hline & Maprounea guianensis Aubl. ${ }^{(1)}$ & Bonifácio \\
\hline & Pera glabrata (Schott) Poepp. ex Baill. ${ }^{(1)}$ & \\
\hline \multirow[t]{7}{*}{ Fabaceae } & Acosmium subelegans (Mohlenbr.) Yakovlev ${ }^{(1)}$ & Peroba-do-campo \\
\hline & Andira anthelmia (Vell.) J. F. Macbr. & Angelim-de-morcego \\
\hline & Bowdichia virgilioides Kunth ${ }^{(1)}$ & Sucupira \\
\hline & Dalbergia miscolobium Benth. ${ }^{(1)}$ & Jacarandá-violeta \\
\hline & Machaerium acutifolium Vogel ${ }^{(1)}$ & Jacarandá-do-campo \\
\hline & Machaerium brasiliense Vogel ${ }^{(1)}$ & Sapuva \\
\hline & Platypodium elegans Vogel ${ }^{(1)}$ & Amendoim-do-campo \\
\hline Lacistemaceae & Lacistema hasslerianum Chodat & \\
\hline \multirow[t]{4}{*}{ Lauraceae } & Nectandra cuspidata Nees ${ }^{(1)}$ & \\
\hline & Nectandra oppositifolia Nees \& Mart. & \\
\hline & Ocotea corymbosa (Meisn.) Mez ${ }^{(1)}$ & Canelinha \\
\hline & Persea pyrifolia (D. Don) Spreng. ${ }^{(1)}$ & \\
\hline Loganiaceae & Strychnos pseudoquina A. St.-Hil. & \\
\hline Lythraceae & Lafoensia pacari A. St.-Hil. & Dedaleiro \\
\hline \multirow[t]{4}{*}{ Malpighiaceae } & Byrsonima basiloba A. Juss. & \\
\hline & Byrsonima coccolobifolia Kunth & Murici \\
\hline & Byrsonima laxiflora Griseb. $^{(1)}$ & \\
\hline & Byrsonima cf. verbascifolia (L.) DC. & \\
\hline \multirow[t]{3}{*}{ Melastomataceae } & Miconia langsdorffii Cogn. & \\
\hline & $\begin{array}{l}\text { Miconia ligustroides (DC.) Naudin }{ }^{(1)} \\
\text { Miconia sp. }{ }^{(1)} \\
\text { Miconia sp. } 2\end{array}$ & \\
\hline & Tibouchina stenocarpa (DC.) Cogn. ${ }^{(1)}$ & Quaresmeira \\
\hline \multirow[t]{4}{*}{ Mimosaceae } & Anadenanthera falcata (Benth.) Speg. ${ }^{(1)}$ & Angico-do-cerrado \\
\hline & Enterolobium gummiferum (Mart.) J.F. Macbr. & \\
\hline & Plathymenia reticulata Benth. ${ }^{(1)}$ & Vinhático-do-campo \\
\hline & Stryphnodendron obovatum Benth. ${ }^{(1)}$ & Barbatimão \\
\hline
\end{tabular}




\section{Tabela 1. Lista de ocorrência de espécies na amostragem pelo método de parcelas de $900 \mathrm{~m}^{2}$}

\begin{tabular}{|c|c|c|}
\hline Famílias & Espécies & Nomes populares \\
\hline Monimiaceae & Siparuna guianensis Aubl. ${ }^{(1)}$ & Café-de-bugre \\
\hline Moraceae & Brosimum sp. ${ }^{(1)}$ & \\
\hline \multirow[t]{2}{*}{ Myrsinaceae } & Rapanea lancifolia (Mart.) Mez ${ }^{(1)}$ & Pororoca \\
\hline & Rapanea umbellata (Mart.) Mez. ${ }^{(1)}$ & Mangue \\
\hline \multirow[t]{13}{*}{ Myrtaceae } & Eugenia aurata O.Berg ${ }^{(1)}$ & \\
\hline & Eugenia pluriflora DC. & \\
\hline & Eugenia livida O. Berg & \\
\hline & Myrcia bella Cambess ${ }^{(1)}$ & \\
\hline & Myrcia fallax (Rich.) DC. ${ }^{(1)}$ & \\
\hline & Myrcia guianensis DC. ${ }^{(1)}$ & \\
\hline & Myrcia linguaeformis (Berg) N. Silveira ${ }^{(1)}$ & \\
\hline & Myrcia multiflora (Lam.) DC. ${ }^{(1)}$ & Cambuí \\
\hline & Myrcia cf. dictyophylla (O. Berg) Mattos \& D. Legrand ${ }^{(1)}$ & \\
\hline & Myrcia tomentosa (Aubl.) DC. ${ }^{(1)}$ & Goiabeira-brava \\
\hline & Myrcia venulosa DC. ${ }^{(1)}$ & \\
\hline & Myrciaria floribunda (H. West ex Willd) O. Berg & \\
\hline & Psidium cinereum Mart. ex DC. & \\
\hline \multirow[t]{3}{*}{ Nyctaginaceae } & Guapira graciliflora (Schmidt) Lundell & \\
\hline & Guapira noxia (Netto) Lundell ${ }^{(1)}$ & \\
\hline & Guapira sp. & \\
\hline Ochnaceae & Ouratea spectabilis (Mart.) Engl. ${ }^{(1)}$ & Folha-de-serra \\
\hline Pinaceae & Pinus elliottii Engelm. & Pinheiro \\
\hline Proteaceae & Roupala montana Aubl. ${ }^{(1)}$ & Carne-de-vaca \\
\hline Rosaceae & Prunus myrtifolia (L.) Urb. ${ }^{(1)}$ & Pessegueiro-bravo \\
\hline \multirow[t]{4}{*}{ Rubiaceae } & Alibertia sessilis (Vell.) K. Schum. ${ }^{(1)}$ & Marmelo \\
\hline & Amaioua intermedia Mart. ${ }^{(1)}$ & Pau-carvão \\
\hline & Faramea montevidensis (Cham. \& Schltdl.) DC. ${ }^{(1)}$ & \\
\hline & Ixora brevifolia Benth. & \\
\hline Sapindaceae & Matayba elaeagnoides Radlk. ${ }^{(1)}$ & \\
\hline Sapotaceae & Pouteria ramiflora (Mart.) Radlk. ${ }^{(1)}$ & Abiu-do-cerrado \\
\hline \multirow[t]{2}{*}{ Styracaceae } & Styrax camporum Pohl ${ }^{(1)}$ & Estoraque-do-campo \\
\hline & Styrax ferrugineus Nees \& Mart. ${ }^{(1)}$ & \\
\hline \multirow[t]{2}{*}{ Symplocaceae } & Symplocos mosenii Brand. ${ }^{(1)}$ & \\
\hline & Symplocos pubescens Klotzsch ex Benth. ${ }^{(1)}$ & \\
\hline Thymelaeaceae & Daphnopsis fasciculata (Meisn.) Nevling ${ }^{(1)}$ & \\
\hline Tiliaceae & Luehea grandiflora Mart. ${ }^{(1)}$ & Açoita-cavalo \\
\hline \multirow[t]{5}{*}{ Vochysiaceae } & Qualea cordata (Mart.) Spreng. ${ }^{(1)}$ & Pau-terra \\
\hline & Qualea grandiflora Mart. ${ }^{(1)}$ & Pau-terra-do-campo \\
\hline & Qualea multiflora Mart. ${ }^{(1)}$ & Pau-terra \\
\hline & Qualea parviflora Mart. ${ }^{(1)}$ & Pau-terra-mirim \\
\hline & Vochysia tucanorum Mart. ${ }^{(1)}$ & Pau-de-tucano \\
\hline
\end{tabular}

${ }^{(1)}$ Espécies também ocorrentes no método de ponto quadrante. 
Foram amostradas 102 espécies pelo método de parcelas, distribuídas em 45 famílias. No método de ponto quadrante, 71 espécies foram amostradas, distribuídas em 37 famílias. Cabe salientar a ocorrência de um indivíduo invasor de Pinus elliottii na grade de amostragem, possivelmente facilitada pela existência de plantios da espécie para extração de resina em área próxima, sob a responsabilidade da administração da Floresta Estadual de Assis.

Há muita variação no número de espécies encontradas nos levantamentos por parcela no bioma cerrado. Durigan et al. (1994) listaram 44 espécies no cerrado de Itirapina (SP), enquanto que Cesar et al. (1988), em uma área de cerrado em Corumbataí (SP), encontraram 101 espécies. Gomes et al. (2004) encontraram 118 espécies em um cerradão em Brotas (SP).

Deve-se destacar também $0 \mathrm{n}^{\circ}$ de indivíduos mortos amostrados na grade, equivalente a 376. Este valor indica que a taxa de mortalidade entre o período de instalação da grade amostral (10 semestre de 2002) até o final da fase de identificação das árvores ( $1^{\circ}$ semestre de 2004 ), corresponde a 3,44\%. O número de árvores vivas amostradas totalizou 10.561 indivíduos.

A morte natural de espécies pioneiras foi citada por Dias (1993) como a responsável pela grande quantidade de árvores mortas em seu estudo em uma mata secundária de floresta ombrófila densa. $\mathrm{Na}$ área de cerradão do presente estudo, isso também parece ocorrer, visto que ocorreram muitos indivíduos mortos de Vochysia tucanorum, espécie mais freqüente em áreas de cerrado sensu strictu e em áreas de transição entre cerrado sensu stricto e cerradão. Estes dois aspectos fisionômicos encontrados na área estudada estão representados na Figura 6. 

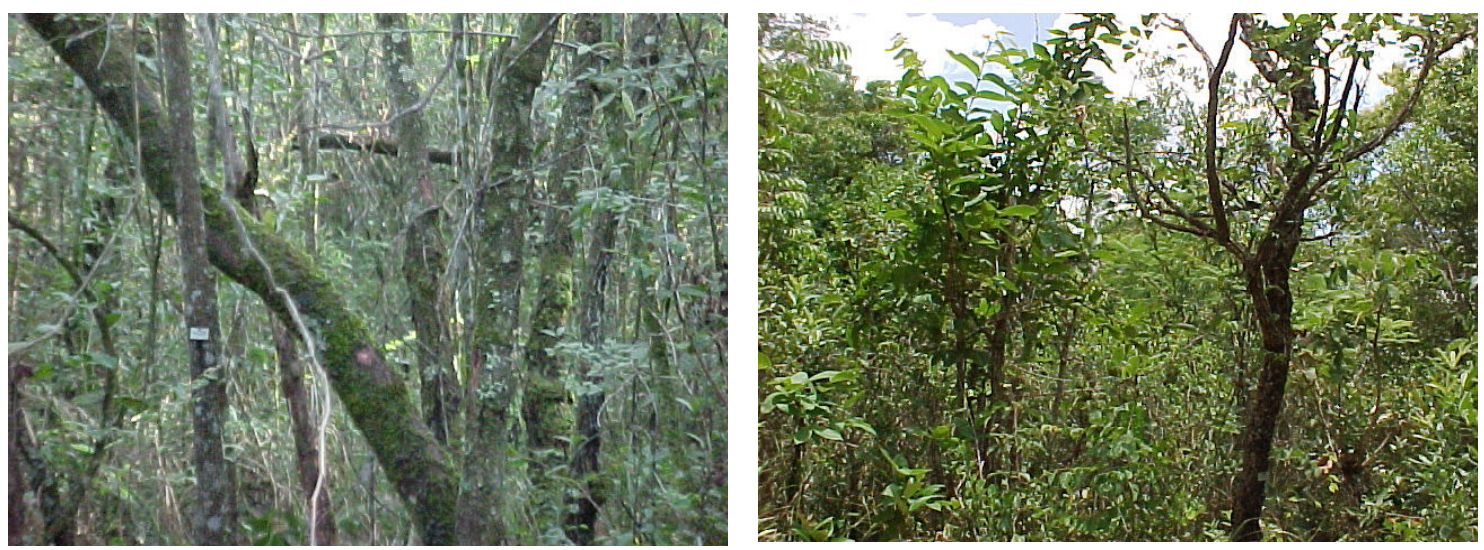

Figura 6 - Comparação das fisionomias cerradão (à esquerda) e cerrado sensu stricto (à direita) na E. E. Assis

\subsection{Fitossociologia}

A Tabela 2 apresenta as estimativas dos parâmetros fitossociológicos encontrados no método de parcelas, no qual o IVI (Índice de Valor de Importância), é listado em ordem decrescente.

Tabela 2. Estimativas de parâmetros fitossociológicos encontrados por espécie para o método de parcela de área fixa de $900 \mathrm{~m}^{2}$

\begin{tabular}{lccccccccc}
\hline \multicolumn{1}{c}{ Espécie } & $\mathbf{n}^{\circ}$ ind. & Do.a $^{(\mathbf{1})}$ & Do.r & De.a & De.r & Fr.a & Fr.r & IVC(\%) & IVI(\%) \\
\hline Copaifera langsdorffii & 1709 & 6,1 & 24,6 & 296,7 & 16,2 & 100,0 & 3,9 & 20,4 & 14,9 \\
Vochysia tucanorum & 1567 & 3,6 & 14,5 & 272,0 & 14,8 & 100,0 & 3,9 & 14,7 & 11,1 \\
Ocotea corymbosa & 1121 & 3,0 & 11,8 & 194,6 & 10,6 & 100,0 & 3,9 & 11,2 & 8,8 \\
Tapirira guianensis & 475 & 2,2 & 8,7 & 82,5 & 4,5 & 93,8 & 3,7 & 6,6 & 5,6 \\
Xylopia aromatica & 1037 & 0,9 & 3,6 & 180,0 & 9,8 & 76,6 & 3,0 & 6,7 & 5,5 \\
Machaerium acutifolium & 378 & 0,8 & 3,1 & 65,6 & 3,6 & 95,3 & 3,7 & 3,4 & 3,5 \\
Anadenanthera falcata & 257 & 1,1 & 4,4 & 44,6 & 2,4 & 62,5 & 2,5 & 3,4 & 3,1 \\
Pera glabrata & 186 & 1,0 & 4,2 & 32,3 & 1,8 & 59,4 & 2,3 & 3,0 & 2,8 \\
Rapanea umbellata & 335 & 0,4 & 1,4 & 58,2 & 3,2 & 90,6 & 3,6 & 2,3 & 2,7 \\
Myrcia multiflora & 388 & 0,4 & 1,5 & 67,4 & 3,7 & 67,2 & 2,6 & 2,6 & 2,6 \\
Plathymenia reticulata & 253 & 0,7 & 2,7 & 43,9 & 2,4 & 62,5 & 2,5 & 2,6 & 2,5 \\
Qualea cordata & 268 & 0,3 & 1,2 & 46,5 & 2,5 & 87,5 & 3,4 & 1,9 & 2,4 \\
Qualea grandiflora & 176 & 0,6 & 2,2 & 30,6 & 1,7 & 75,0 & 2,9 & 2,0 & 2,3 \\
Myrcia guianensis & 200 & 0,3 & 1,3 & 34,7 & 1,9 & 79,7 & 3,1 & 1,6 & 2,1
\end{tabular}

${ }^{(1)}$ Do.a: Dominância absoluta $\left(\mathrm{m}^{2} / \mathrm{ha}\right)$, Do.r: Dominância relativa (\%), De.a:Densidade absoluta ( $\mathrm{n}$ ㅇ ind/ha), De.r: Densidade relativa (\%), Fr.a: Freqüência absoluta (\%), Fr.r: Freqüência relativa (\%), IVC(\%): Índice de Valor de Cobertura, IVI (\%): Índice de Valor de Importância. 
Tabela 2. Estimativas de parâmetros fitossociológicos encontrados por espécie para o método de parcela de área fixa de $900 \mathrm{~m}^{2}$

\begin{tabular}{|c|c|c|c|c|c|c|c|c|c|}
\hline Espécie & $\mathrm{n}-$ ind. & Do.a $a^{(1)}$ & Do.r & De.a & De.r & Fr.a & Fr.r & IVC(\%) & IVI(\%) \\
\hline Protium heptaphyllum & 215 & 0,4 & 1,7 & 37,3 & 2,0 & 57,8 & 2,3 & 1,9 & 2,0 \\
\hline Faramea montevidensis & 223 & 0,2 & 1,0 & 38,7 & 2,1 & 48,4 & 1,9 & 1,5 & 1,7 \\
\hline Siparuna guianensis & 191 & 0,2 & 0,8 & 33,2 & 1,8 & 54,7 & 2,2 & 1,3 & 1,6 \\
\hline indeterminadas & 112 & 0,2 & 0,8 & 19,4 & 1,1 & 71,9 & 2,8 & 0,9 & 1,6 \\
\hline Terminalia brasiliensis & 122 & 0,2 & 0,8 & 21,2 & 1,2 & 53,1 & 2,1 & 1,0 & 1,3 \\
\hline Rapanea lancifolia & 154 & 0,2 & 0,6 & 26,7 & 1,5 & 50,0 & 2,0 & 1,0 & 1,3 \\
\hline Myrcia venulosa & 84 & 0,1 & 0,5 & 14,6 & 0,8 & 57,8 & 2,3 & 0,6 & 1,2 \\
\hline Gochnatia polymorpha & 50 & 0,2 & 0,8 & 8,7 & 0,5 & 48,4 & 1,9 & 0,6 & 1,1 \\
\hline Myrcia linguaeformis & 78 & 0,2 & 0,8 & 13,5 & 0,7 & 42,2 & 1,7 & 0,8 & 1,1 \\
\hline Syagrus romanzoffiana & 56 & 0,1 & 0,5 & 9,7 & 0,5 & 51,6 & 2,0 & 0,5 & 1,0 \\
\hline Byrsonima laxiflora & 70 & 0,1 & 0,4 & 12,2 & 0,7 & 46,9 & 1,8 & 0,5 & 1,0 \\
\hline Persea pyrifolia & 64 & 0,2 & 0,8 & 11,1 & 0,6 & 32,8 & 1,3 & 0,7 & 0,9 \\
\hline Acosmium subelegans & 47 & 0,1 & 0,3 & 8,2 & 0,5 & 42,2 & 1,7 & 0,4 & 0,8 \\
\hline Amaioua intermedia & 58 & 0,1 & 0,4 & 10,1 & 0,6 & 35,9 & 1,4 & 0,5 & 0,8 \\
\hline Pouteria ramiflora & 45 & 0,1 & 0,4 & 7,8 & 0,4 & 37,5 & 1,5 & 0,4 & 0,8 \\
\hline Eugenia aurata & 39 & 0,1 & 0,2 & 6,8 & 0,4 & 39,1 & 1,5 & 0,3 & 0,7 \\
\hline Ouratea spectabilis & 39 & 0,1 & 0,3 & 6,8 & 0,4 & 35,9 & 1,4 & 0,3 & 0,7 \\
\hline Eriotheca gracilipes & 55 & 0,1 & 0,3 & 9,5 & 0,5 & 31,3 & 1,2 & 0,4 & 0,7 \\
\hline Annona crassiflora & 40 & 0,1 & 0,3 & 6,9 & 0,4 & 31,3 & 1,2 & 0,3 & 0,6 \\
\hline Daphnopsis fasciculata & 36 & 0,0 & 0,1 & 6,3 & 0,3 & 34,4 & 1,4 & 0,2 & 0,6 \\
\hline Stryphnodendron obovatum & 31 & 0,0 & 0,1 & 5,4 & 0,3 & 31,3 & 1,2 & 0,2 & 0,6 \\
\hline Bowdichia virgilioides & 19 & 0,1 & 0,3 & 3,3 & 0,2 & 25,0 & 1,0 & 0,2 & 0,5 \\
\hline Plenckia populnea & 18 & 0,0 & 0,2 & 3,1 & 0,2 & 25,0 & 1,0 & 0,2 & 0,4 \\
\hline Guapira noxia & 19 & 0,1 & 0,2 & 3,3 & 0,2 & 23,4 & 0,9 & 0,2 & 0,4 \\
\hline Miconia ligustroides & 20 & 0,0 & 0,1 & 3,5 & 0,2 & 25,0 & 1,0 & 0,1 & 0,4 \\
\hline Symplocos mosenii & 23 & 0,1 & 0,3 & 4,0 & 0,2 & 17,2 & 0,7 & 0,3 & 0,4 \\
\hline Maprounea guianensis & 22 & 0,0 & 0,1 & 3,8 & 0,2 & 23,4 & 0,9 & 0,2 & 0,4 \\
\hline Platypodium elegans & 31 & 0,0 & 0,2 & 5,4 & 0,3 & 18,8 & 0,7 & 0,2 & 0,4 \\
\hline Myrcia bella & 21 & 0,0 & 0,1 & 3,6 & 0,2 & 18,8 & 0,7 & 0,2 & 0,4 \\
\hline Roupala montana & 13 & 0,0 & 0,1 & 2,3 & 0,1 & 15,6 & 0,6 & 0,1 & 0,3 \\
\hline Nectandra cuspidata & 12 & 0,0 & 0,1 & 2,1 & 0,1 & 14,1 & 0,6 & 0,1 & 0,3 \\
\hline Machaerium brasiliense & 10 & 0,0 & 0,1 & 1,7 & 0,1 & 15,6 & 0,6 & 0,1 & 0,3 \\
\hline Tabebuia aurea & 10 & 0,0 & 0,1 & 1,7 & 0,1 & 14,1 & 0,6 & 0,1 & 0,2 \\
\hline Symplocos pubescens & 10 & 0,0 & 0,1 & 1,7 & 0,1 & 12,5 & 0,5 & 0,1 & 0,2 \\
\hline Couepia grandiflora & 10 & 0,0 & 0,1 & 1,7 & 0,1 & 10,9 & 0,4 & 0,1 & 0,2 \\
\hline Dimorphandra mollis & 10 & 0,0 & 0,1 & 1,7 & 0,1 & 10,9 & 0,4 & 0,1 & 0,2 \\
\hline Myrcia fallax & 10 & 0,0 & 0,0 & 1,7 & 0,1 & 9,4 & 0,4 & 0,1 & 0,2 \\
\hline Qualea multiflora & 8 & 0,0 & 0,1 & 1,4 & 0,1 & 7,8 & 0,3 & 0,1 & 0,1 \\
\hline Dalbergia miscolobium & 7 & 0,0 & 0,0 & 1,2 & 0,1 & 7,8 & 0,3 & 0,1 & 0,1 \\
\hline Brosimum sp. & 10 & 0,0 & 0,1 & 1,7 & 0,1 & 6,3 & 0,3 & 0,1 & 0,1 \\
\hline Tabebuia sp. & 5 & 0,0 & 0,0 & 0,9 & 0,1 & 7,8 & 0,3 & 0,0 & 0,1 \\
\hline
\end{tabular}

(1)Do.a: Dominância absoluta $\left(\mathrm{m}^{2} / \mathrm{ha}\right)$, Do.r: Dominância relativa (\%), De.a:Densidade absoluta (no ind/ha), De.r: Densidade relativa (\%), Fr.a: Freqüência absoluta (\%), Fr.r: Freqüência relativa (\%), IVC(\%): Índice de Valor de Cobertura, IVI (\%): Índice de Valor de Importância. 
Tabela 2. Estimativas de parâmetros fitossociológicos encontrados por espécie para o método de parcela de área fixa de $900 \mathrm{~m}^{2}$

\begin{tabular}{|c|c|c|c|c|c|c|c|c|c|}
\hline Espécie & $\mathrm{n}=$ ind. & Do. $a^{(1)}$ & Do.r & De.a & De.r & Fr.a & Fr.r & IVC(\%) & IVI(\%) \\
\hline Styrax camporum & 5 & 0,0 & 0,0 & 0,9 & 0,1 & 7,8 & 0,3 & 0,0 & 0,1 \\
\hline Alibertia sessilis & 7 & 0,0 & 0,0 & 1,2 & 0,1 & 6,3 & 0,3 & 0,1 & 0,1 \\
\hline Luehea grandiflora & 5 & 0,0 & 0,0 & 0,9 & 0,1 & 6,3 & 0,3 & 0,0 & 0,1 \\
\hline Miconia sp.2 & 4 & 0,0 & 0,0 & 0,7 & 0,0 & 6,3 & 0,3 & 0,0 & 0,1 \\
\hline Licania humilis & 3 & 0,0 & 0,0 & 0,5 & 0,0 & 4,7 & 0,2 & 0,0 & 0,1 \\
\hline Byrsonima coccolobifolia & 3 & 0,0 & 0,0 & 0,5 & 0,0 & 4,7 & 0,2 & 0,0 & 0,1 \\
\hline Aspidosperma tomentosum & 4 & 0,0 & 0,0 & 0,7 & 0,0 & 4,7 & 0,2 & 0,0 & 0,1 \\
\hline Piptocarpha axillaris & 3 & 0,0 & 0,0 & 0,5 & 0,0 & 4,7 & 0,2 & 0,0 & 0,1 \\
\hline Tibouchina stenocarpa & 3 & 0,0 & 0,0 & 0,5 & 0,0 & 4,7 & 0,2 & 0,0 & 0,1 \\
\hline Diospyros cf. hispida & 3 & 0,0 & 0,0 & 0,5 & 0,0 & 4,7 & 0,2 & 0,0 & 0,1 \\
\hline Kielmeyera sp. & 3 & 0,0 & 0,0 & 0,5 & 0,0 & 4,7 & 0,2 & 0,0 & 0,1 \\
\hline Myrcia tomentosa & 3 & 0,0 & 0,0 & 0,5 & 0,0 & 4,7 & 0,2 & 0,0 & 0,1 \\
\hline Styrax ferrugineus & 3 & 0,0 & 0,0 & 0,5 & 0,0 & 4,7 & 0,2 & 0,0 & 0,1 \\
\hline Enterolobium gummiferum & 3 & 0,0 & 0,0 & 0,5 & 0,0 & 4,7 & 0,2 & 0,0 & 0,1 \\
\hline Lafoensia pacari & 3 & 0,0 & 0,0 & 0,5 & 0,0 & 4,7 & 0,2 & 0,0 & 0,1 \\
\hline Nectandra oppositifolia & 6 & 0,0 & 0,0 & 1,0 & 0,1 & 3,1 & 0,1 & 0,0 & 0,1 \\
\hline Tabebuia sp.2 & 2 & 0,0 & 0,0 & 0,3 & 0,0 & 3,1 & 0,1 & 0,0 & 0,1 \\
\hline Eugenia pluriflora & 2 & 0,0 & 0,0 & 0,3 & 0,0 & 3,1 & 0,1 & 0,0 & 0,1 \\
\hline Byrsonima basiloba & 3 & 0,0 & 0,0 & 0,5 & 0,0 & 3,1 & 0,1 & 0,0 & 0,1 \\
\hline Cletra scraba & 2 & 0,0 & 0,0 & 0,3 & 0,0 & 3,1 & 0,1 & 0,0 & 0,1 \\
\hline Guapira graciliflora & 2 & 0,0 & 0,0 & 0,3 & 0,0 & 3,1 & 0,1 & 0,0 & 0,1 \\
\hline Myrciaria floribunda & 3 & 0,0 & 0,0 & 0,5 & 0,0 & 3,1 & 0,1 & 0,0 & 0,1 \\
\hline Croton floribundus & 2 & 0,0 & 0,0 & 0,3 & 0,0 & 3,1 & 0,1 & 0,0 & 0,1 \\
\hline Lithraea molleoides & 2 & 0,0 & 0,0 & 0,3 & 0,0 & 3,1 & 0,1 & 0,0 & 0,1 \\
\hline Caryocar brasiliense & 2 & 0,0 & 0,0 & 0,3 & 0,0 & 3,1 & 0,1 & 0,0 & 0,0 \\
\hline Piptocarpha rotundifolia & 2 & 0,0 & 0,0 & 0,3 & 0,0 & 3,1 & 0,1 & 0,0 & 0,0 \\
\hline Tabebuia ochracea & 2 & 0,0 & 0,0 & 0,3 & 0,0 & 3,1 & 0,1 & 0,0 & 0,0 \\
\hline Prunus myrtifolia & 2 & 0,0 & 0,0 & 0,3 & 0,0 & 3,1 & 0,1 & 0,0 & 0,0 \\
\hline Erythroxylum deciduum & 2 & 0,0 & 0,0 & 0,3 & 0,0 & 3,1 & 0,1 & 0,0 & 0,0 \\
\hline Miconia langsdorffii & 2 & 0,0 & 0,0 & 0,3 & 0,0 & 3,1 & 0,1 & 0,0 & 0,0 \\
\hline Lacistema hasslerianum & 1 & 0,0 & 0,1 & 0,2 & 0,0 & 1,6 & 0,1 & 0,0 & 0,0 \\
\hline Matayba elaeagnoides & 6 & 0,0 & 0,0 & 1,0 & 0,1 & 1,6 & 0,1 & 0,0 & 0,0 \\
\hline Eugenia livida & 1 & 0,0 & 0,0 & 0,2 & 0,0 & 1,6 & 0,1 & 0,0 & 0,0 \\
\hline Byrsonima cf. verbascifolia & 1 & 0,0 & 0,0 & 0,2 & 0,0 & 1,6 & 0,1 & 0,0 & 0,0 \\
\hline Pinus elliottii & 1 & 0,0 & 0,0 & 0,2 & 0,0 & 1,6 & 0,1 & 0,0 & 0,0 \\
\hline Qualea parviflora & 1 & 0,0 & 0,0 & 0,2 & 0,0 & 1,6 & 0,1 & 0,0 & 0,0 \\
\hline Miconia sp. & 1 & 0,0 & 0,0 & 0,2 & 0,0 & 1,6 & 0,1 & 0,0 & 0,0 \\
\hline Psidium cinereum & 1 & 0,0 & 0,0 & 0,2 & 0,0 & 1,6 & 0,1 & 0,0 & 0,0 \\
\hline Guapira sp. & 1 & 0,0 & 0,0 & 0,2 & 0,0 & 1,6 & 0,1 & 0,0 & 0,0 \\
\hline Cordia sp. & 1 & 0,0 & 0,0 & 0,2 & 0,0 & 1,6 & 0,1 & 0,0 & 0,0 \\
\hline Ixora brevifolia & 1 & 0,0 & 0,0 & 0,2 & 0,0 & 1,6 & 0,1 & 0,0 & 0,0 \\
\hline
\end{tabular}

(1)Do.a: Dominância absoluta $\left(\mathrm{m}^{2} / \mathrm{ha}\right)$, Do.r: Dominância relativa (\%), De.a:Densidade absoluta (no ind/ha), De.r: Densidade relativa (\%), Fr.a: Freqüência absoluta (\%), Fr.r: Freqüência relativa (\%), IVC(\%): Índice de Valor de Cobertura, IVI (\%): Índice de Valor de Importância. 
Tabela 2. Estimativas de parâmetros fitossociológicos encontrados por espécie para o método de parcela de área fixa de $900 \mathrm{~m}^{2}$

\begin{tabular}{lccccccccc}
\hline \multicolumn{1}{c}{ Espécie } & $\mathbf{n}^{\text {* ind. }}$ & Do.a $^{(\mathbf{1})}$ & Do.r & De.a & De.r & Fr.a & Fr.r & IVC(\%) & IVI(\%) \\
\hline Maytenus robusta & 1 & 0,0 & 0,0 & 0,2 & 0,0 & 1,6 & 0,1 & 0,0 & 0,0 \\
Connarus suberosus & 1 & 0,0 & 0,0 & 0,2 & 0,0 & 1,6 & 0,1 & 0,0 & 0,0 \\
Andira anthelmia & 1 & 0,0 & 0,0 & 0,2 & 0,0 & 1,6 & 0,1 & 0,0 & 0,0 \\
Strychnos pseudoquina & 1 & 0,0 & 0,0 & 0,2 & 0,0 & 1,6 & 0,1 & 0,0 & 0,0 \\
Myrcia cf. dictyophylla & 1 & 0,0 & 0,0 & 0,2 & 0,0 & 1,6 & 0,1 & 0,0 & 0,0 \\
Erythroxylum suberosum & 1 & 0,0 & 0,0 & 0,2 & 0,0 & 1,6 & 0,1 & 0,0 & 0,0 \\
Erythroxylum cuneifolium & 1 & 0,0 & 0,0 & 0,2 & 0,0 & 1,6 & 0,1 & 0,0 & 0,0 \\
\hline
\end{tabular}

${ }^{(1)}$ Do.a: Dominância absoluta $\left(\mathrm{m}^{2} / \mathrm{ha}\right)$, Do.r: Dominância relativa (\%), De.a:Densidade absoluta (no ind/ha), De.r: Densidade relativa (\%), Fr.a: Freqüência absoluta (\%), Fr.r: Freqüência relativa (\%), IVC(\%): Índice de Valor de Cobertura, IVI (\%): Índice de Valor de Importância.

A Tabela 3 apresenta as estimativas dos parâmetros fitossociológicos para o método de ponto quadrante, no qual o IVI (Índice de Valor de Importância), é listado em ordem decrescente.

Tabela 3. Estimativas de parâmetros fitossociológicos encontrados por espécie para o método de ponto quadrante

\begin{tabular}{|c|c|c|c|c|c|c|c|c|c|}
\hline Espécie & no ind & Do.a $a^{(1)}$ & Do.r & De.a & De.r & Fr.a & Fr.r & IVC(\%) & IVI(\%) \\
\hline Copaifera langsdorffii & 271 & 6,3 & 23,3 & 264,0 & 14,0 & 39,5 & 12,1 & 18,6 & 16,5 \\
\hline Vochysia tucanorum & 286 & 4,5 & 16,6 & 279,0 & 14,8 & 37,4 & 11,5 & 15,7 & 14,3 \\
\hline Ocotea corymbosa & 210 & 2,8 & 10,2 & 205,0 & 10,8 & 34,5 & 10,6 & 10,5 & 10,6 \\
\hline Xylopia aromatica & 201 & 1,1 & 4,0 & 196,0 & 10,4 & 30,2 & 9,3 & 7,2 & 7,9 \\
\hline Tapirira guianensis & 88 & 2,5 & 9,1 & 85,8 & 4,6 & 15,7 & 4,8 & 6,8 & 6,2 \\
\hline Machaerium acutifolium & 77 & 1,0 & 3,7 & 75,1 & 4,0 & 15,1 & 4,6 & 3,8 & 4,1 \\
\hline Anadenanthera falcata & 51 & 1,2 & 4,5 & 49,7 & 2,6 & 8,7 & 2,7 & 3,6 & 3,3 \\
\hline Myrcia multiflora & 73 & 0,3 & 1,3 & 71,2 & 3,8 & 13,2 & 4,1 & 2,5 & 3,0 \\
\hline Plathymenia reticulata & 46 & 0,9 & 3,2 & 44,8 & 2,4 & 7,9 & 2,4 & 2,8 & 2,7 \\
\hline Pera glabrata & 33 & 1,1 & 4,1 & 32,2 & 1,7 & 6,8 & 2,1 & 2,9 & 2,6 \\
\hline Qualea cordata & 54 & 0,3 & 1,1 & 52,6 & 2,8 & 10,7 & 3,3 & 1,9 & 2,4 \\
\hline Rapanea umbellata & 54 & 0,2 & 0,8 & 52,6 & 2,8 & 10,5 & 3,2 & 1,8 & 2,3 \\
\hline Qualea grandiflora & 37 & 0,6 & 2,1 & 36,1 & 1,9 & 7,0 & 2,2 & 2,0 & 2,1 \\
\hline Faramea montevidensis & 38 & 0,3 & 0,9 & 37,0 & 2,0 & 6,4 & 2,0 & 1,4 & 1,6 \\
\hline Protium heptaphyllum & 31 & 0,4 & 1,3 & 30,2 & 1,6 & 5,8 & 1,8 & 1,4 & 1,6 \\
\hline Siparuna guianensis & 33 & 0,2 & 0,6 & 32,2 & 1,7 & 6,2 & 1,9 & 1,2 & 1,4 \\
\hline Myrcia guianensis & 31 & 0,2 & 0,8 & 30,2 & 1,6 & 6,0 & 1,8 & 1,2 & 1,4 \\
\hline
\end{tabular}


Tabela 3. Estimativas de parâmetros fitossociológicos encontrados por espécie no método de ponto quadrante

\begin{tabular}{|c|c|c|c|c|c|c|c|c|c|}
\hline Espécie & no ind & Do.a $a^{(1)}$ & Do.r & De.a & De.r & Fr.a & Fr.r & IVC(\%) & IVI(\%) \\
\hline Terminalia brasiliensis & 22 & 0,3 & 1,2 & 21,4 & 1,1 & 4,3 & 1,3 & 1,2 & 1,2 \\
\hline Rapanea lancifolia & 29 & 0,1 & 0,4 & 28,3 & 1,5 & 5,6 & 1,7 & 0,9 & 1,2 \\
\hline Gochnatia polymorpha & 16 & 0,4 & 1,6 & 15,6 & 0,8 & 3,3 & 1,0 & 1,2 & 1,2 \\
\hline Myrcia linguaeformis & 14 & 0,2 & 0,8 & 13,6 & 0,7 & 2,9 & 0,9 & 0,7 & 0,8 \\
\hline indeterminadas & 17 & 0,1 & 0,4 & 16,6 & 0,9 & 3,3 & 1,0 & 0,7 & 0,8 \\
\hline Byrsonima laxiflora & 15 & 0,1 & 0,5 & 14,6 & 0,8 & 3,1 & 1,0 & 0,6 & 0,8 \\
\hline Syagrus romanzoffiana & 12 & 0,2 & 0,6 & 11,7 & 0,6 & 2,3 & 0,7 & 0,6 & 0,6 \\
\hline Eugenia aurata & 12 & 0,1 & 0,4 & 11,7 & 0,6 & 2,5 & 0,8 & 0,5 & 0,6 \\
\hline Myrcia venulosa & 13 & 0,1 & 0,3 & 12,7 & 0,7 & 2,7 & 0,8 & 0,5 & 0,6 \\
\hline Persea pyrifolia & 9 & 0,2 & 0,7 & 8,8 & 0,5 & 1,7 & 0,5 & 0,6 & 0,5 \\
\hline Ouratea spectabilis & 11 & 0,1 & 0,3 & 10,7 & 0,6 & 2,3 & 0,7 & 0,5 & 0,5 \\
\hline Acosmium subelegans & 11 & 0,1 & 0,3 & 10,7 & 0,6 & 2,3 & 0,7 & 0,4 & 0,5 \\
\hline Amaioua intermedia & 11 & 0,1 & 0,3 & 10,7 & 0,6 & 2,1 & 0,6 & 0,4 & 0,5 \\
\hline Pouteria ramiflora & 7 & 0,2 & 0,7 & 6,8 & 0,4 & 1,4 & 0,4 & 0,5 & 0,5 \\
\hline Eriotheca gracilipes & 11 & 0,1 & 0,2 & 10,7 & 0,6 & 1,9 & 0,6 & 0,4 & 0,5 \\
\hline Bowdichia virgilioides & 7 & 0,1 & 0,4 & 6,8 & 0,4 & 1,4 & 0,4 & 0,4 & 0,4 \\
\hline Stryphnodendron obovatum & 9 & 0,1 & 0,2 & 8,8 & 0,5 & 1,9 & 0,6 & 0,3 & 0,4 \\
\hline Myrcia bella & 8 & 0,1 & 0,3 & 7,8 & 0,4 & 1,7 & 0,5 & 0,3 & 0,4 \\
\hline Annona crassiflora & 8 & 0,0 & 0,2 & 7,8 & 0,4 & 1,4 & 0,4 & 0,3 & 0,3 \\
\hline Symplocos pubescens & 6 & 0,1 & 0,3 & 5,9 & 0,3 & 1,2 & 0,4 & 0,3 & 0,3 \\
\hline Symplocos mosenii & 5 & 0,1 & 0,2 & 4,9 & 0,3 & 1,0 & 0,3 & 0,2 & 0,3 \\
\hline Platypodium elegans & 5 & 0,1 & 0,2 & 4,9 & 0,3 & 1,0 & 0,3 & 0,2 & 0,2 \\
\hline Guapira noxia & 5 & 0,0 & 0,2 & 4,9 & 0,3 & 1,0 & 0,3 & 0,2 & 0,2 \\
\hline Plenckia populnea & 4 & 0,1 & 0,2 & 3,9 & 0,2 & 0,8 & 0,3 & 0,2 & 0,2 \\
\hline Couepia grandiflora & 4 & 0,1 & 0,3 & 3,9 & 0,2 & 0,4 & 0,1 & 0,3 & 0,2 \\
\hline Machaerium brasiliense & 4 & 0,0 & 0,1 & 3,9 & 0,2 & 0,8 & 0,3 & 0,1 & 0,2 \\
\hline Nectandra cuspidata & 4 & 0,0 & 0,1 & 3,9 & 0,2 & 0,6 & 0,2 & 0,2 & 0,2 \\
\hline Qualea multiflora & 3 & 0,0 & 0,2 & 2,9 & 0,2 & 0,6 & 0,2 & 0,2 & 0,2 \\
\hline Maprounea guianensis & 3 & 0,0 & 0,1 & 2,9 & 0,2 & 0,6 & 0,2 & 0,1 & 0,1 \\
\hline Daphnopsis fasciculata & 3 & 0,0 & 0,1 & 2,9 & 0,2 & 0,6 & 0,2 & 0,1 & 0,1 \\
\hline Matayba elaeagnoides & 3 & 0,0 & 0,0 & 2,9 & 0,2 & 0,6 & 0,2 & 0,1 & 0,1 \\
\hline Tabebuia aurea & 2 & 0,0 & 0,1 & 2,0 & 0,1 & 0,4 & 0,1 & 0,1 & 0,1 \\
\hline Alibertia sessilis & 2 & 0,0 & 0,1 & 2,0 & 0,1 & 0,4 & 0,1 & 0,1 & 0,1 \\
\hline Brosimum sp. & 2 & 0,0 & 0,1 & 2,0 & 0,1 & 0,4 & 0,1 & 0,1 & 0,1 \\
\hline Dimorphandra mollis & 2 & 0,0 & 0,0 & 2,0 & 0,1 & 0,4 & 0,1 & 0,1 & 0,1 \\
\hline Myrcia fallax & 2 & 0,0 & 0,0 & 2,0 & 0,1 & 0,4 & 0,1 & 0,1 & 0,1 \\
\hline Miconia ligustroides & 2 & 0,0 & 0,0 & 2,0 & 0,1 & 0,4 & 0,1 & 0,1 & 0,1 \\
\hline Aspidosperma tomentosum & 2 & 0,0 & 0,0 & 2,0 & 0,1 & 0,2 & 0,1 & 0,1 & 0,1 \\
\hline Piptocarpha axillaris & 1 & 0,0 & 0,1 & 1,0 & 0,1 & 0,2 & 0,1 & 0,1 & 0,1 \\
\hline Styrax ferrugineus & 1 & 0,0 & 0,1 & 1,0 & 0,1 & 0,2 & 0,1 & 0,1 & 0,1 \\
\hline Tibouchina stenocarpa & 1 & 0,0 & 0,1 & 1,0 & 0,1 & 0,2 & 0,1 & 0,1 & 0,1 \\
\hline
\end{tabular}


Tabela 3. Estimativas de parâmetros fitossociológicos encontrados por espécie no método de ponto quadrante

\begin{tabular}{|c|c|c|c|c|c|c|c|c|c|}
\hline Espécie & $\mathrm{n}=$ ind & Do.a $a^{(1)}$ & Do.r & De.a & De.r & Fr.a & Fr.r & IVC(\%) & IVI(\%) \\
\hline Diospyros cf. hispida & 1 & 0,0 & 0,1 & 1,0 & 0,1 & 0,2 & 0,1 & 0,1 & 0,1 \\
\hline Styrax camporum & 1 & 0,0 & 0,0 & 1,0 & 0,1 & 0,2 & 0,1 & 0,0 & 0,1 \\
\hline Luehea grandiflora & 1 & 0,0 & 0,0 & 1,0 & 0,1 & 0,2 & 0,1 & 0,0 & 0,1 \\
\hline Qualea parviflora & 1 & 0,0 & 0,0 & 1,0 & 0,1 & 0,2 & 0,1 & 0,0 & 0,1 \\
\hline Miconia sp. & 1 & 0,0 & 0,0 & 1,0 & 0,1 & 0,2 & 0,1 & 0,0 & 0,1 \\
\hline Dalbergia miscolobium & 1 & 0,0 & 0,0 & 1,0 & 0,1 & 0,2 & 0,1 & 0,0 & 0,0 \\
\hline Myrcia tomentosa & 1 & 0,0 & 0,0 & 1,0 & 0,1 & 0,2 & 0,1 & 0,0 & 0,0 \\
\hline Cordia sp. & 1 & 0,0 & 0,0 & 1,0 & 0,1 & 0,2 & 0,1 & 0,0 & 0,0 \\
\hline Tabebuia sp. & 1 & 0,0 & 0,0 & 1,0 & 0,1 & 0,2 & 0,1 & 0,0 & 0,0 \\
\hline Roupala montana & 1 & 0,0 & 0,0 & 1,0 & 0,1 & 0,2 & 0,1 & 0,0 & 0,0 \\
\hline Prunus myrtifolia & 1 & 0,0 & 0,0 & 1,0 & 0,1 & 0,2 & 0,1 & 0,0 & 0,0 \\
\hline Myrcia cf. dictyophylla & 1 & 0,0 & 0,0 & 1,0 & 0,1 & 0,2 & 0,1 & 0,0 & 0,0 \\
\hline Erythroxylum cuneifolium & 1 & 0,0 & 0,0 & 1,0 & 0,1 & 0,2 & 0,1 & 0,0 & 0,0 \\
\hline Croton floribundus & 1 & 0,0 & 0,0 & 1,0 & 0,1 & 0,2 & 0,1 & 0,0 & 0,0 \\
\hline
\end{tabular}

As espécies Copaifera langsdorffi, Vochysia tucanorum e, em menor proporção, Anadenanthera falcata, se destacaram por apresentar, tanto no método de parcelas de $900 \mathrm{~m}^{2}$ quanto no método de ponto quadrante, maiores valores de dominância, indicando que essas espécies contêm grande parte de seus indivíduos representados por árvores de grande porte.

A espécie Tapirira guianensis obteve a 4⿳亠丷a . colocação em IVI no método de parcelas de $900 \mathrm{~m}^{2}$, favorecida principalmente pelo alto valor de dominância em relação à $5^{\text {a }}$. colocada, Xylopia aromatica. Isto se deve ao seu expressivo número de indivíduos bifurcados, sendo somados seus valores de CAP. Apesar de a espécie Xylopia aromatica apresentar densidade mais de duas vezes maior, não obteve IVI maior devido à superioridade da Tapirira guianensis quanto à dominância e freqüência.

Elevados valores de dominância de espécies que não ocupam necessariamente o primeiro lugar em IVI ocorreram também em outros estudos. No levantamento fitossociológico realizado por Toledo Filho et al. (1989) em 
Moji-Mirim, a espécie Tapirira guianensis, apesar de aparecer em 6임 lugar quanto ao IVI, também foi superior quanto à dominância (4⿳ạ. posição), em relação à Xylopia aromatica (7ª . posição). O mesmo aconteceu em Corumbataí, no estudo de Cesar et al (1988); neste caso, a espécie Copaifera langsdorffii apresentou maior dominância, mas foi a 5ª . colocada em IVI.

Com relação à freqüência das espécies, Copaifera langsdorffii, seguida por Vochysia tucanorum e Ocotea corymbosa, apresentaram distribuição mais regular na população estudada nas parcelas de $900 \mathrm{~m}^{2}$, com $100 \%$ de freqüência.

Apesar de ser muito comum na E. E. Assis, na amostragem realizada por Gomes et al. (2004) em um cerradão de Brotas (SP), a espécie Copaifera langsdorffii foi representada por apenas um indivíduo, sendo as espécies Xylopia aromatica e Vochysia tucanorum as mais freqüentes. Em Itirapina (SP), por sua vez, Durigan et al. (1994) não encontraram nenhum indivíduo de Copaifera langsdorffii, talvez por se tratar de uma área de cerrado sensu stricto, onde é rara sua ocorrência, visto que ela não está presente na lista de espécies do cerradão também comuns ao cerrado sensu stricto, elaborada por Silberbauer-Gottsberger \& Gottsberger (1984).

Indivíduos arbóreos indeterminados apareceram em pequena proporção no método de parcelas $(1,06 \%)$ e no método de ponto quadrante $(0,87 \%)$, correspondendo às árvores que, apesar de vivas, não apresentaram nem mesmo ramos vegetativos para que fosse possível a identificação. Pode ter sido o caso de árvores senescentes ou de espécies decíduas.

As distribuições das espécies para as parcelas de 100 a $900 \mathrm{~m}^{2}$ e para os pontos quadrante quanto ao Índice de Valor de Importância - IVI (\%), Dominância absoluta - Do.a ( $\left.\mathrm{m}^{2} / \mathrm{ha}\right)$, Densidade absoluta - De.a (ind/ha) e Freqüência absoluta - Fr.a (\%), estão representadas nas figuras 7 a 10, onde cada ponto representa uma espécie. 

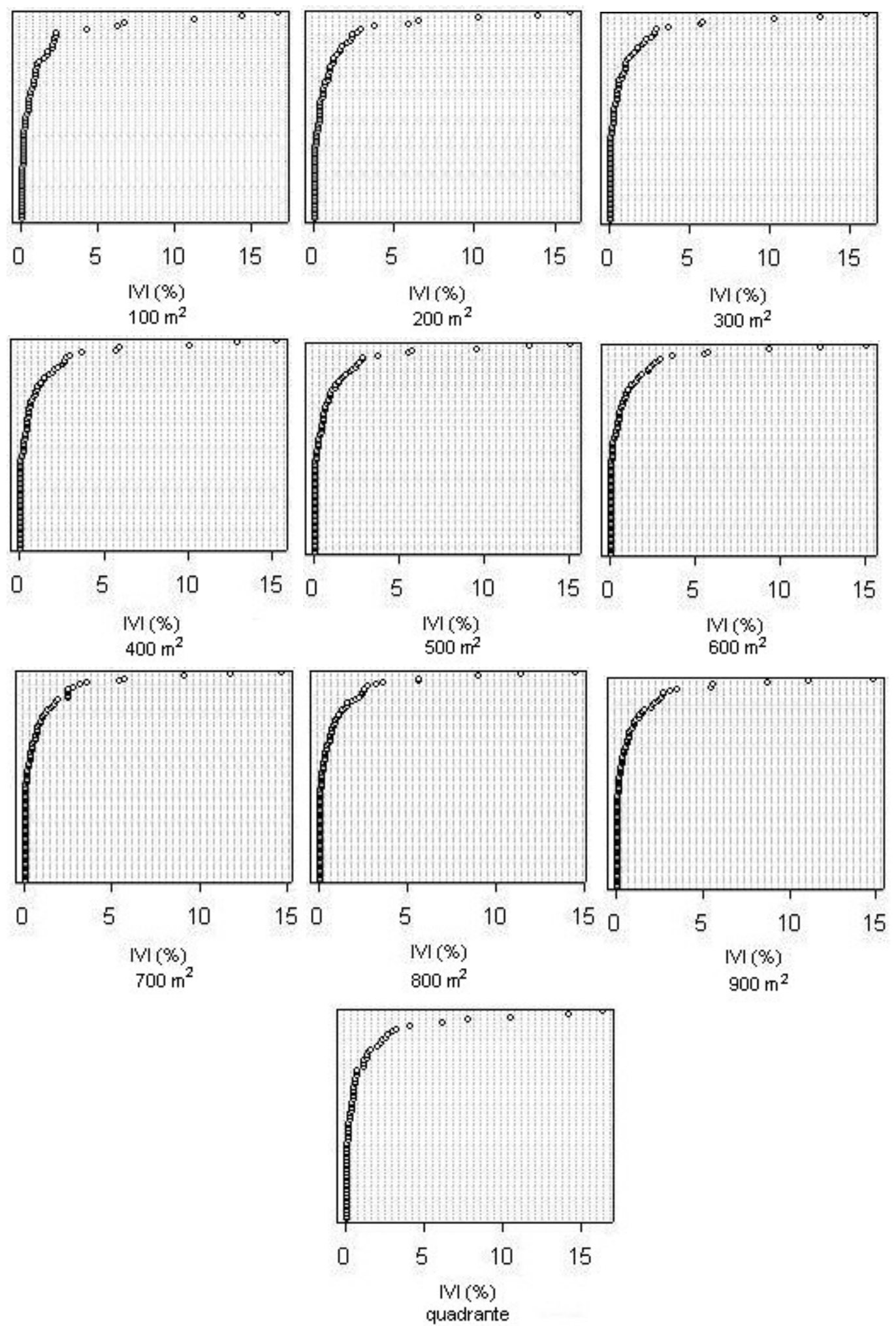

Figura 7 - Distribuição das espécies quanto ao IVI (\%) para parcelas de área fixa de diferentes tamanhos e pontos quadrante 

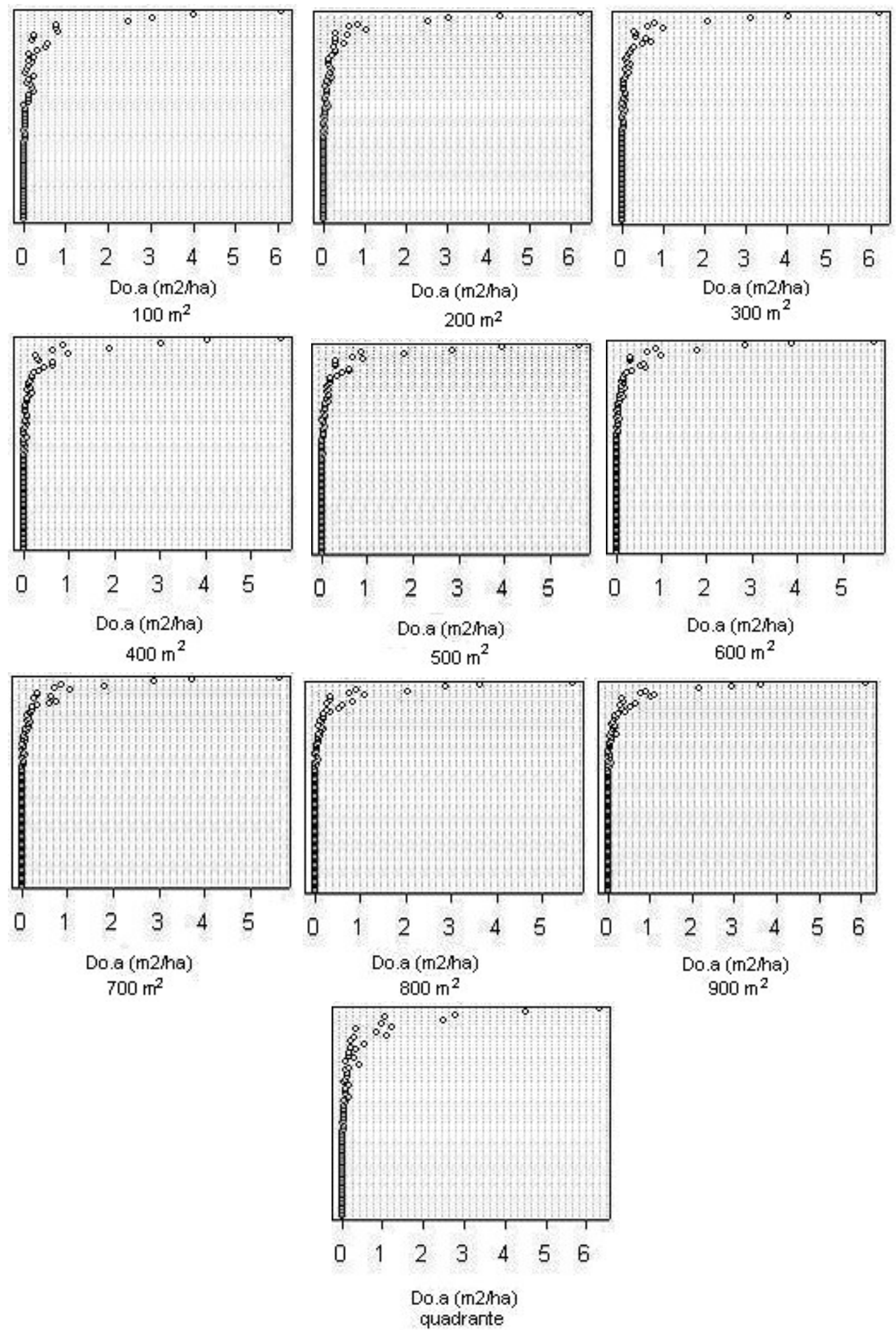

Figura 8 - Distribuição das espécies quanto à Dominância absoluta para parcelas de área fixa de diferentes tamanhos e pontos quadrante 

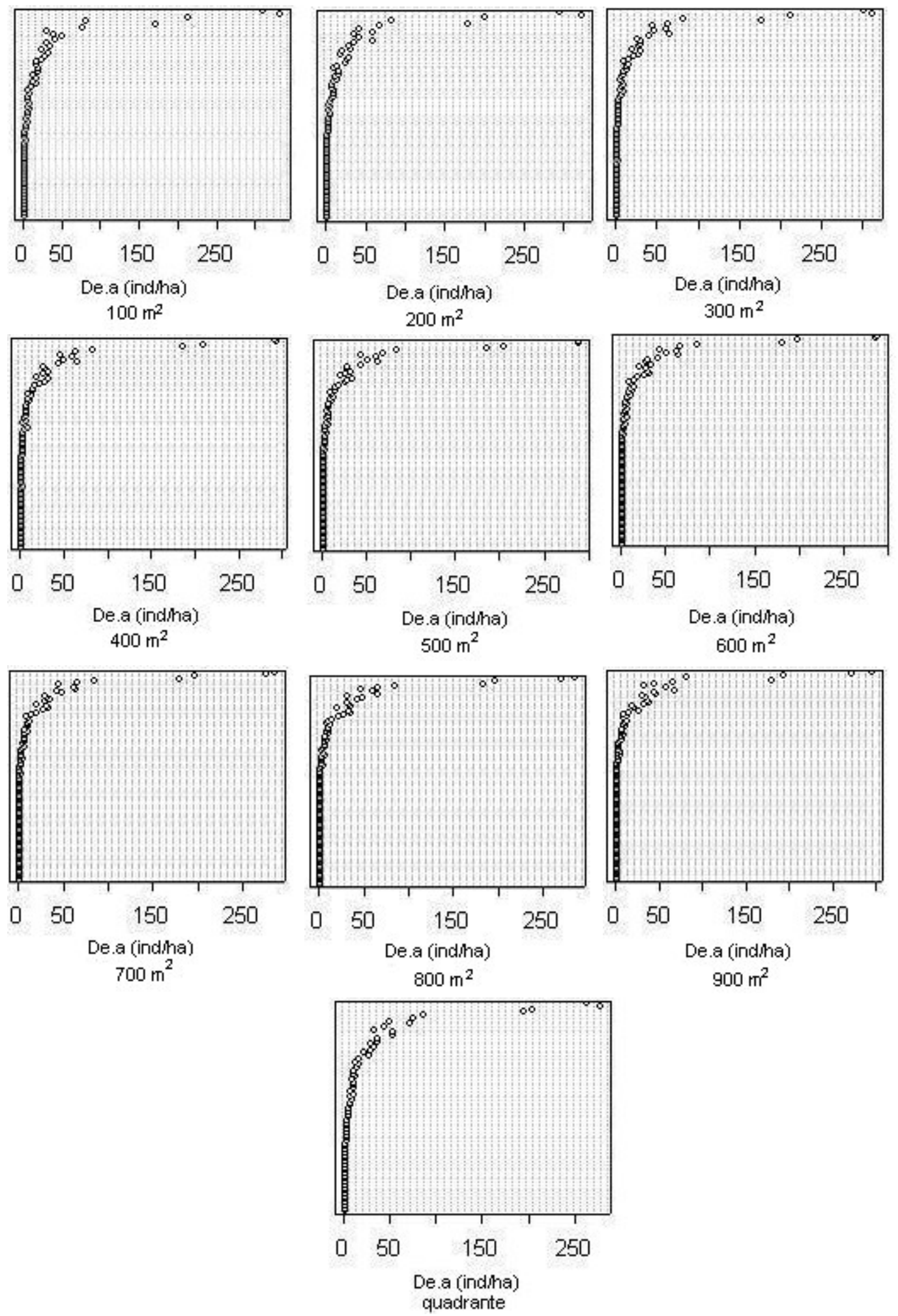

Figura 9 - Distribuição das espécies quanto à Densidade absoluta para parcelas de área fixa de diferentes tamanhos e pontos quadrante 



Fr.a $(\%)$
$100 \mathrm{~m}^{2}$
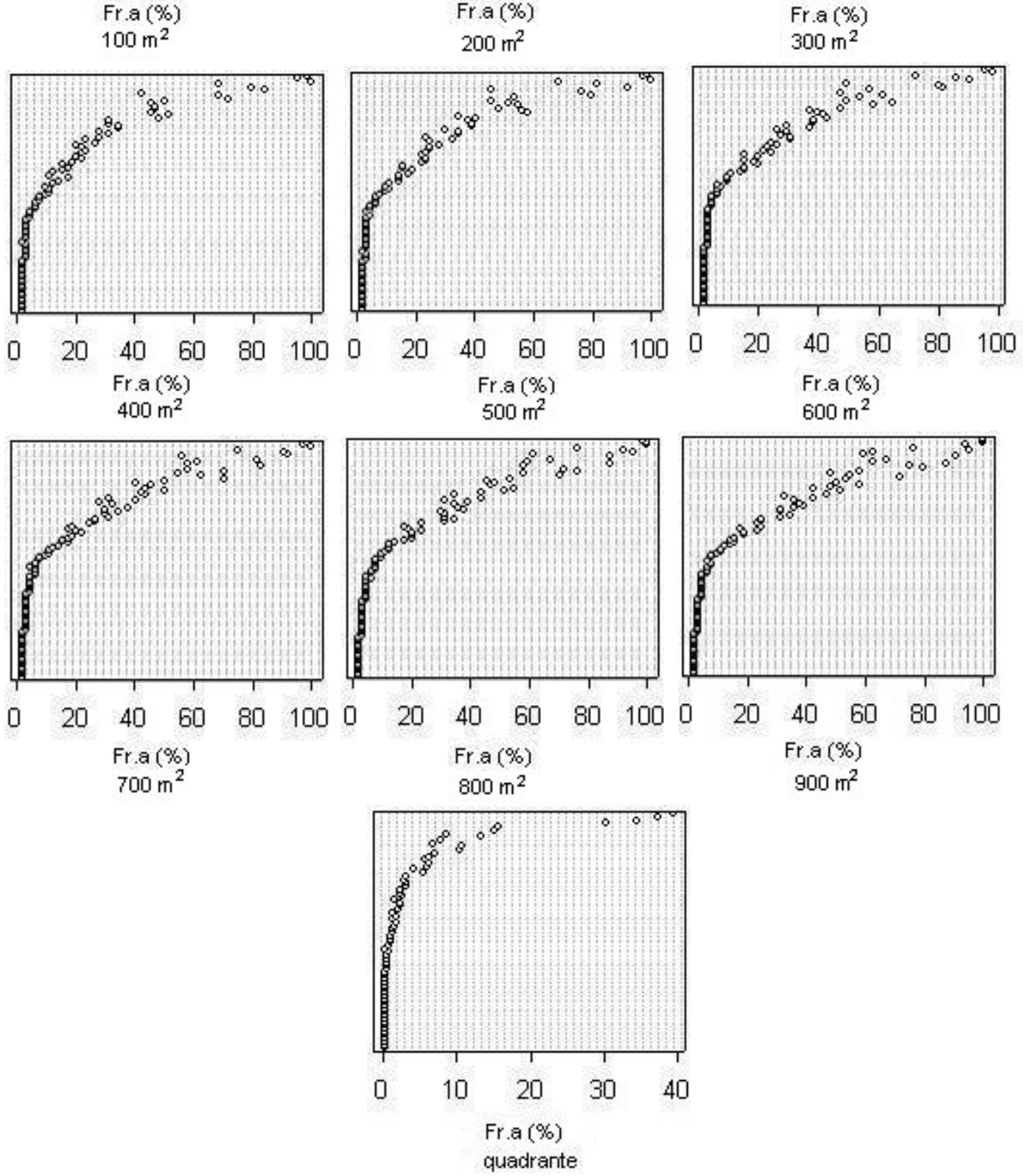

Figura 10 - Distribuição das espécies quanto à Freqüência absoluta para parcelas de área fixa de diferentes tamanhos e pontos quadrante 
Diante da projeção do IVI (\%) (Figura 7), notam-se poucas espécies se destacando com altos valores deste índice em todos os tamanhos de parcela, bem como no método de ponto quadrante. Em contrapartida, a maioria das espécies apresenta baixo IVI, tornando-se mais aparente com aumento da parcela. $O$ mesmo ocorre com os parâmetros Dominância absoluta $\left(\mathrm{m}^{2} / \mathrm{ha}\right)$ (Figura 8) e Densidade (ind/ha) (Figura 9).

No presente estudo, $76 \%$ das espécies do método de parcelas e $73 \%$ das espécies do método de quadrantes apresentaram valores de IVI (\%) menores que 1,0 . Os levantamentos fitossociológicos realizados tanto em áreas de cerrado como em áreas de floresta estacional semidecidual e floresta ombrófila densa também apresentaram muitas espécies com baixo IVI. Vieira (1997) observou este comportamento na floresta ombrófila densa do Parque Estadual Carlos Botelho. Nos levantamentos realizados por Cesar et al. (1988) e Gomes et al. (2004) em áreas de cerrado sensu lato isto também ocorre. No estudo de Rocha (2003), em uma floresta estacional semidecidual, as espécies com IVI inferior a $1 \%$ correspondem à cerca de $63,5 \%$ do total de espécies levantadas, enquanto que Aguiar (2003) encontrou o valor de $64,8 \%$ em uma floresta ombrófila densa. Por fim, Vieira (1997) salienta que as espécies com baixo IVI são as principais responsáveis pela diversidade do bioma.

Quanto à Freqüência absoluta (\%), observa-se, na Figura 10, um maior número de espécies com maior freqüência para todos os tamanhos de parcela, o que é menos evidente para o método de ponto quadrantes, em que há apenas quatro espécies mais freqüentes, sendo o restante menos freqüente. Isso ocorre porque neste método a escala de porcentagem é diferente do método de parcelas de área fixa, podendo ser explicado por sua própria metodologia de amostragem, que insere apenas quatro indivíduos por ponto, enquanto que nas parcelas são incluídos todos os indivíduos arbóreos contidos na área determinada. Logo, a probabilidade de um indivíduo de uma espécie comum como Copaifera langsdorffii ser inserido em todos os pontos quadrantes passa a ser menor. 
Nas figuras 11 a 13 constam as principais espécies em IVI(\%) para as parcelas menores, de $100 \mathrm{~m}^{2}$, para as intermediárias, de $500 \mathrm{~m}^{2}$ e para as parcelas maiores, de $900 \mathrm{~m}^{2}$. A figura 14 apresenta as espécies mais importantes em IVI (\%) para o método de ponto quadrante.
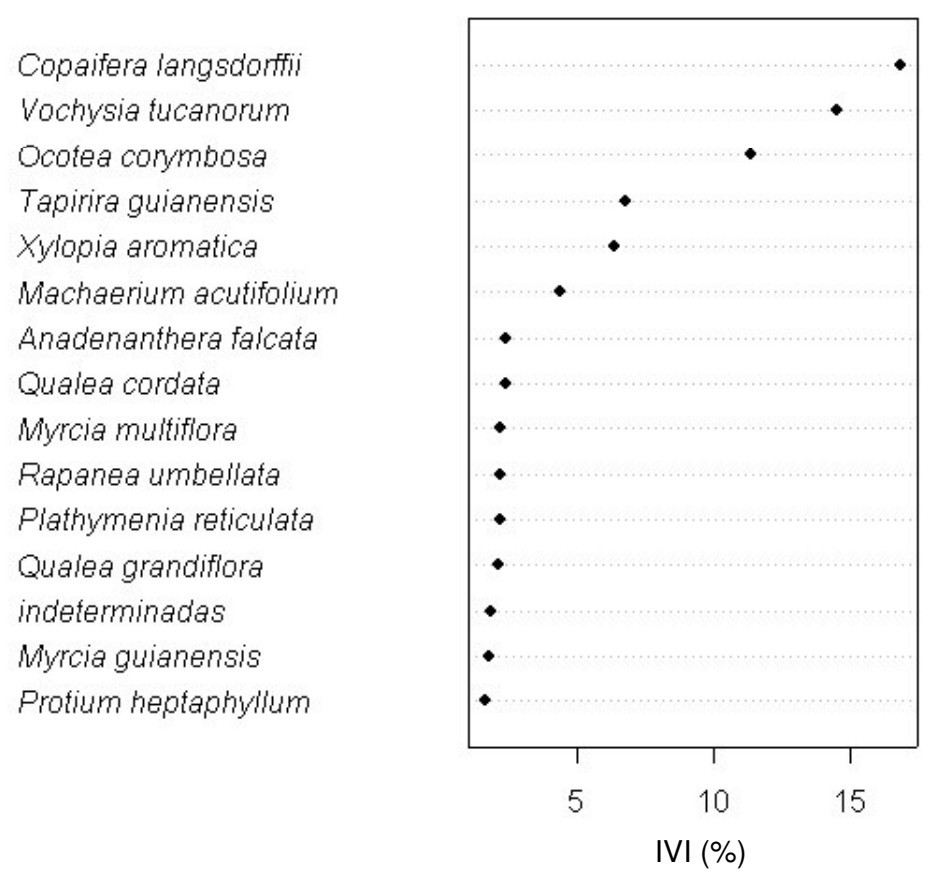

Figura 11 - Distribuição das principais espécies quanto ao IVI (\%) para parcelas de $100 \mathrm{~m}^{2}$ 
Copaifera langsdorffii Vochysia tucanorum

Ocotea corymbosa

Xylopia aromatica

Tapirira guianensis

Machaerium acutifolium

Anadenanthera faicata

Rapanea umbellata

Qualea cordata

Myrcia multifiora

Plathymenia reticulata

Pera glabrata

Qualea grandifiora

Protium heptaphyllum

Myrcia guianensis



Figura 12 - Distribuição das principais espécies quanto ao IVI (\%) para parcelas de $500 \mathrm{~m}^{2}$

Copaifera langsdorfii
Vochysia tucanorum
Ocotea corymbosa
Tapirira guianensis
Xylopia aromatica
Machaerium acutifolium
Anadenanthera falcata
Pera glabrata
Rapanea umbellata
Myrcia muitifiora
Plathymenia reticulata
Qualea cordata
Qualea grandifiora
Myrcia guianensis
Protium heptaphylium

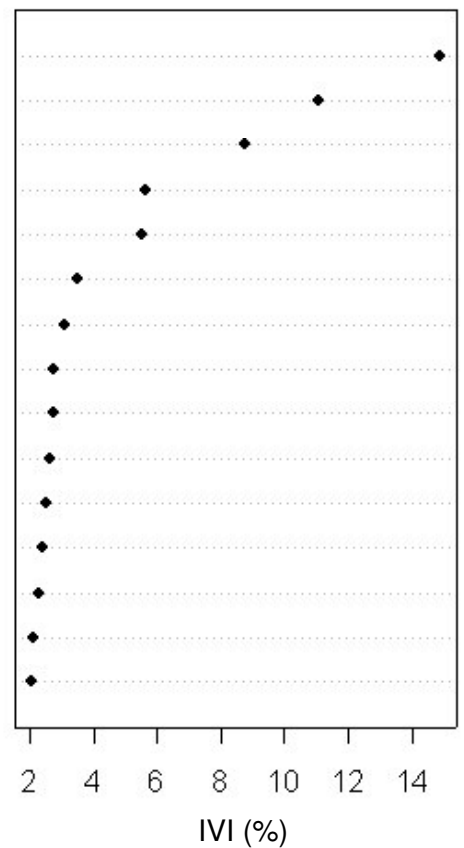

Figura 13 - Distribuição das principais espécies quanto ao IVI (\%) para parcelas de $900 \mathrm{~m}^{2}$ 
Copaifera langsdorffii

Vochysia tucanorum

Ocotea corymbosa

Xylopia aromatica

Tapirira guianensis

Machaerium acutifolium

Anadenanthera falcata

Myrcia muitifiora

Plathymenia reticulata

Pera glabrata

Qualea cordata

Rapanea umbellata

Qualea grandifiora

Faramea montevidensis

Protium heptaphyllum

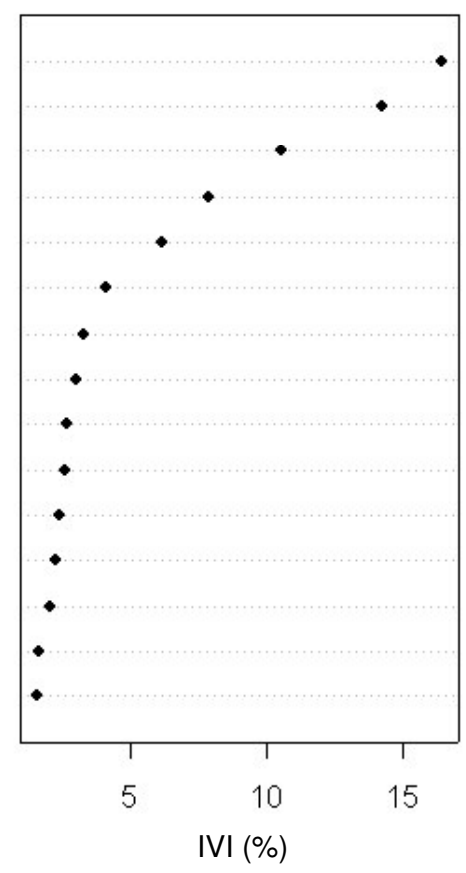

Figura 14 - Distribuição das principais espécies quanto ao IVI (\%) para o método de ponto quadrante

Nota-se, nas figuras 11 a 13, que as três espécies de maior IVI não sofreram mudança de posição quanto ao valor deste índice com o aumento do tamanho da parcela. Entretanto, houve uma inversão de espécies entre a 4⿳a . e a 5ạ. posição (Tapirira guianensis e Xylopia aromatica) quando a parcela aumentou de $100 \mathrm{~m}^{2}$ para $500 \mathrm{~m}^{2}$; esta inversão ocorreu novamente quando seu tamanho aumentou de $500 \mathrm{~m}^{2}$ para $900 \mathrm{~m}^{2}$. Logo, constata-se o tamanho da parcela pode também interferir na ordem de importância das espécies mais comuns.

O método de ponto quadrante, por sua vez, se mostrou eficiente, pois, como consta na figura 14, a maioria das espécies de maior IVI encontra-se também no método de parcelas, com exceção da ausência da espécie Myrcia guianensis e do surgimento da espécie Faramea montevidensis.

As espécies que apresentaram IVI mais elevados para as metodologias de amostragem estudadas, neste caso, Copaifera langsdorffii, Vochysia 
tucanorum e Ocotea corymbosa, compreendem o maior número de indivíduos, caracterizando a fisionomia do cerradão.

A representatividade das famílias, no que se refere à porcentagem do número de indivíduos amostrados, está relacionada na Tabela 4:

Tabela 4. Número de indivíduos (\%) e número de espécies por família, para os métodos de parcelas e pontos quadrante

\begin{tabular}{lcclcc}
\hline Parcela $\left(900 \mathrm{~m}^{2}\right)$ & & & Ponto Quadrante & & \\
Famílias & $\mathrm{n}$ 으. ind.(\%) & $\mathrm{n}$ ㅇ sp. & Famílias & no sp. \\
\hline Vochysiaceae & 19,13 & 5 & Vochysiaceae & 19,68 & 5 \\
Caesalpiniaceae & 16,28 & 2 & Caesalpiniaceae & 14,10 & 2 \\
Lauraceae & 10,78 & 4 & Lauraceae & 11,52 & 3 \\
Annonaceae & 10,20 & 2 & Annonaceae & 10,80 & 2 \\
Myrtaceae & 7,90 & 13 & Myrtaceae & 8,01 & 9 \\
Mimosaceae & 5,15 & 4 & Mimosaceae & 5,48 & 3 \\
Fabaceae & 4,67 & 7 & Fabaceae & 5,42 & 6 \\
Myrsinaceae & 4,63 & 2 & Anacardiaceae & 4,55 & 1 \\
Anacardiaceae & 4,52 & 2 & Myrsinaceae & 4,29 & 2 \\
Rubiaceae & 2,74 & 4 & Rubiceae & 2,63 & 3 \\
Burseraceae & 2,04 & 1 & Euphorbiaceae & 1,91 & 3 \\
Euphorbiaceae & 1,99 & 3 & Monimiaceae & 1,70 & 1 \\
Monimiaceae & 1,81 & 1 & Burseraceae & 1,60 & 1 \\
Combretaceae & 1,16 & 1 & Combretaceae & 1,14 & 1 \\
Outras & 5,39 & 51 & Outras & 7,44 & 29 \\
\hline
\end{tabular}

Nota-se, na Tabela 4, que as famílias mais representativas em números de indivíduos foram as mesmas para os métodos de parcelas de $900 \mathrm{~m}^{2}$ e de ponto quadrante, alterando-se apenas a ordem de algumas delas. Isto indica que o método de ponto quadrante mostrou-se eficiente para tal determinação, tendo a vantagem de ser um método mais rápido, tanto na instalação no campo como na obtenção dos dados. No levantamento de Aguiar (2003) em uma floresta ombrófila densa, também houve alteração na ordem de abundância de algumas famílias, mas as dez principais famílias no método de parcelas também foram as dez principais no método de quadrantes. Em uma floresta estacional semidecidual, Rocha (2003) detectou que houve cinco famílias principais ocorrendo em ambos os métodos. 
No estudo de um cerrado em Itirapina (SP) realizado por Durigan et al. (1994), a família Caesalpiniaceae foi a última colocada quanto à densidade de indivíduos, ao contrário do presente estudo, que apontou esta família como a segunda mais abundante. Contudo, a família Vochysiaceae foi a mais abundante em ambos os levantamentos. Já no cerrado de Corumbataí (SP), Cesar et al. (1988) encontraram como mais abundante a família Myrtaceae, enquanto que Toledo Filho et al. (1989), encontraram uma situação oposta no cerrado de Moji-Mirim (SP), com esta família ocupando a 17ª . colocação quanto à densidade de indivíduos.

Quanto à relação entre densidade e riqueza de espécies por família, nota-se, pela Tabela 4, que algumas famílias com elevada abundância de indivíduos são pouco representativas quanto ao número de espécies, como é o caso das famílias Caesalpiniaceae e Annonaceae, ambas contando com apenas duas espécies, ocorrendo nos dois métodos de amostragem empregados.

As Figuras 15 e 16 ilustram a riqueza relativa das principais famílias para o método de parcelas e pontos quadrante, respectivamente. 


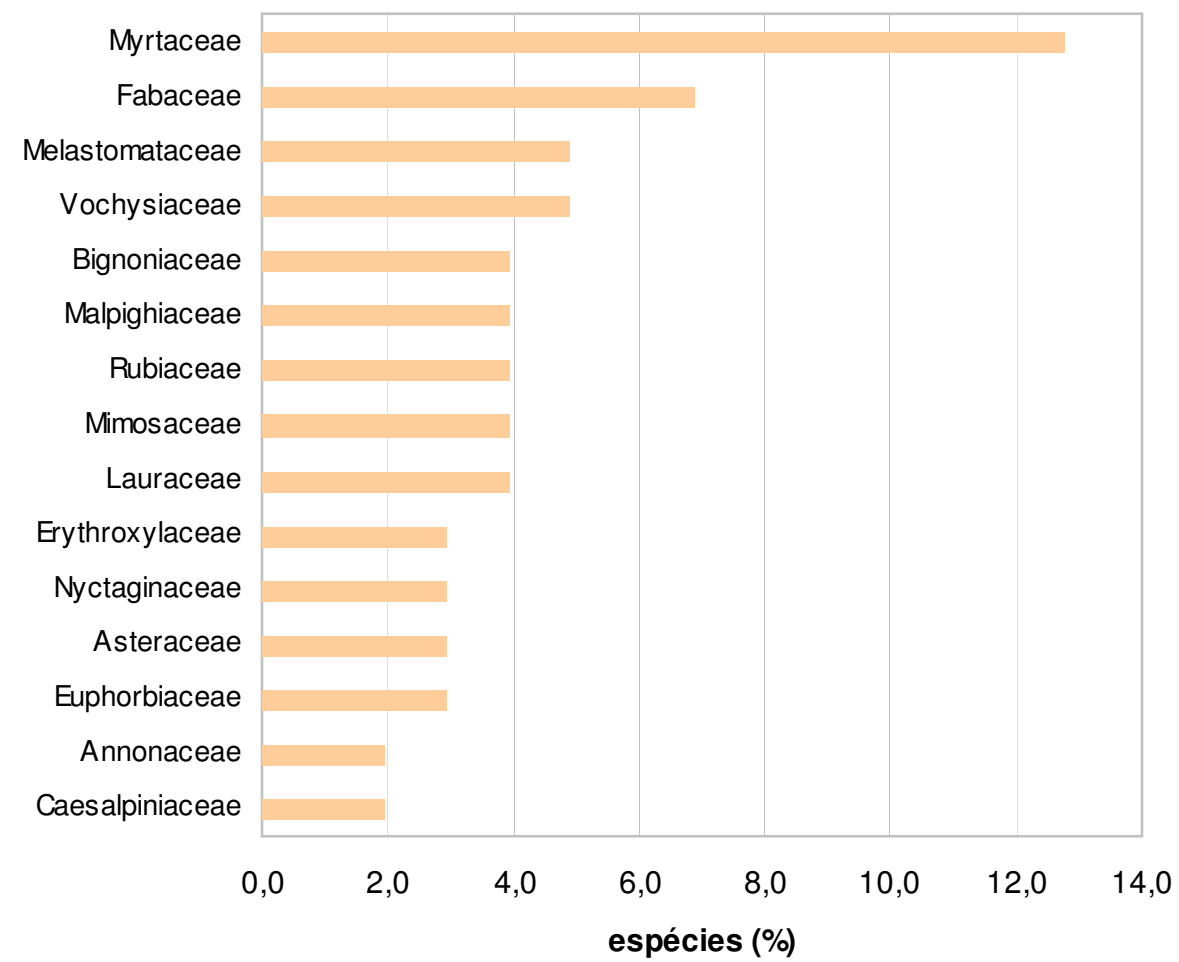

Figura 15 - Riqueza relativa das principais famílias no método de parcelas de $900 \mathrm{~m}^{2}$

De acordo com a Figura 15, no método de parcelas a família Myrtaceae foi a mais representativa, com $12,7 \%$ do total de espécies. Entretanto, neste método, a maioria das famílias foi representada por poucas espécies, mas que somadas representam cerca de $35 \%$ da riqueza da área, contribuindo, assim, com a diversidade do bioma no qual estão inseridas. 


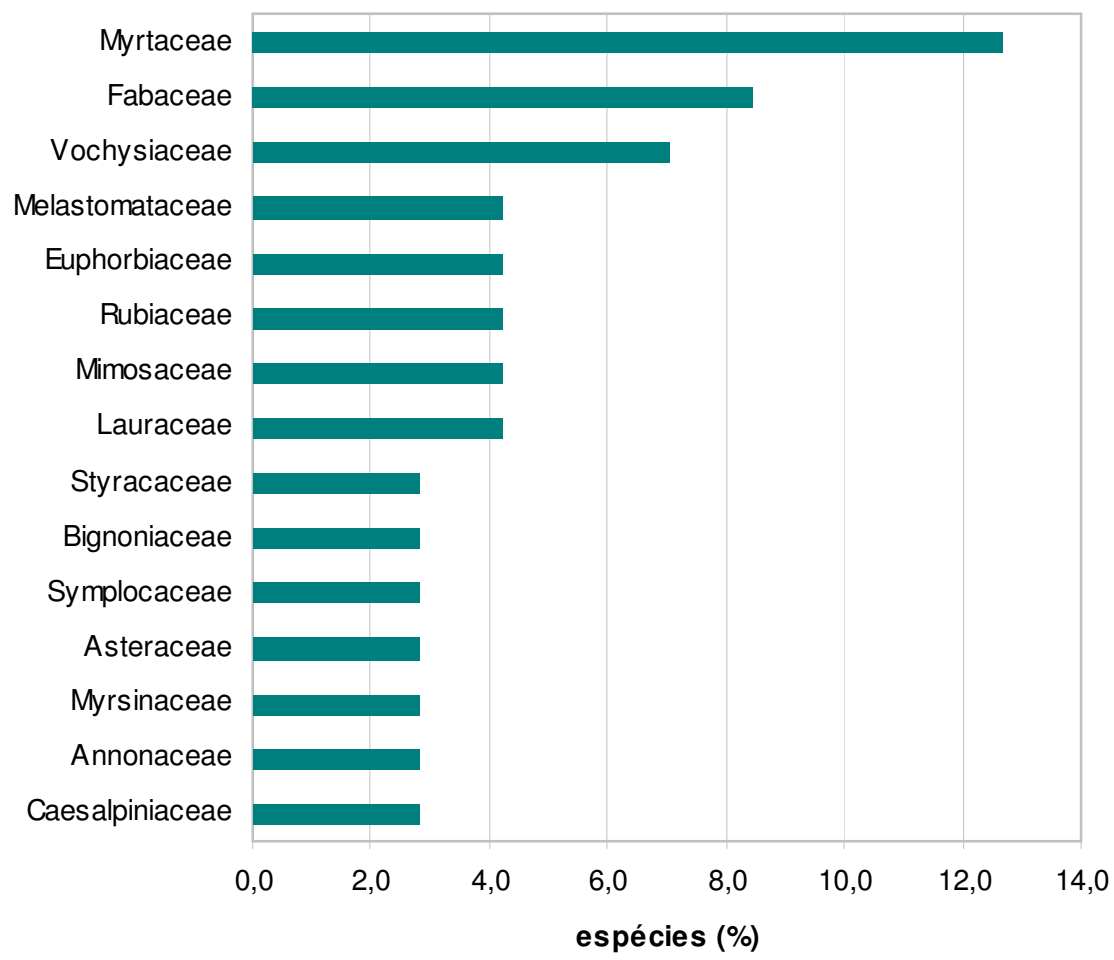

Figura 16 - Riqueza relativa das principais famílias no método de ponto quadrante

No método de ponto quadrante, como mostra a Figura $17,12,7 \%$ das espécies pertencem à família Myrtaceae, enquanto a família Fabaceae contém $8,5 \%$ das espécies. Dentre as 22 famílias menos representativas neste método estão incluídas $31 \%$ das espécies (ou 22 espécies, uma por família).

A família Myrtaceae também foi a mais rica em espécies no levantamento de Toledo Filho et al. (1989), em um cerrado de Moji-Mirim (SP), seguida das famílias Fabaceae e Caesalpiniaceae. Batalha \& Mantovani (2001), no cerrado da Reserva Pé-de-Gigante (Santa Rita do Passa Quatro, $\mathrm{SP}$ ), encontraram como mais ricas em número de espécies as famílias Fabaceae, Myrtaceae e Melastomataceae e Vochysiaceae, as mesmas encontradas no método de parcelas de $900 \mathrm{~m}^{2}$ do presente estudo, alternandose apenas a ordem das duas primeiras famílias. 
Diante do exposto, é notório que nem sempre as famílias mais ricas em número de espécies são também as mais abundantes, e vice-versa.

\subsection{Suficiência amostral}

A Figura 17 compara o esforço amostral exercido com o aumento do número de indivíduos, entre o método de ponto quadrante e parcelas de 900 $m^{2}$.

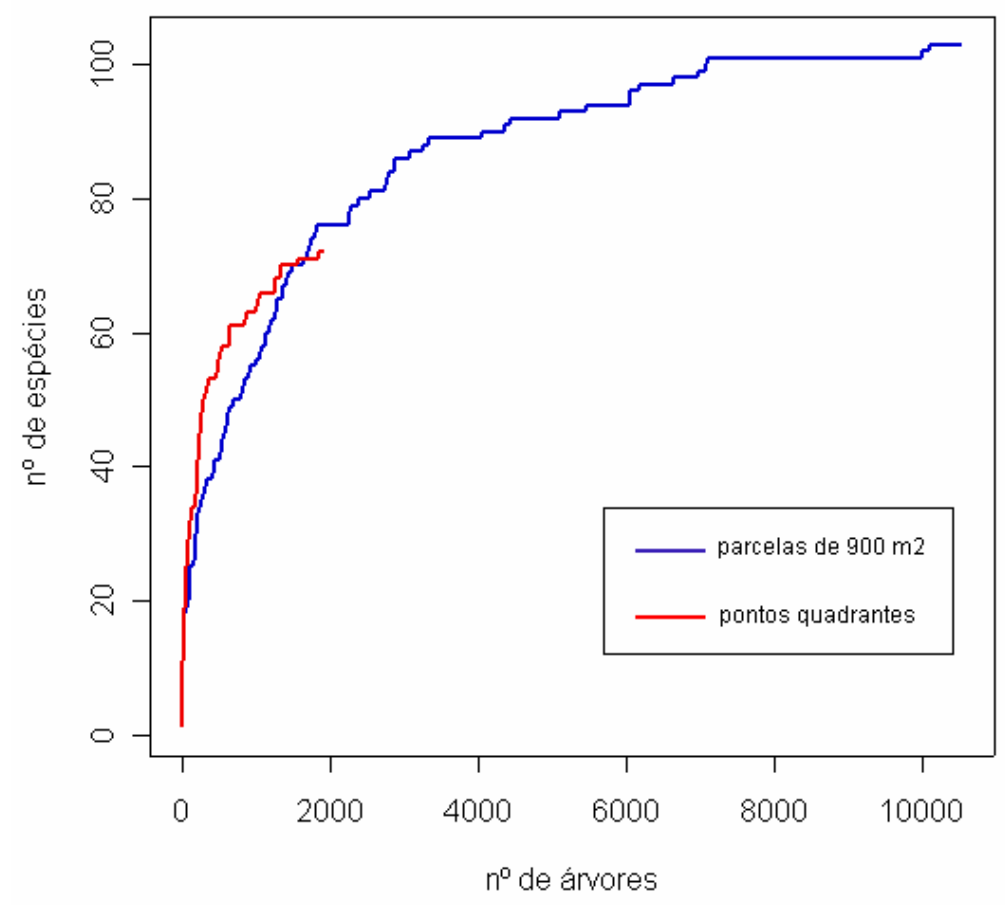

Figura 17 - Curva de suficiência amostral para parcelas de $900 \mathrm{~m}^{2}$ e para o método de ponto quadrante

As curvas representadas na Figura 17 comparam a suficiência amostral para os métodos de parcelas de $900 \mathrm{~m}^{2}$ e ponto quadrante, indicando uma curva inicialmente mais acentuada no método de ponto quadrante. Isto porque enquanto este método captura 60 espécies com a amostragem de cerca de 800 indivíduos, as parcelas de $900 \mathrm{~m}^{2}$ necessitam de aproximadamente 1.200 indivíduos para amostrar a mesma quantia de espécies. Porém, a eficiência dos 
pontos quadrantes passou a ser menor a partir do ponto em que o método amostrou cerca de 70 espécies, havendo um empate em relação às parcelas de $900 \mathrm{~m}^{2}$.

Entretanto, Gorenstein (2002) comparou os métodos de parcelas, ponto quadrante e Bitterlich em uma floresta estacional semidecidual, obtendo semelhança nas formas das curvas de suficiência amostral entre parcelas e pontos quadrante, com um número um pouco maior de espécies no método de parcelas. As curvas do levantamento de Aguiar (2003) em uma floresta ombrófila densa foram paralelas, mas o método de parcelas capturou maior riqueza em relação ao método de ponto quadrante.

A Figura 18 compara o esforço de amostragem dos pontos quadrantes em relação às parcelas de $200 \mathrm{~m}^{2}$.

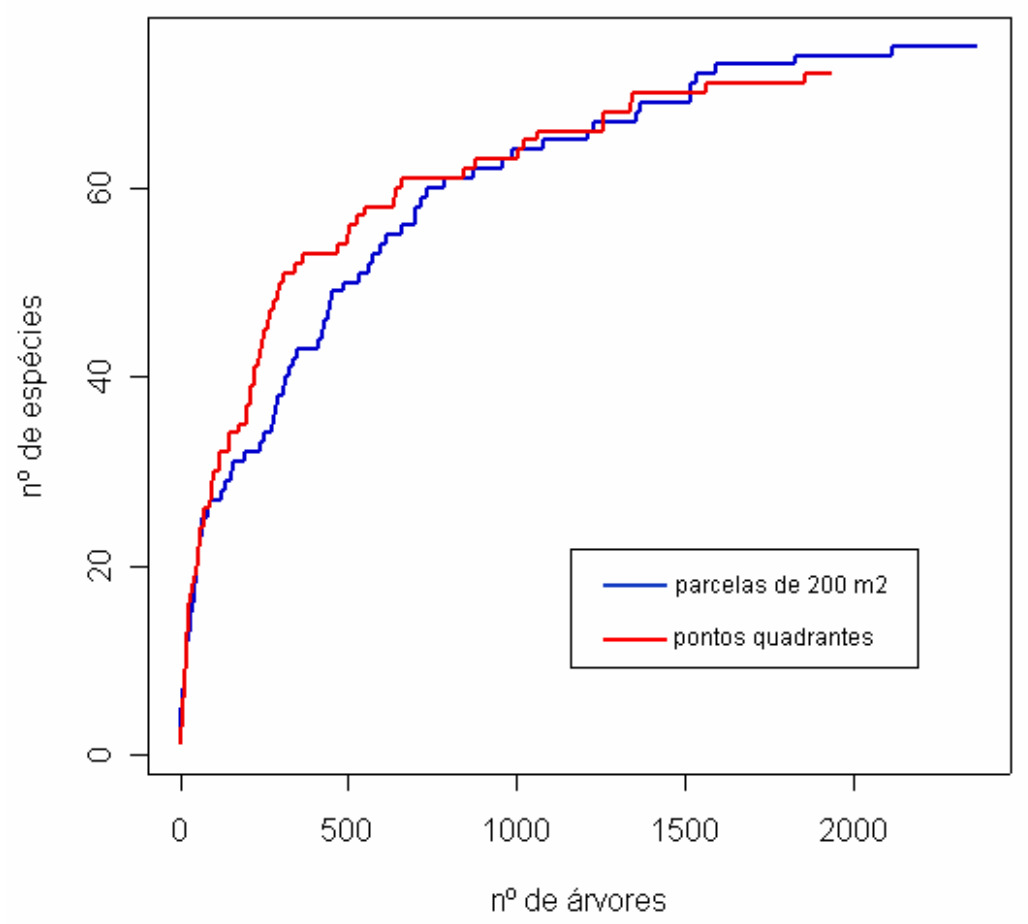

Figura 18 - Curva de suficiência amostral para parcelas de $200 \mathrm{~m}^{2}$ e para o método de ponto quadrante

A Figura 18 ilustra a comparação de esforço amostral entre parcelas de $200 \mathrm{~m}^{2}$ e os pontos quadrantes, já que houve semelhança quanto à riqueza e o 
número de árvores amostradas nesses dois métodos. Nota-se que as parcelas de $200 \mathrm{~m}^{2}$ necessitaram de cerca de 500 indivíduos para atingir 50 espécies, os pontos quadrantes, por sua vez, inseriram 50 espécies amostrando cerca de metade dos indivíduos.

Com isto, esta diferença de esforço amostral entre estes dois métodos existe porque o método de quadrantes é mais eficaz, amostrando apenas quatro indivíduos por ponto, enquanto que para as parcelas este número é variável. Com a instalação dos pontos ocorrendo ao longo das trilhas principais da grade e também por sua própria metodologia de amostragem, o método de ponto quadrante apresentou maior agilidade no levantamento de indivíduos arbóreos, mesmo apresentando um número de pontos na grade amostral cerca de 7,5 vezes maior que o número de parcelas de $200 \mathrm{~m}^{2}$.

Logo, no levantamento da riqueza do cerradão da E. E. Assis, a utilização de parcelas de até $200 \mathrm{~m}^{2}$ não é conveniente; neste caso, o método de ponto quadrante torna-se mais interessante por sua praticidade e reduzido tempo de instalação.

A Figura 19 compara o esforço de amostragem entre todos os tamanhos de parcelas testados. 


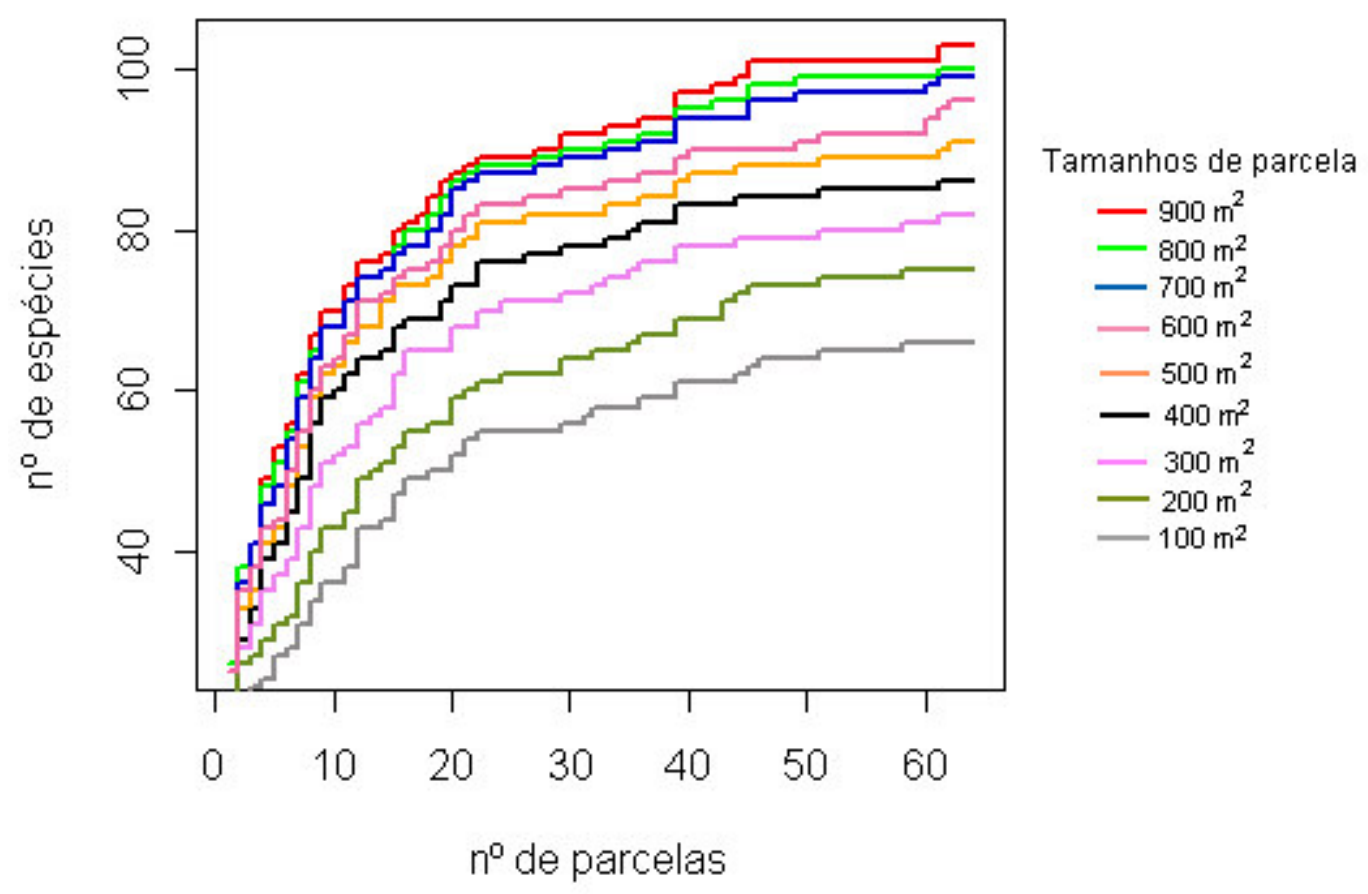

Figura 19 - Curva de suficiência amostral para os nove tamanhos de parcelas testados

As curvas de suficiência amostral da Figura 19 visam comparar o esforço amostral com o emprego de parcelas variando de 100 a $900 \mathrm{~m}^{2}$. Nota-se que o comportamento das curvas de 900,800 e $700 \mathrm{~m}^{2}$ são semelhantes, havendo sobreposição entre elas em alguns pontos da curva. Estes tamanhos de parcela conseguiram capturar uma maior riqueza de espécies, sendo indicados apenas quando a finalidade é amostrar o maior número possível de espécies. Já as curvas das parcelas com área entre 400 e $600 \mathrm{~m}^{2}$ mostram que o número de espécies amostradas diminui consideravelmente. As curvas das parcelas de $100 \mathrm{~m}^{2}$ a $300 \mathrm{~m}^{2}$ apresentaram um crescimento mais lento na inclusão de novas espécies desde as primeiras parcelas, diminuindo ainda mais com o aumento do número de parcelas amostradas. Trata-se de um grande esforço para acrescentar poucas novas espécies. Constata-se, com isso, que parcelas com área inferior a $700 \mathrm{~m}^{2}$ não são suficientes para se ter conhecimento da riqueza de espécies da E. E. Assis. 
A Tabela 5 mostra o esforço amostral para os diferentes tamanhos de parcela e para o método de ponto quadrante, indicando quantos indivíduos arbóreos foram necessários amostrar para que uma nova espécie fosse incluída.

Tabela 5. Esforço amostral (ind/sp) para os diferentes tamanhos de parcela e para o método de ponto quadrante

\begin{tabular}{cccc}
\hline parcela $\left.\mathbf{( m}^{\mathbf{2}}\right)$ & $\mathbf{n} \mathbf{\text { sp. }} \mathbf{( 1 )}^{(\mathbf{1}}$ & $\mathbf{n} \mathbf{\text { ind. }}$ & ind/sp \\
\hline 100 & 65 & 1174 & 18 \\
200 & 74 & 2372 & 32 \\
300 & 81 & 3559 & 44 \\
400 & 85 & 4691 & 55 \\
500 & 90 & 5840 & 65 \\
600 & 95 & 6971 & 73 \\
700 & 98 & 8139 & 83 \\
800 & 99 & 9345 & 94 \\
900 & 102 & 10561 & 103 \\
quadrantes & $\mathbf{7 1}$ & $\mathbf{1 9 3 6}$ & $\mathbf{2 7}$ \\
\hline
\end{tabular}

(1) no sp.: número de espécies; no ind.: número de indivíduos amostrados; ind/sp: número de indivíduos amostrados para cada nova espécie encontrada.

Com exceção da parcela de $100 \mathrm{~m}^{2}$, o método de parcelas de área fixa amostrou um maior número de indivíduos e um maior número de espécies, se comparado ao método de ponto quadrante. Entretanto, no caso da parcela de $900 \mathrm{~m}^{2}$, por exemplo, o que deve ser considerado é o esforço realizado para inserir 31 espécies a mais que os pontos quadrante. Enquanto neste método uma espécie nova foi identificada a cada 27 indivíduos amostrados, no método de parcelas de área fixa de $900 \mathrm{~m}^{2}$ foram necessários em média 103 indivíduos para cada espécie nova inserida. Isto significa que as parcelas de $900 \mathrm{~m}^{2}$ são quase quatro vezes mais trabalhosas que os pontos quadrante no que diz respeito ao levantamento de espécies.

Entretanto, levando-se em conta o que a Figura 17 demonstra sobre este levantamento, conclui-se que para a obtenção das 31 espécies a mais em relação aos pontos quadrantes, necessitou-se amostrar 8.625 indivíduos. Isto 
corresponde a um esforço de amostragem de cerca de 278 árvores para cada nova espécie, a partir do ponto em que somente a curva da parcela continua. Diante do exposto, é notória a desvantagem do uso de parcelas de $900 \mathrm{~m}^{2}$ no cerradão da E. E. Assis, pois sua densidade arbórea é alta, mas sua riqueza de espécies é baixa.

\section{4 Índices de Diversidade}

A tabela 6 compara as médias de 64 repetições entre os nove tamanhos de parcela testados, para os Índices de Diversidade de Shannon e Simpson, e entre o valor encontrado para o método de ponto quadrantes e para a grade amostral como um todo.

Tabela 6. Média dos índices de diversidade de Shannon e Simpson para parcelas de 100 a $900 \mathrm{~m}^{2}$, comparadas com os valores obtidos no método de ponto quadrante e na grade amostral

\begin{tabular}{ccc} 
Parcela $\left(\mathbf{m}^{\mathbf{2}}\right)$ & Shannon & Simpson \\
\hline 100 & 1,79 & 0,81 \\
200 & 2,07 & 0,84 \\
300 & 2,14 & 0,83 \\
400 & 2,23 & 0,84 \\
500 & 2,30 & 0,85 \\
600 & 2,34 & 0,85 \\
700 & 2,39 & 0,86 \\
800 & 2,44 & 0,86 \\
900 & 2,45 & 0,86 \\
\hline grade & $\mathbf{3 , 0 5}$ & $\mathbf{0 , 9 2}$ \\
quadrantes & $\mathbf{3 , 1 0}$ & $\mathbf{0 , 9 2}$ \\
\hline
\end{tabular}

A tabela 6 demonstra um crescimento nas médias dos Índices de Shannon conforme o aumento da área da parcela, indicando que parcelas pequenas não são indicadas para capturar a diversidade da área. As médias 
destes índices são inferiores aos valores encontrados quando se considera toda a grade amostral e todos os pontos quadrantes. Isto acontece porque não há como constar todas as espécies do levantamento em cada parcela, geralmente o que ocorre é o aparecimento das espécies raras em poucas parcelas.

Levando-se em conta toda a grade amostral, o cálculo do Índice de diversidade de Shannon para o método de parcelas gerou o valor 3,05 e para o método de ponto quadrante, 3,10. O valor deste índice varia muito, de acordo com as fisionomias estudadas. Felfili \& Imaña-Encinas (2001) obtiveram Índices de diversidade de Shannon variando entre 3,44 até 3,73, no estudo de quatro áreas de cerrado na Chapada do Espigão Mestre do São Francisco. Dias (1993) obteve os valores 4,26 e 4,46 no método de ponto quadrante, para duas classes diamétricas consideradas, em mata secundária da floresta ombrófila densa do Parque Estadual Carlos Botelho (PECB). Vieira (1997) obteve, também no PECB, o valor de 3,66. Já Gorenstein (2002), em uma área de floresta estacional semidecidual da Estação Ecológica dos Caetetus, obteve os valores 2,85 e 3,23 para os métodos de parcela e ponto quadrante, respectivamente. Sztutman (2000) encontrou valores entre 0,82 e 4,06, estudando três tipos florestais de uma planície litorânea em Pariquera-Açu (SP).

Silva (2002), em uma floresta amazônica de Paragominas (PA), estudou as diferenças de diversidade entre uma Área de Proteção Permanente e uma área cuja forma de manejo se adapta ao modelo exploração tradicional, e encontrou valores 4,21 e 3,79, respectivamente, para o Índice de Diversidade de Shannon; já o Índice de Diversidade de Simpson gerou os valores 0,97 e 0,96 , respectivamente. No presente estudo, o Índice de Diversidade de Simpson variou de 0,81 (parcelas de $100 \mathrm{~m}^{2}$ ) a 0,86 (parcelas de $900 \mathrm{~m}^{2}$ ). No entanto, tanto para o método de ponto quadrante quanto para a grade amostral, o valor deste índice foi de 0,92 .

A Figura 20 ilustra o comportamento do Coeficiente de Variação (\%) dos Índices de Shannon e Simpson, conforme o aumento do tamanho da parcela. 


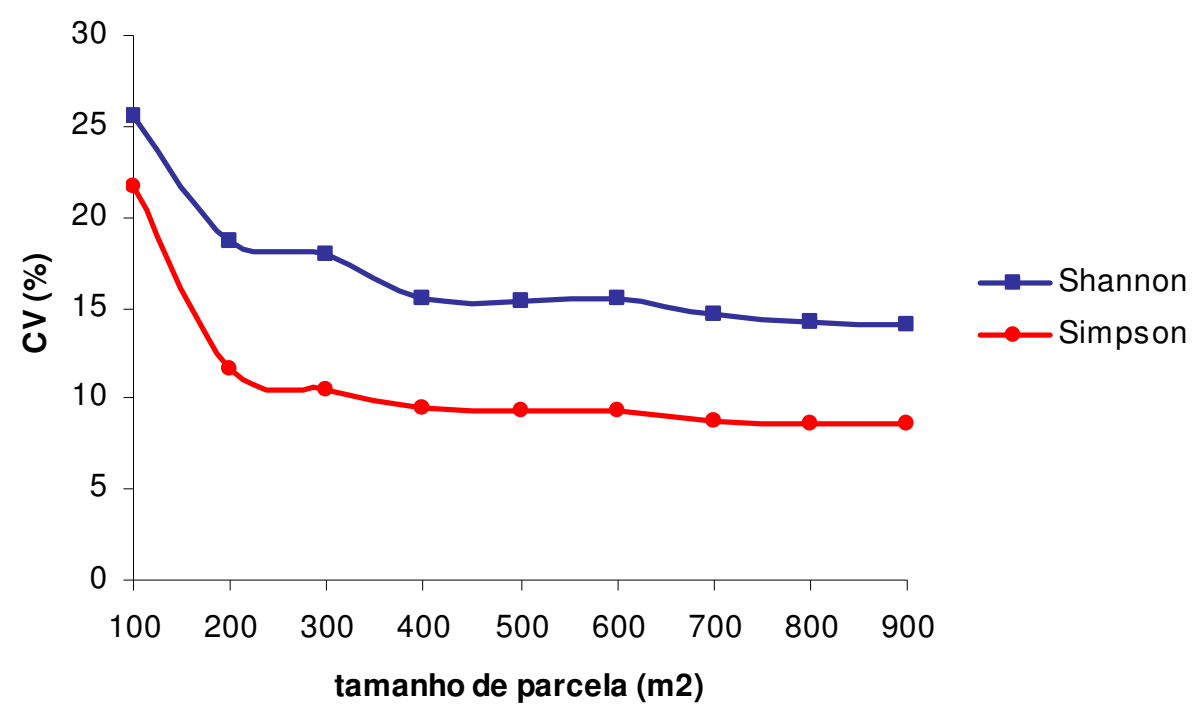

Figura 20 - Coeficiente de Variação dos Índices de Diversidade de Shannon e Simpson nos nove tamanhos de parcela testados

$\mathrm{Na}$ Figura 20 nota-se um decréscimo acentuado no Coeficiente de Variação do Índice de Shannon quando a área da parcela aumenta de 100 para $200 \mathrm{~m}^{2}$, passando a decrescer lentamente a partir do tamanho $400 \mathrm{~m}^{2}$. O mesmo acontece com o Índice de Simpson. Logo, para a fisionomia da área de estudo, parcelas menores que $400 \mathrm{~m}^{2}$ não são indicadas para a determinação da diversidade, devido à variação no número de espécies entre essas parcelas, já que algumas delas acabam por inserir fragmentos de cerrado sensu stricto, enquanto outras abrangem as áreas de cerradão. Parcelas maiores que $400 \mathrm{~m}^{2}$ também são inviáveis, devido ao aumento no tempo de instalação.

Silberbauer-Gottsberger \& Eiten (1983) verificaram uma variação do número de espécies entre as parcelas em um levantamento arbóreo do cerrado na região de Botucatu (SP) e enfatizaram esta questão argumentando que esta diferença pode estar relacionada ao histórico de perturbação da área. Diante disto, Durigan et al. (1987), estudando a evolução da densidade da vegetação da E. E. Assis, deduziram que a área sofreu ação antrópica em um período 
anterior a 1962. Mas, quando passou a ser propriedade do Estado, deu-se início a um processo de conservação, culminando no aumento de sua densidade arbórea. Ainda neste estudo, os autores descartaram a possibilidade de as diferentes fisionomias da vegetação estarem associadas às condições de fertilidade do solo.

Deve-se ressaltar que no caso do cerradão estudado, a forma da parcela interfere na diversidade. Parcelas de $40 \times 10 \mathrm{~m}$, tais como foram simuladas, provavelmente resultam em uma diversidade maior que parcelas de $20 \times 20 \mathrm{~m}$, devido à ocorrência de gradientes de transição entre o cerrado sensu stricto e o cerradão, somente perceptíveis quando se percorre maiores transectos.

A Figura 21 representa o gráfico de caixa ou "box-plot" para o Índice de Shannon em relação ao tamanho da parcela.

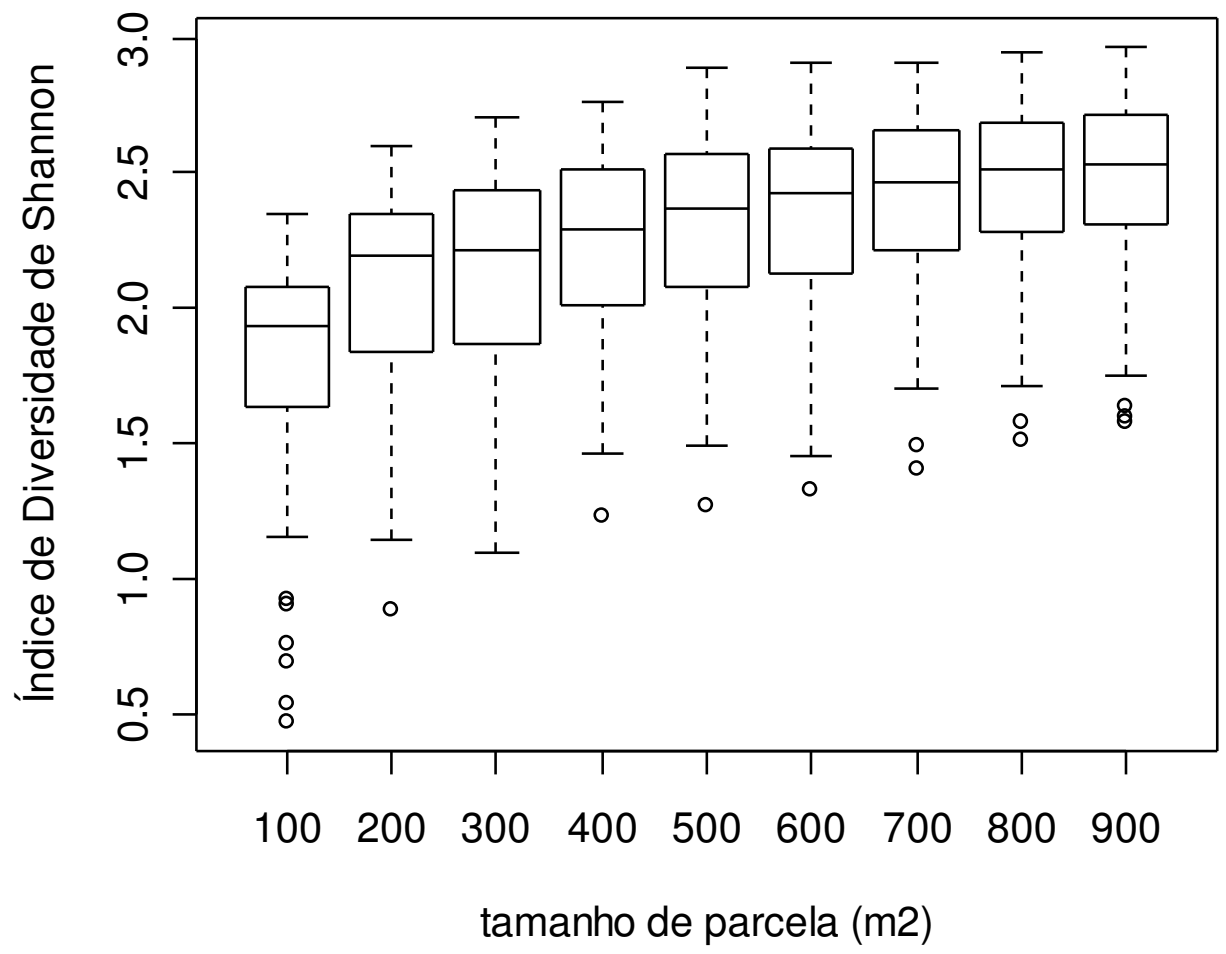

Figura 21 - Gráfico "box-plot" para o Índice de Shannon

Na Figura 21 nota-se a existência de pontos extremos correspondendo aos baixos valores de diversidade para todos os tamanhos de parcela, com 
exceção das parcelas de $300 \mathrm{~m}^{2}$. Apesar disso, pode-se dizer que o Índice de Shannon conseguiu capturar a diversidade da área, pois se observa um aumento crescente do Índice conforme o aumento da parcela.

O gráfico ilustra ainda que principalmente entre as parcelas de 100 e 300 $\mathrm{m}^{2}$ há grande amplitude entre o primeiro quartil e a mediana, indicando maior variabilidade entre as médias dos índices de Shannon nesta faixa. Entretanto, esta amplitude tende a diminuir, sobretudo para as parcelas de $400 \mathrm{~m}^{2}$ e para as parcelas de 700 a $900 \mathrm{~m}^{2}$, apesar da ocorrência de alguns valores extremos de baixa diversidade.

A Figura 22 representa o gráfico "box-plot" para o índice de Simpson em relação ao tamanho da parcela.

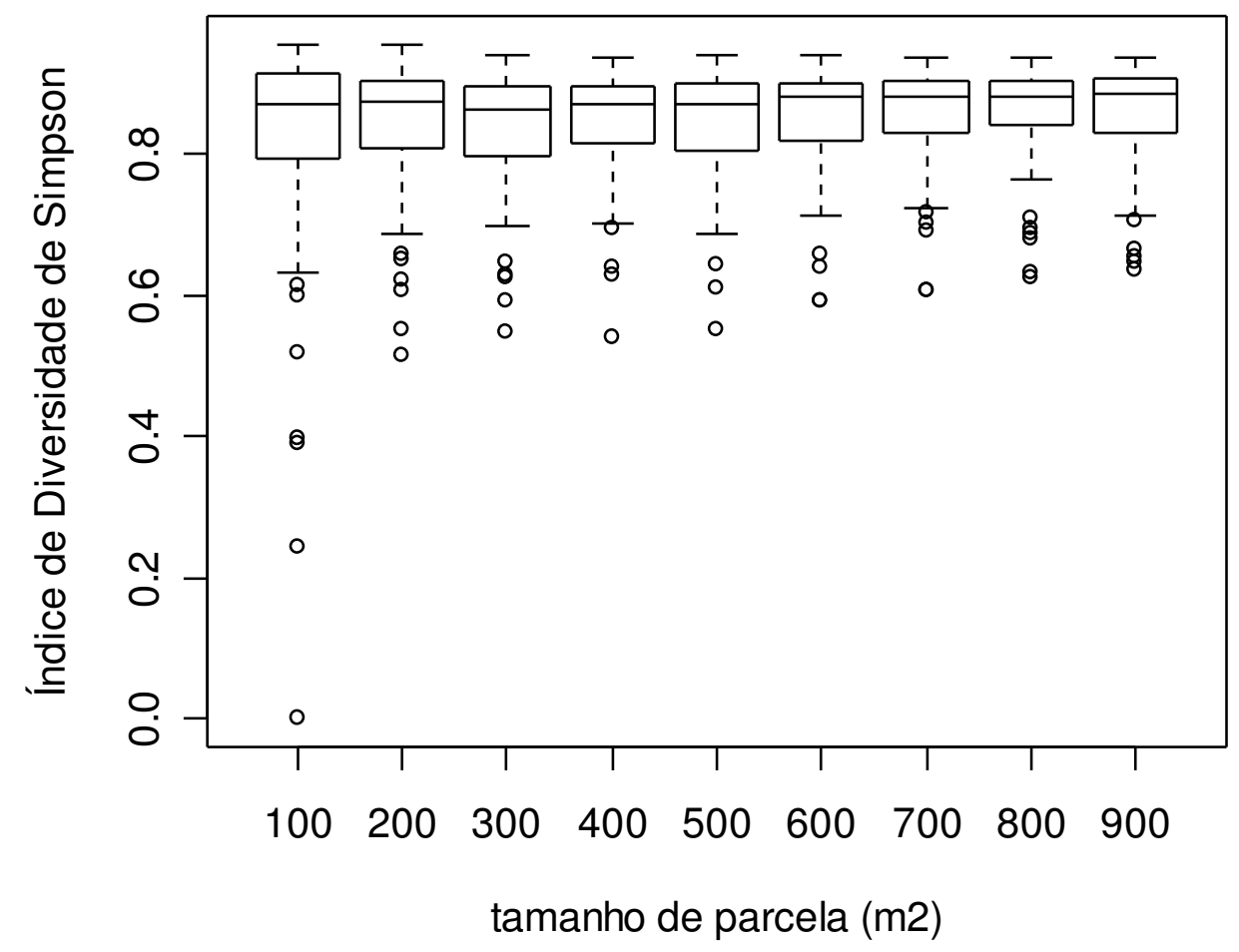

Figura 22 - Gráfico "box-plot” para o Índice de Simpson

No caso da variabilidade do Índice de Simpson referente à Figura 22, ocorrem valores extremos para todos os tamanhos de parcela; entretanto, são mais evidentes nas parcelas de $100 \mathrm{~m}^{2}$, onde uma delas, localizada na segunda 
unidade amostral da 6‥ linha (localização na grade: F2), apresentou um valor de Índice de Simpson equivalente a zero. Isto ocorre devido à sua própria equação, que somente incorpora a diversidade das espécies que apresentam mais de um indivíduo na parcela. Nesta parcela de $100 \mathrm{~m}^{2}$ existem somente duas espécies, com um indivíduo cada uma. Magurran (2004) explica esta questão afirmando que o Índice de Simpson é mais influente para as espécies mais abundantes na amostra, enquanto é menos sensível à riqueza de espécies.

Se comparado ao Índice de Shannon, o Índice de Simpson não apresentou um acréscimo expressivo em seu valor com o aumento do tamanho da parcela, justamente por ser pouco sensível à riqueza de espécies. Logo, não pode ser indicado como uma medida de diversidade para o cerradão estudado.

Cabe comentar ainda, em relação à Figura 22, que o maior intervalo entre o primeiro quartil e a mediana, notado em todos os tamanhos de parcela, indica uma maior variabilidade entre as médias deste índice, influenciada pela existência de parcelas que representam baixa diversidade.

\subsection{Densidade de indivíduos}

Com relação à densidade de espécies, a estimativa considerando-se toda a grade amostral resultou num valor de 1.833,5 ind/ha, enquanto que 0 método de ponto quadrante, utilizando a equação proposta por Pollard (1971), resultou em 1.887,2 ind/ha.

A Tabela 7 compara as estimativas de densidade e os limites do Intervalo de Confiança (95\%) para os tamanhos de parcela, para o método de ponto quadrante e para todas as subparcelas. 
Tabela 7. Média e intervalo de confiança (95\%) da estimativa da densidade para parcelas de 100 a $900 \mathrm{~m}^{2}$, pontos quadrantes e subparcelas

\begin{tabular}{cccc} 
parcela $\left(\mathbf{m}^{\mathbf{2}}\right)$ & lim. inf. ${ }^{\left({ }^{(1)}\right.}$ & D média & lim. sup \\
\hline 100 & 1681,9 & $\mathbf{1 8 3 4 , 4}$ & 1986,8 \\
200 & 1725,1 & $\mathbf{1 8 5 7 , 8}$ & 1990,5 \\
300 & 1739,2 & $\mathbf{1 8 5 6 , 8}$ & 1974,3 \\
400 & 1726,0 & $\mathbf{1 8 3 7 , 1}$ & 1948,2 \\
500 & 1721,7 & $\mathbf{1 8 2 8 , 8}$ & 1935,8 \\
600 & 1718,5 & $\mathbf{1 8 1 9 , 8}$ & 1921,1 \\
700 & 1721,7 & $\mathbf{1 8 1 9 , 9}$ & 1918,0 \\
800 & 1729,3 & $\mathbf{1 8 2 6 , 8}$ & 1924,2 \\
900 & 1737,2 & $\mathbf{1 8 3 5 , 2}$ & 1933,3 \\
\hline quadrante & 1804,7 & $\mathbf{1 8 8 7 , 2}$ & 1972,9 \\
subparcelas & 1783,3 & $\mathbf{1 8 3 3 , 5}$ & 1883,7 \\
\hline${ }^{(1)}$ lim. inf.: limite inferior, D média: Densidade média, lim. sup.: limite superior.
\end{tabular}

Na tabela 7 observa-se que o aumento no tamanho das parcelas não está ocasionando uma maior densidade arbórea. Entretanto, o Intervalo de Confiança a uma probabilidade de $95 \%$ torna-se menor conforme a área da parcela aumenta, sendo que a parcela de $800 \mathrm{~m}^{2}$ apresenta o menor intervalo. No caso do método de ponto quadrante, a equação de Pollard para estimativa da densidade superestimou este parâmetro, se comparado ao método de parcelas. Pollard (1971) explica uma das possíveis causas de situações de imprecisão na estimativa da densidade em seu método, afirmando que em áreas com grande variação de densidade é necessário considerar as proporções em que as áreas de maior ou menor densidade aparecem.

A Figura 23 ilustra o desempenho do Coeficiente de Variação (\%) da estimativa da densidade (ind/ha), conforme o aumento do tamanho da parcela. 


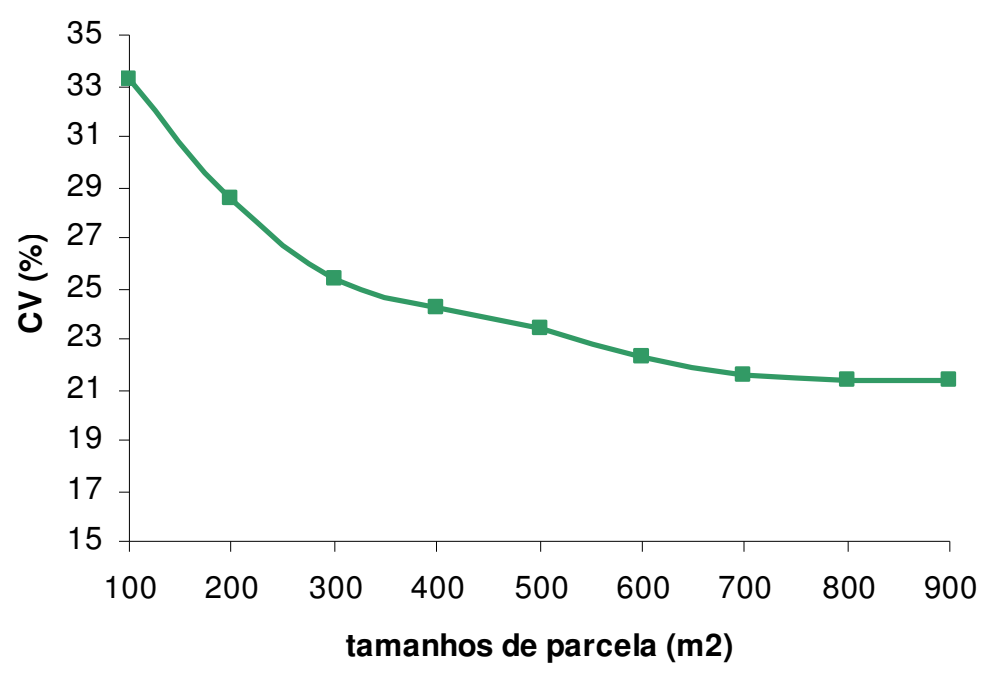

Figura 23 - Coeficiente de Variação da estimativa da densidade para os nove tamanhos de parcela testados

Na Figura 23 nota-se um decréscimo mais acentuado do Coeficiente de Variação (\%) para a estimativa da densidade até o aumento da área da parcela para $300 \mathrm{~m}^{2}$; a partir de então esta redução torna-se mais lenta. Para parcelas entre 700 e $900 \mathrm{~m}^{2}$, nota-se que este coeficiente se estabiliza.

Os valores de densidade por subparcela de $100 \mathrm{~m}^{2}$ encontrados apresentaram variação de $200 \mathrm{ind} / \mathrm{ha}$ até $3900 \mathrm{ind} / \mathrm{ha}$. Isto significa que o número de indivíduos nestas subparcelas variou de 2 a 39. A densidade de indivíduos encontrada por Silberbauer-Gottsberger \& Gottsberger (1984), em uma área de transição entre o cerrado sensu strictu e o cerradão em Botucatu (SP), variou de 1000 a $4000 \mathrm{ind} / \mathrm{ha}$ para o cerrado e entre 200 e $5000 \mathrm{ind} / \mathrm{ha}$ para o cerradão.

Goodland (1979) verificou, em uma área de cerrado do Triângulo Mineiro, uma maior densidade e um maior número de espécies no cerradão, se comparado à uma área de cerrado sensu stricto. Contudo, não foi o que verificaram Batalha et al. (2000), no estudo de três fisionomias de cerrado em Santa Rita do Passa Quatro (SP). Neste caso, em relação ao cerrado sensu 
stricto, tanto o número de espécies quanto a densidade arbórea foram inferiores no cerradão; já a área basal foi superior nesta fisionomia.

A Figura 24 representa o gráfico "box-plot" para a variação da densidade de acordo com o tamanho da parcela.

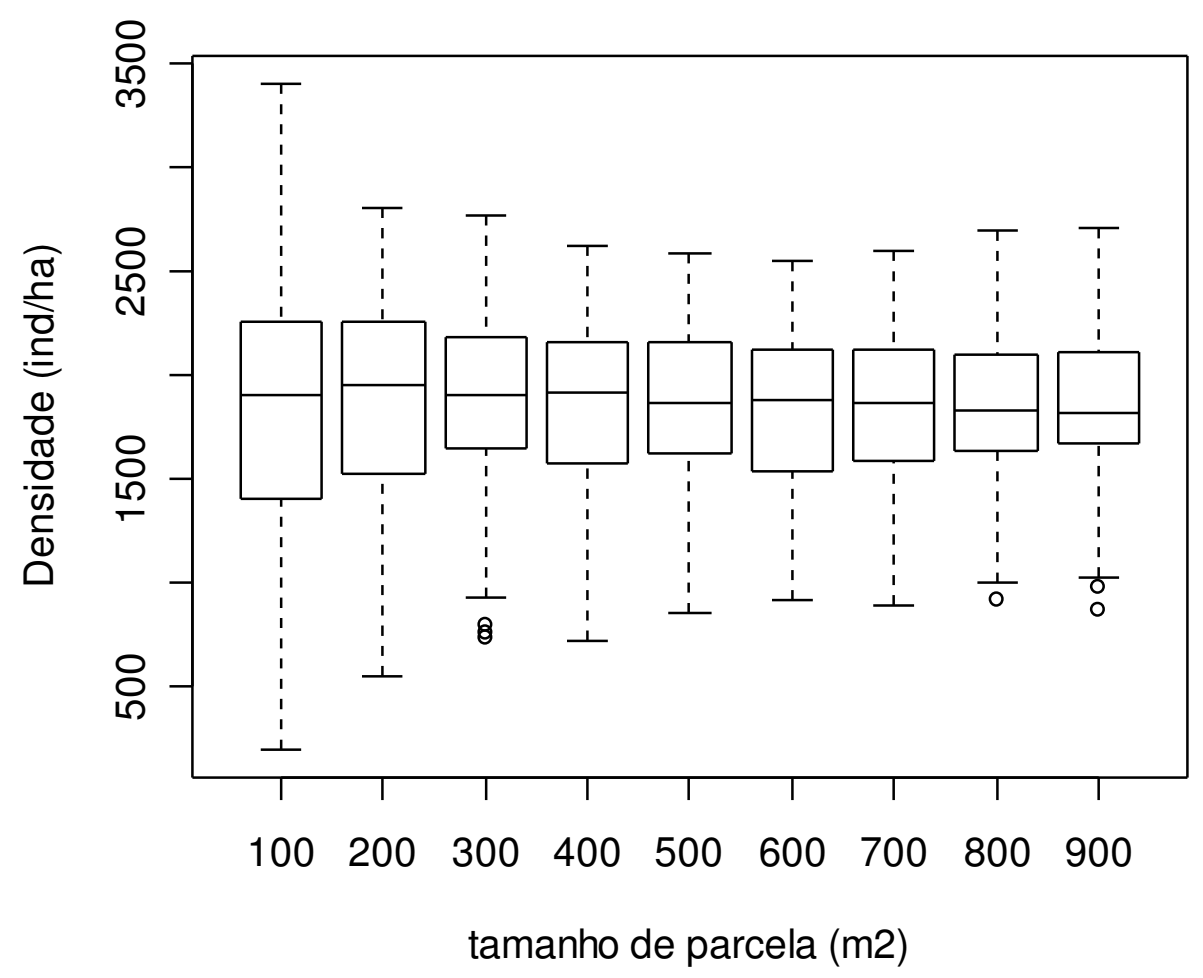

Figura 24 - Gráfico "box-plot” para a variação da densidade

De acordo com a Figura 24, nota-se que a amplitude da densidade diminui com o aumento da parcela, e que a posição da mediana é mais central em relação ao primeiro e o terceiro quartil, especialmente nas parcelas de 700 $\mathrm{m}^{2}$. Neste caso, a amplitude das variações entre as densidades é mais homogênea, tanto acima como abaixo da linha da mediana, fazendo-se com que a mediana se aproxime da média da densidade de indivíduos.

Apesar de as distribuições de densidade das parcelas de 800 e $900 \mathrm{~m}^{2}$ conterem valores extremos em relação às parcelas de $700 \mathrm{~m}^{2}$, como mostra a Figura 24, isto não deve significar que parcelas maiores que $700 \mathrm{~m}^{2}$ não são indicadas para determinação da densidade, visto que nesta área de cerradão 
existem peculiaridades na fisionomia que podem interferir no resultado dos levantamentos. Manchas de cerrado sensu stricto, por exemplo, freqüentemente aparecem na área, apesar de o cerradão predominar na E. E. Assis. Logo, seria necessário um estudo preliminar da área a fim de classificar seus diferentes tipos de mosaicos, para, num segundo momento, estimar a densidade de cada um deles. 


\section{CONCLUSÕES}

A partir do levantamento utilizando-se os métodos de parcelas e pontos quadrantes e da comparação entre esses métodos e entre os tamanhos de parcela, chega-se a algumas conclusões sobre o estudo do cerradão da $E$. E. Assis:

1) As espécies Copaifera langsdorffii, Vochysia tucanorum e Ocotea corymbosa se destacaram na área de estudo por apresentarem os maiores valores de IVI (\%) da grade (parcelas de $900 \mathrm{~m}^{2}$ ). O mesmo fato se repetiu no método de ponto quadrante.

2) Essas três espécies também obtiveram 100\% de freqüência considerando-se as 64 unidades amostrais da grade.

3) Quanto à riqueza de espécies, a família Myrtaceae se destacou por apresentar um maior número de espécies tanto nas parcelas de $900 \mathrm{~m}^{2}$ como nos pontos quadrante.

4) $O$ método de ponto quadrante foi semelhante às parcelas de $200 \mathrm{~m}^{2}$ em relação à quantidade de espécies incluídas, porém apresentou como vantagem a facilidade de instalação no campo, tornando este método mais prático e rápido, devido à amostragem de apenas quatro indivíduos arbóreos por ponto, resultando em um menor esforço amostral.

5) O Índice de Diversidade de Shannon resultou, de modo geral, em valores inferiores se comparado a outros biomas.

6) O Índice de Diversidade de Simpson não é o mais indicado para o cerradão estudado, pelo fato de não ser sensível à ocorrência de espécies com apenas um indivíduo na parcela. 
7) No caso do cerradão da E. E. Assis, parcelas de $400 \mathrm{~m}^{2}$ com dimensões de $40 \times 10 \mathrm{~m}$ são as mais indicadas na escolha do tamanho ideal de parcela visando determinar a diversidade arbórea deste bioma.

8) No levantamento deste estudo, parcelas de $700 \mathrm{~m}^{2}$ foram as melhores na estimativa da densidade de indivíduos arbóreos do cerradão da E. E. Assis, estando menos sujeitas a erros se comparada aos métodos de distância, como acontece com os pontos quadrante. Entretanto, para uma precisão maior nesta estimativa, uma das sugestões possíveis seria uma amostragem estratificada da vegetação, a partir de uma classificação prévia das áreas de maior e menor densidade. 


\section{REFERÊNCIAS BIBLIOGRÁFICAS}

AGUIAR, O. T. de. Comparação entre os Métodos de Quadrantes e Parcelas na Caracterização da Composição Florística e Fitossociológica de um Trecho de Floresta Ombrófila Densa no Parque Estadual "Carlos Botelho" - São Miguel Arcanjo, São Paulo. Piracicaba, 2003. 119 p. Dissertação (Mestrado)

- Escola Superior de Agricultura "Luiz de Queiroz", Universidade de São Paulo.

BASE DE DADOS TROPICAL (BDT). Bases para Conservação e Uso Sustentável das Áreas de Cerrado do Estado de São Paulo. Workshop. http://www.bdt.fat.org.br/sma/cerrado/legislacao/emenda1 (08 jun. 2004).

BATALHA, M. A.; MANTOVANI, W. Floristic composition of the Cerrado in the Pé-de-Gigante Reserve (Santa Rita do Passa Quatro, Southeastern Brazil). Acta Botânica Brasilica, v. 15 n. 3, p. 289-304, 2001.

BATALHA, M. A.; MANTOVANI, W.; MESQUITA JÚNIOR, H. N de. Vegetation Structure in Cerrado Physiognomies in South-Eastern Brazil. Brazilian Journal of Biology, v. 61, n. 3, p. 475-483, 2001.

CAVASSAN, O.; CESAR, O.; MARTINS, F. R. Fitossociologia da vegetação arbórea da Reserva Estadual de Bauru, Estado de São Paulo. Revista Brasileira de Botânica, v. 7, n. 2, p. 91-106, 1984. 
CESAR, O.; PAGANO, S. N.; LEITÃO-FILHO, H. F.; MONTEIRO, R.; SILVA, O. A. da; MARINIS, G. de; SHEPHERD, G. J. Estrutura fitossociológica do estrato arbóreo de uma área de vegetação de cerrado no município de Corumbataí (Estado de São Paulo). Naturalia, v. 13, p. 91-101, 1988.

CETESB. Relatório Zero da UGRHI 17. 347 p. http://www.sigrh.sp.gov.br/cgibin/sigrh_home_colegiado.exe/download?COLEGIADO=CRH/CBHMP\&ID=1979 (08 jun. 2004).

CHAPMAN, S. B. Methods in plant ecology. New York: John Wiley, 1976. $536 \mathrm{p}$.

COLWELL, R. K.; CODDINGTON, J. A. Estimating terrestrial biodiversity through extrapolation. Philosophical Transactions: Biological Sciences, v. 345, p. 101-118, 1994.

COTTAM, G.; CURTIS, J. T. The use of distance measures in phytosociological sampling. Ecology, v. 37, n. 3, Jul., p. 451-460, 1956.

COUTINHO, L. M. O conceito de cerrado. Revista Brasileira de Botânica, v. 1, p. 17-23, 1978.

DIAS, A. C. Estrutura e diversidade do componente arbóreo e a regeneração do palmito (Euterpe edulis) em um trecho de mata secundária, no Parque Estadual de Carlos Botelho, SP. Piracicaba, 1993. 126 p. Dissertação (Mestrado) - Escola Superior de Agricultura "Luiz de Queiroz", Universidade de São Paulo.

DURIGAN, G. Revegetação em áreas de cerrado. In: SIMPÓSIO IPEF, 6., São Pedro, 1996. Anais. Piracicaba: IPEF, 1996. v. 1, p. 23-26. 
DURIGAN, G. Bases e diretrizes para a restauração da vegetação de cerrado. In: KAGEYAMA, P. Y. (Org.) Restauração ecológica de ecossistemas naturais. Botucatu: FEPAF, 2003. p. 185-204.

DURIGAN, G.; LEITÃO-FILHO, H. F. de; RODRIGUES, R. R. Phytosociology and structure of a frequently burnt cerrado vegetation in SE-Brazil. Flora, n. 189, p. 153-160, 1994.

DURIGAN, G.; BACIC, M. A.; FRANCO, G. A. D. C; SIQUeIRA, M. F de. Inventário florístico do cerrado na Estação Ecológica de Assis, SP. Hoehnea, v. 26, n. 2, p. 149-172, 1999.

DURIGAN, G.; BAITELLO, J. B.; FRANCO, G. A. D. C.; SIQUEIRA, M. F de. Plantas do cerrado paulista: Imagens de uma paisagem ameaçada. São Paulo: Páginas \& Letras Editora e Gráfica, 2004. 475 p.

DURIGAN, G.; SARAIVA, I. R.; GURGEL GARRIDO, L. M.do A.; GARRIDO, M. A. de O; PECHE FILHO, A. Fitossociologia e evolução da densidade da vegetação do cerrado, Assis, SP. Boletim Técnico do Instituto Florestal, v. 41 , n. 1 , p. 59-78, mar. 1987.

DURIGAN, G.; SIQUEIRA, M. F. de; FRANCO, G. A. D. C.; BRIDGEWATER, S.; RATTER, J. A. The vegetation of priority areas for cerrado conservation in São Paulo State, Brazil. Edinburgh Journal of Botany, v. 60, n. 2, p. 217-241, 2003.

EITEN, G. Formas fisionômicas do cerrado. Revista Brasileira de Botânica, v. 2, p. 139-148, 1979. 
EITEN, G. Vegetação do cerrado. In: PINTO, M. N. (Org.). Cerrado. Brasília: Editora Universidade de Brasília, 1993. p. 17-73.

EMPRESA BRASILEIRA DE PESQUISA AGROPECUÁRIA. Sistema brasileiro de classificação de solos. Brasília: Embrapa, Produção de Informação, 1999. $412 \mathrm{p}$.

FELFILI, J. M. Principais fisionomias do Espigão Mestre do São Francisco. In: FELFILI, J. M.; SILVA JÚNIOR, M. C. da (Org.). Biogeografia do bioma cerrado: estudo fitofisionômico da Chapada do Espigão Mestre do São Francisco. Brasília: UNB, 2001. p. 18-28.

FELFILI, J. M.; IMAÑA-ENCINAS, J. Suficiência da amostragem no cerrado sensu stricto das quatro áreas estudadas na Chapada do Espigão Mestre do São Francisco. In: FELFILI, J. M.; SILVA JÚNIOR, M. C. da (Org.). Biogeografia do bioma cerrado: estudo fitofisionômico da Chapada do Espigão Mestre do São Francisco. Brasília: UNB, 2001, p. 31-35.

FERRI, M. G. Ecologia dos cerrados. In: SIMPÓSIO SOBRE O CERRADO: BASES PARA UTILIZAÇÃO AGROPECUÁRIA, 4., Brasília, 1976. Anais. São Paulo: EDUSP, 1977. p. 15-37.

FERRI, M. G. Vegetação brasileira. Belo Horizonte: Editora Itatiaia, 1980. $153 \mathrm{p}$.

FRACKER, S. B.; BRISCHLE, H. A. Measuring the local distributions of ribes. Ecology, v. 25 n. 3, p. 283-303, jul. 1944.

FREESE, F. Relation of plot size to variability: an approximation. Journal of Forestry, v. 59, n. 9, 1961. p. 679. 
FREESE, F. Elementary forest sampling. Agriculture Handbook, n. 232, U. S. Department of Agriculture, 1971. $91 \mathrm{p}$.

GIBBS, P. E.; LEITÃO-FILHO, H. de F.; ABBOT, R. J. Application of the pointcentered quarter method in a floristic survey of an area of gallery forest at Mogi-Guaçu, SP, Brazil. Revista Brasileira de Botânica, v. 3, n. 1/2, p. 17-22, 1980.

GOMES, B. Z.; MARTINS, F.R.; TAMASHIRO, J. Y. Estrutura do cerradão e da transição entre cerradão e floresta paludícola num fragmento da International Paper do Brasil Ltda., em Brotas, SP. Revista Brasileira de Botânica, v. 27, n. 2, p. 249-62, abr.-jun. 2004.

GOODLAND, R. J. A. Análise Ecológica da Vegetação do Cerrado. In: GOODLAND, R. J. A.; FERRI, M. G. (Org.). Ecologia do Cerrado. Trad. de Eugênio Amado. Belo Horizonte: Itatiaia/EDUSP, 1979. p. 61-177.

GORENSTEIN, M. R. Métodos de amostragem no levantamento da comunidade arbórea em floresta estacional semidecidual. Piracicaba, 2002, 92 p. Dissertação (Mestrado) - Escola Superior de Agricultura "Luiz de Queiroz", Universidade de São Paulo.

HEISEKE, D. R. Estudos de tipologias florestais de cerrado na região central de Minas Gerais. Série Técnica PRODEPEF, v. 7, p.1-58, 1976.

INSTITUTO BRASILEIRO DE GEOGRAFIA E ESTATÍSTICA. Manual técnico da vegetação brasileira. In: VELOSO, H. P. (Org.). Rio de Janeiro: IBGE/Departamento de Recursos Naturais e Estudos Ambientais, 1992. $93 \mathrm{p}$. 
INSTITUTO FLORESTAL. Estação Ecológica de Assis. http://www.iflorestsp.br/unidades.htm (06 mar. 2004).

KREBS, C. J. Ecological methodology. 2. ed. Menlo Park: Addison Wesley Longman, 1999. $620 \mathrm{p}$.

KRONKA, F. J. N. Áreas de domínio do cerrado no Estado de São Paulo. São Paulo: Secretaria do Meio Ambiente, 1998. 84 p.

LORENZI, H. Árvores brasileiras: manual de identificação e cultivo de plantas arbóreas nativas do Brasil. Nova Odessa: Editora Plantarum, 1992. 352 p.

MAGURRAN, A. E. Ecological diversity and its measurement. New Jersey: Princeton University Press, 1988. $179 \mathrm{p}$.

MAGURRAN, A. E. Measuring biological diversity. Malden: Blackwell Publishing, 2004. $256 \mathrm{p}$.

MARTINS, F. R. O método de quadrantes e a fitossociologia de uma floresta residual do interior do Estado de São Paulo: Parque Estadual de Vassununga. São Paulo, 1979. 239 p. Tese (Doutorado) - Instituto de Biociências, Universidade de São Paulo.

MARTINS, F. R. Estrutura de uma floresta mesófila. Campinas: Editora da Unicamp, 1993. 246 p. 
MARTINS, F. R.; SANTOS, F. A. M. Técnicas usuais de estimativa da biodiversidade. Holos, edição especial, UNESP, 1999. http://www.ib.unicamp.br/institucional/departamentos/botanica/labs/eco/holo s.pdf (04 fev. 2004).

MISSOURI BOTANICAL GARDEN. Plant Science: Trópicos. http://mobot.mobot.org/W3T/Search/vast.html (19 nov. 2004).

MITCHELL, K. Quantitative analysis by the point-centered quarter method. Department of Mathematics and Computer Science. Geneva, NY. 2001. http://people.hws.edu/Mitchell/PCQM.pdf (26 abr. 2004).

MÜELLER-DOMBOIS, D.; ELLENBERG, H. Aims and methods of vegetation ecology. USA: Jonh Wiley, 1974. 547 p.

MYERS, N.; MItTERMEIER, R. A.; MItTERMEIER, C. G.; FONSECA, G. A. B. da; KENT, J. Biodiversity hotspots for conservation priorities. Nature, v. 403 , p. $853-858$, fev. 2000.

ODUM, E. P. Ecologia. Rio de Janeiro: Ed. Guanabara, 1986. 434 p.

ORIANS, G. H. Global biodiversity I: patterns and processes. In: MEFFE, G. K.; C. R. CARROL (Ed.). Principles of conservation biology. Sunderland, Massachusetts: Sinauer Associates, 1994. p. 78-109.

OOSTING, H. J. The study of plant communities. 2. ed. San Francisco: W. H. Freeman, 1956. 440 p.

PEET, R. K. The measurement of species diversity. Annual Review of Ecology and Systematics, v. 5, p. 285-307, 1974. 
PIELOU, E. C. Ecological diversity. New York: John Wiley, 1975. 165 p.

POLLARD, J. H. On distance estimators of density in randomly distributed forests. Biometrics, v. 27, n. 4, p. 991-1002, 1971.

PRODAN, M. Forest Biometrics. New York: Pergamon Press, 1968. 447 p.

RATTER, J. A. Transitions between cerrado and forest vegetation in Brazil. In: FURLEY, P. A., PROCTOR, J.; RATTER, J. A. (Ed.) Nature and dynamics of forest savanna boundaries. London, New York: Chapman \& Hall, 1992. p 417-429.

RATTER, J. A.; LEITÃO-FILHO, H. de F.; ARGENT, G.; GIBBS, P. E.; SEMIR, J.; SHEPHERD, G.; TAMASHIRO, J. Floristic composition and the community structure of a southern cerrado area in Brazil. Notes from Royal Botanical Gardens of Edinburgh, v. 45, n. 1, p. 137-151, 1988.

RIZZINI, C. T. Tratado de fitogeografia do Brasil: aspectos ecológicos, sociológicos e florísticos. Rio de Janeiro: Âmbito Cultural, 1997. 747 p.

ROCHA, F. T. Levantamento florestal na Estação Ecológica dos Caetetus como subsídio para laudos de desapropriação ambiental. Piracicaba, 2003. 156 p. Dissertação (Mestrado) - Escola Superior de Agricultura "Luiz de Queiroz", Universidade de São Paulo.

SARMIENTO, G. The Savannas of tropical America. In: BOURLIÈRE, F. (Ed.). Ecosystems of the World 13: Tropical Savannas. Amsterdam: Elsevier, 1983. cap. 10 , p. $245-288$. 
SCHREUDER, H. T.; GREGOIRE, T. G.; WOOD, G. B. Sampling methods for multiresource forest inventory. New York: John Wiley, 1993. 446 p.

SILBERBAUER-GOTTSBERGER, I.; EITEN, G. Fitossociologia de um hectare de cerrado. Brasil Florestal, n. 54, p. 55-70, 1983.

SILBERBAUER-GOTTSBERGER, I., GOTTSBERGER, G. Cerrado - cerradão: a comparison with respect to number of species and growth forms. Phytocoenologia, v. 12, n. 2/3, p. 293-303, 1984.

SILVA, L. N. Exploração tradicional e planejada numa área da Amazônia Oriental: fitossociologia e diversidade de espécies arbóreas. Piracicaba, 2002. 62 p. Dissertação (Mestrado) - Escola Superior de Agricultura "Luiz de Queiroz", Universidade de São Paulo.

SIMPSON, E. H. Measurement of diversity. Nature, v. 30, n. 163, p. 688, 1949.

SPURR, S. H. Forest Inventory. New York: Ronald Press, 1952. 476 p.

SZTUTMAN, M. O mosaico vegetacional da planície litorânea de Cananéia/lguape (SP) e suas relações com o ambiente: um estudo de caso no Parque Estadual da Campina do Encantado, Pariquera-Açu. Piracicaba, 2000. 128 p. Dissertação (Mestrado) - Escola Superior de Agricultura "Luiz de Queiroz", Universidade de São Paulo.

THOMAS, M. A Generalization of Poisson binomial limit for use in ecology. Biometrica, v. 36, n.1/2, p. 18-25, jun.1949. 
TOLEDO FILHO, D. V.; LEITÃO-FILHO, H. de F.; SHEPHERD, J. Estrutura fitossociológica da vegetação de cerrado de Moji-Mirim (SP). Revista do Instituto Florestal, v. 1, n. 2, p. 1-12, dez. 1989.

VELOSO, H. P.; GÓES-FILHO, L. Fitogeografia brasileira: classificação fisionômico-ecológica da vegetação neotropical. (Boletim Técnico Projeto RADAMBRASIL), Série Vegetação, Salvador: v. 1 p. 1-80, 1982.

VIEIRA, M. G. L. Tamanho e número de parcelas para amostragem do estrato arbóreo num trecho de floresta secundária do Parque Estadual de Carlos Botelho (SP). Piracicaba, 1997. 69 p. Dissertação (Mestrado) - Escola Superior de Agricultura "Luiz de Queiroz", Universidade de São Paulo.

WHITTAKER, R. H. Communities and ecosystems. 2. ed. New York: Macmillan, 1975. 387 p. 